\title{
Applicability of Federal and State Hazardous Waste Regulatory Programs to Waste Chemical Weapons and Chemical Warfare Agents
}

Environmental Assessment Division Argonne National Laboratory 
Argonne National Laboratory, with facilities in the states of Illinois and Idaho, is owned by the United States Government and operated by The University of Chicago under the provisions of a contract with the U.S. Department of Energy.

\title{
DISCLAIMER
}

This report was prepared as an account of work sponsored by an agency of the United States Government. Neither the United States Government nor any agency thereof, nor The University of Chicago, nor any of their employees or officers, makes any warranty, express or implied, or assumes any legal liability or responsibility for the accuracy, completeness, or usefulness of any information, apparatus, product, or process disclosed, or represents that its use would not infringe privately owned rights. Reference herein to any specific commercial product, process, or service by trade name, trademark, manufacturer, or otherwise does not necessarily constitute or imply its endorsement, recommendation, or favoring by the United States Government or any agency thereof. The views and opinions of document authors expressed herein do not necessarily state or reflect those of the United States Government or any agency thereof, Argonne National Laboratory, or The University of Chicago.

Available electronically at http://www.doe.gov/bridge

Available for a processing fee to U.S. Department of Energy and its contractors, in paper, from:

\author{
U.S. Department of Energy \\ Office of Scientific and Technical Information \\ P.O. Box 62 \\ Oak Ridge, TN 37831-0062 \\ phone: (865) 576-8401 \\ fax: (865) 576-5728 \\ email: reports@adonis.osti.gov
}




\section{Applicability of Federal and State Hazardous Waste Regulatory Programs to Waste Chemical Weapons and Chemical Warfare Agents}

by R. Haffenden and T. Kimmell

Environmental Assessment Division

Argonne National Laboratory, 9700 South Cass Avenue, Argonne, Illinois 60439

December 2001

Prepared for U.S. Army Soldier and Biological Chemical Command (SBCCOM) 


\section{NOTICE}

This technical memorandum is an information product of Argonne's Environmental Assessment Division (EAD). It presents results of ongoing work or work that is more limited in scope and depth than that described in formal reports issued by $E A D$. This memorandum has undergone internal technical review and has been edited according to EAD's quality assurance requirements. In contrast to a formal technical report, this memorandum has not been externally peer reviewed.

For more information on the division's scientific and engineering activities, contact:

Director, Environmental Assessment Division

Argonne National Laboratory

Argonne, Illinois 60439

Telephone (630) 252-3107

email: ead@anl.gov

Publishing support services were provided by Argonne's Information and Publishing Division (for more information, see IPD's home page: http://www.ipd.anl.gov).

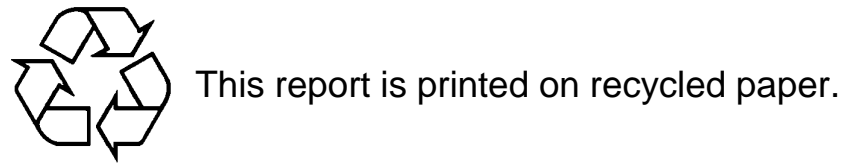




\section{CONTENTS}

ACKNOWLEDGMENTS .............................................................................. vii

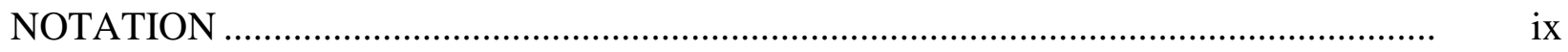

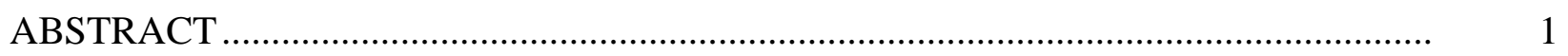

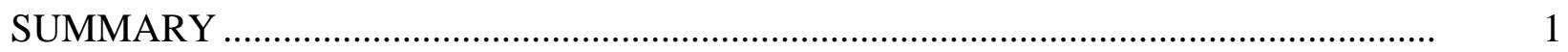

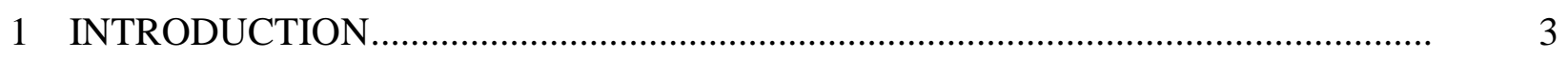

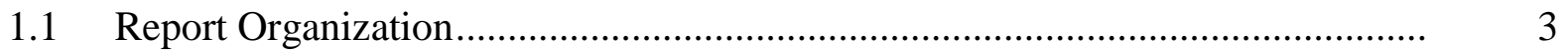

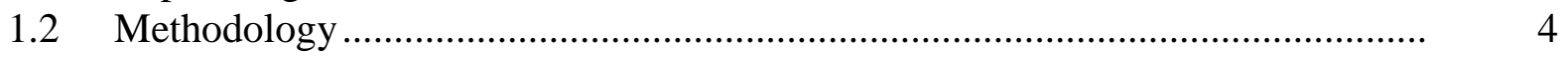

2 FEDERAL ENVIRONMENTAL PROGRAMS ................................................... 6

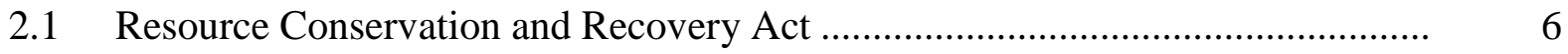

2.1.1 Listed Hazardous Waste Designation ................................................ 6

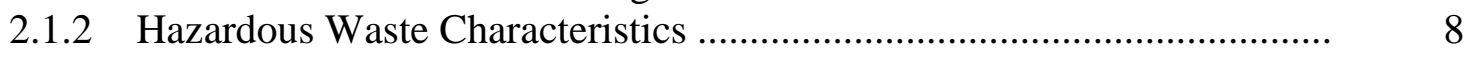

2.1.3 The RCRA Military Munitions Rule .............................................. 10

2.1.4 State RCRA Authorization Programs .................................................. 12

2.2 Comprehensive Environmental Response, Compensation,

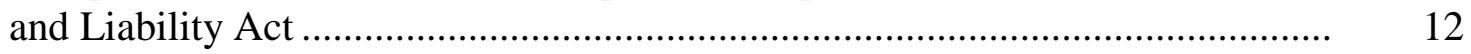

2.3 Emergency Planning and Community Right-to-Know Act ............................. 13

2.3.1 EPCRA Emergency Planning .............................................................. 13

2.3.2 EPCRA Emergency Release Notification.......................................... 14

2.3.3 EPCRA Emergency and Hazardous Chemical Inventories ..................... 14

2.3.4 EPCRA Toxics Release Inventory Reporting.................................... 15

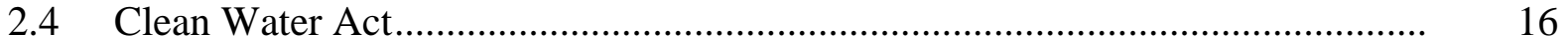

2.5 Clean Air Act ........................................................................................... 16

2.6 Hazardous Materials Transportation Act ................................................... 17

3 STATE ENVIRONMENTAL PROGRAMS ................................................... 18

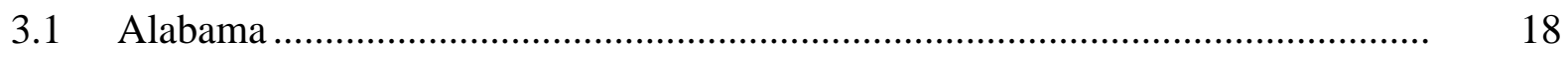

3.1.1 Hazardous Waste Regulations ........................................................ 18

3.1.2 Additional Pertinent Statutory or Regulatory Provisions ....................... 19

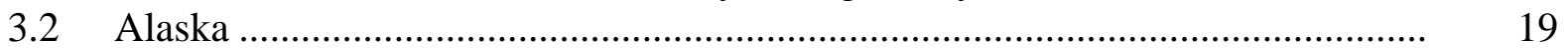

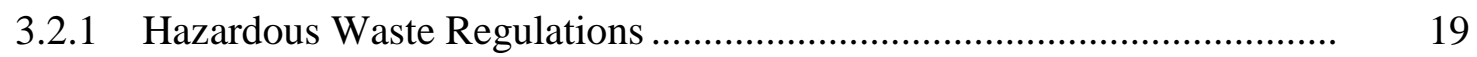

3.2.2 Additional Pertinent Statutory or Regulatory Provisions ....................... 19

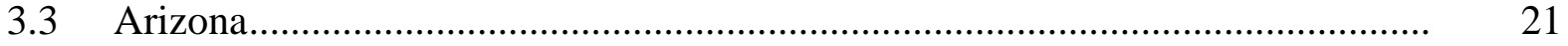

3.3.1 Hazardous Waste Regulations ......................................................... 21

3.3.2 Additional Pertinent Statutory or Regulatory Provisions ........................ 22

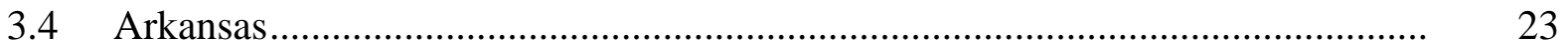




\section{CONTENTS (Cont.)}

3.4.1 Hazardous Waste Regulations .................................................................. 23

3.4.2 Additional Pertinent Statutory or Regulatory Provisions .......................... 23

3.5 California ............................................................................................... 24

3.5.1 Hazardous Waste Regulations ............................................................... 24

3.5.2 Additional Pertinent Statutory or Regulatory Provisions ......................... 25

3.6 Colorado.................................................................................................. 26

3.6.1 Hazardous Waste Regulations ............................................................ 26

3.6.2 Additional Pertinent Statutory or Regulatory Provisions .......................... 27

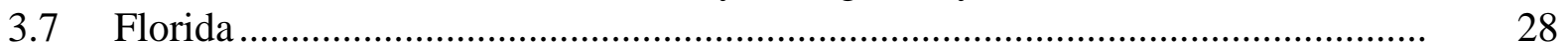

3.7.1 Hazardous Waste Regulations ................................................................ 28

3.7.2 Additional Pertinent Statutory or Regulatory Provisions .......................... 28

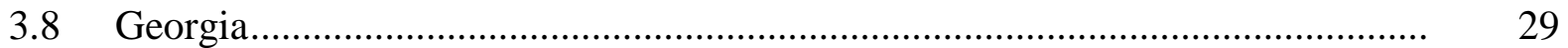

3.8.1 Hazardous Waste Regulations .................................................................. 29

3.8.2 Additional Pertinent Statutory or Regulatory Provisions .......................... $\quad 30$

3.9 Hawaii .................................................................................................. 31

3.9.1 Hazardous Waste Regulations ................................................................ 31

3.9.2 Additional Pertinent Statutory or Regulatory Provisions ......................... 31

3.10 Idaho .................................................................................................... 32

3.10.1 Hazardous Waste Regulations ............................................................... 32

3.10.2 Additional Pertinent Statutory or Regulatory Provisions ……………...... 33

3.11 Illinois .......................................................................................................... 33

3.11.1 Hazardous Waste Regulations ................................................................ 33

3.11.2 Additional Pertinent Statutory or Regulatory Provisions ......................... 33

3.12 Indiana................................................................................................... 34

3.12.1 Hazardous Waste Regulations .............................................................. 34

3.12.2 Additional Pertinent Statutory or Regulatory Provisions ......................... 34

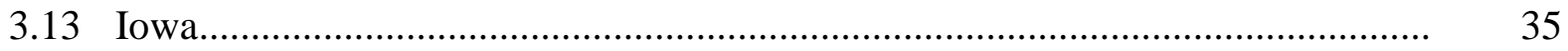

3.13.1 Hazardous Waste Regulations .............................................................. 35

3.13.2 Additional Pertinent Statutory or Regulatory Provisions .......................... 35

3.14 Kansas ....................................................................................................... 36

3.14.1 Hazardous Waste Regulations ............................................................ 36

3.14.2 Additional Pertinent Statutory or Regulatory Provisions ......................... 37

3.15 Kentucky .................................................................................................... 37

3.15.1 Hazardous Waste Regulations ................................................................ 37

3.15.2 Additional Pertinent Statutory or Regulatory Provisions .......................... 40

3.16 Louisiana.............................................................................................

3.16.1 Hazardous Waste Regulations ............................................................... 40

3.16.2 Additional Pertinent Statutory or Regulatory Provisions ......................... 40

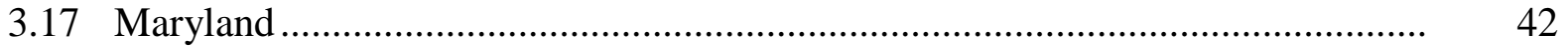

3.17.1 Hazardous Waste Regulations ............................................................ 42

3.17.2 Additional Pertinent Statutory or Regulatory Provisions .......................... 43

3.18 Massachusetts .................................................................................................. 43

3.18.1 Hazardous Waste Regulations ............................................................... 43 


\section{CONTENTS (Cont.)}

3.18.2 Additional Pertinent Statutory or Regulatory Provisions .......................... 44

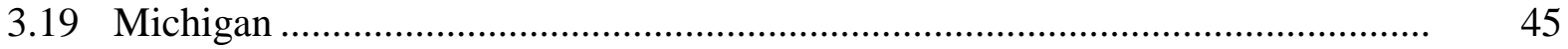

3.19.1 Hazardous Waste Regulations ................................................................ 45

3.19.2 Additional Pertinent Statutory or Regulatory Provisions ......................... 45

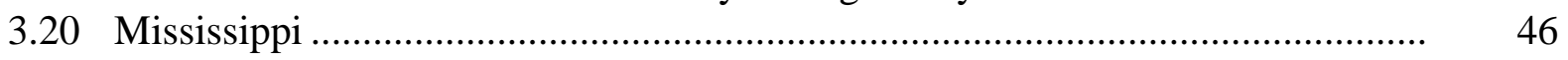

3.20.1 Hazardous Waste Regulations ............................................................... 46

3.20.2 Additional Pertinent Statutory or Regulatory Provisions .......................... 46

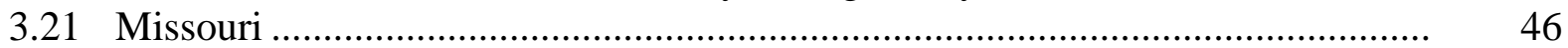

3.21.1 Hazardous Waste Regulations ............................................................... 46

3.21.2 Additional Pertinent Statutory or Regulatory Provisions ......................... 47

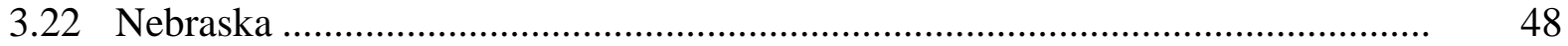

3.22.1 Hazardous Waste Regulations ................................................................. 48

3.22.2 Additional Pertinent Statutory or Regulatory Provisions ......................... 48

3.23 Nevada ....................................................................................................... 48

3.23.1 Hazardous Waste Regulations ................................................................ 48

3.23.2 Additional Pertinent Statutory or Regulatory Provisions .......................... 49

3.24 New Jersey ...................................................................................................... 49

3.24.1 Hazardous Waste Regulations ................................................................. 49

3.24.2 Additional Pertinent Statutory or Regulatory Provisions .......................... $\quad 50$

3.25 New Mexico ..................................................................................... 50

3.25.1 Hazardous Waste Regulations ............................................................... $\quad 50$

3.25.2 Additional Pertinent Statutory or Regulatory Provisions ......................... 50

3.26 New York ................................................................................................ 51

3.26.1 Hazardous Waste Regulations ............................................................. 51

3.26.2 Additional Pertinent Statutory or Regulatory Provisions .......................... 51

3.27 North Carolina ........................................................................................... 52

3.27.1 Hazardous Waste Regulations .............................................................. 52

3.27.2 Additional Pertinent Statutory or Regulatory Provisions ......................... 52

3.28 Ohio ......................................................................................................... 53

3.28.1 Hazardous Waste Regulations .................................................................. 53

3.28.2 Additional Pertinent Statutory or Regulatory Provisions ........................... 53

3.29 Oregon .............................................................................................. 53

3.29.1 Hazardous Waste Regulations .............................................................. 53

3.29.2 Additional Pertinent Statutory or Regulatory Provisions ......................... 56

3.30 Pennsylvania ................................................................................................. 5

3.30.1 Hazardous Waste Regulations .............................................................. 57

3.30.2 Additional Pertinent Statutory or Regulatory Provisions ......................... 57

3.31 South Carolina .............................................................................................. 58

3.31.1 Hazardous Waste Regulations ............................................................. 58

3.31.2 Additional Pertinent Statutory or Regulatory Provisions ……………...... 58

3.32 South Dakota................................................................................................ 59

3.32.1 Hazardous Waste Regulations ............................................................... 59

3.32.2 Additional Pertinent Statutory or Regulatory Provisions .......................... 59 


\section{CONTENTS (Cont.)}

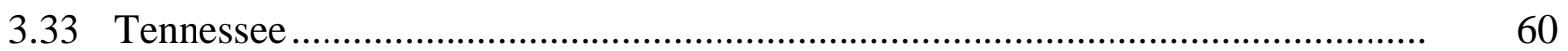

3.33.1 Hazardous Waste Regulations ................................................................. 60

3.33.2 Additional Pertinent Statutory or Regulatory Provisions .......................... 60

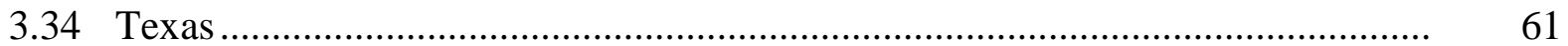

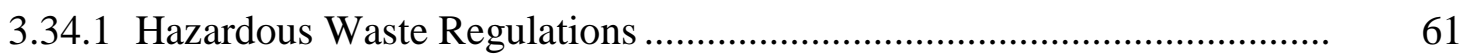

3.34.2 Additional Pertinent Statutory or Regulatory Provisions ......................... 62

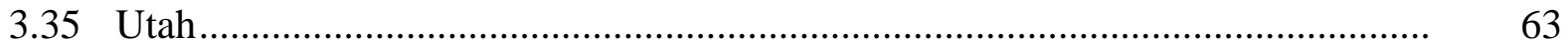

3.35.1 Hazardous Waste Regulations ............................................................. 63

3.35.2 Additional Pertinent Statutory or Regulatory Provisions ......................... 63

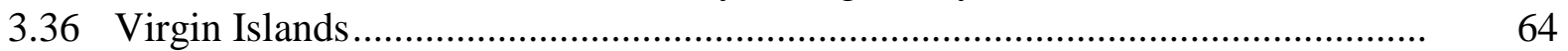

3.36.1 Hazardous Waste Regulations ................................................................ 64

3.36.2 Additional Pertinent Statutory or Regulatory Provisions ………………... 64

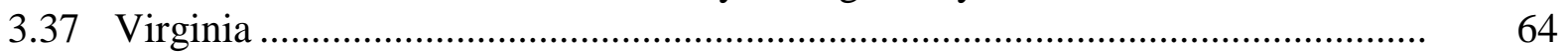

3.37.1 Hazardous Waste Regulations ................................................................. 64

3.37.2 Additional Pertinent Statutory or Regulatory Provisions ........................... 65

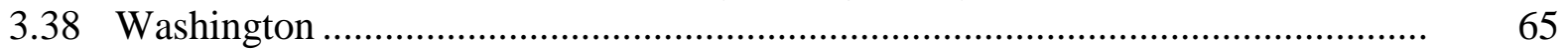

3.38.1 Hazardous Waste Regulations ................................................................ 65

3.38.2 Additional Pertinent Statutory or Regulatory Provisions ……………...... 68

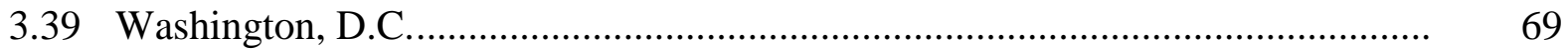

3.39.1 Hazardous Waste Regulations ............................................................... 69

3.39.2 Additional Pertinent Statutory or Regulatory Provisions ……………...... 69

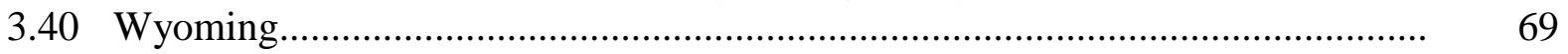

3.40.1 Hazardous Waste Regulations ............................................................... 69

3.40.2 Additional Pertinent Statutory or Regulatory Provisions ......................... $\quad 70$

4 SUMMARY OF APPLICABLE PROVISIONS IN 40 STATES

AND JURISDICTIONS .....................................................................................

\section{TABLES}

1 Chemical Weapons or Chemical Warfare Agents Managed by the U.S. Army ………..... 5

2 Chemical Weapons or Chemical Warfare Agents Listed as Extremely Hazardous

Substances under EPCRA Emergency Planning and Emergency Release

Notification Program

3 Washington State Toxic Categories ........................................................................ 66

4 Statutory or Regulatory Provisions Applicable to Waste Chemical Weapons or Chemical Warfare Agents. 


\section{ACKNOWLEDGMENTS}

The authors wish to thank Peggy L. Gieseking, Environmental Team Leader of the Operations Enterprise, U.S. Army Soldier and Biological Chemical Command, and Terri L. Knudsen, Chemical Demilitarization Manager for the U.S. Army Pueblo Chemical Depot, for their guidance in preparing this document. The authors also wish to thank Nancy L. Ranek of Argonne National Laboratory for her technical review of the document and Catherine Kaicher of Argonne for editing and production support. 


\section{NOTATION}

$\begin{array}{ll}\text { AAC } & \text { Alaska Administrative Code } \\ \text { AAC } & \text { Arizona Administrative Code } \\ \text { AC } & \text { Arkansas Code } \\ \text { ADEC } & \text { Alaska Department of Environmental Conservation } \\ \text { ADEM } & \text { Alabama Department of Environmental Management } \\ \text { ADEQ } & \text { Arizona Department of Environmental Quality } \\ \text { ADEQ } & \text { Arkansas Department of Environmental Quality } \\ \text { ADES } & \text { Alaska Division of Emergency Services } \\ \text { AERC } & \text { Alabama Emergency Response Commission } \\ \text { AR } & \text { Administrative Rules } \\ \text { ARS } & \text { Arizona Revised Statutes } \\ \text { AS } & \text { Alaska Statutes } \\ & \\ \text { BHM } & \text { Idaho Bureau of Hazardous Materials } \\ & \\ \text { CAA } & \text { Clean Air Act } \\ \text { CAIS } & \text { chemical agent identification set } \\ \text { CAPP } & \text { Chemical Accident Prevention Program } \\ \text { CAS } & \text { Chemical Abstract Service } \\ \text { CCR } & \text { California Code of Regulations } \\ \text { CCR } & \text { Code of Colorado Regulations } \\ \text { CDPHE } & \text { Colorado Department of Public Health and Environment } \\ \text { CEPC } & \text { Colorado Emergency Planning Commission } \\ \text { CEPR } & \text { Kansas Commission on Emergency Planning and Response } \\ \text { CERCLA } & \text { Comprehensive Environmental Response, Compensation, and Liability Act } \\ \text { CFR } & \text { Code of Federal Regulations } \\ \text { CG } & \text { phosgene } \\ \text { CMR } & \text { Code of Massachusetts Regulations } \\ \text { COMAR } & \text { Code of Maryland Regulations } \\ \text { CSR } & \text { Missouri Code of State Regulations } \\ \text { CWA } & \text { Clean Water Act } \\ \text { CWM } & \text { chemical warfare materiel } \\ & \\ \text { DCA } & \text { Florida Department of Community Affairs } \\ \text { DCDOH } & \text { Washington, D.C., Department of Health } \\ \text { DCMR } & \text { Washington, D.C., Municipal Regulations } \\ \text { DOD } & \text { U.S. Department of Defense } \\ \text { DOT } & \text { U.S. Department of Transportation } \\ \text { DTSC } & \text { California Department of Toxic Substances Control } \\ & \\ \text { EPA } & \text { U.S. Environmental Protection Agency } \\ \text { EPCRA } & \text { Emergency Planning and Community Right-to-Know Act of 1986 } \\ \text { EPD } & \text { Environmental Protection Division, Georgia Department of Natural Resources } \\ & \end{array}$




\section{NOTATION (Cont.)}

FAC Florida Administrative Code

FDEP Florida Department of Environmental Protection

FFCA Federal Facility Compliance Act of 1992

FR

Federal Register

GA tabun

GB sarin

GD soman

H undistilled mustard

HAP hazardous air pollutant

HAR Hawaii Administrative Rules

HD distilled mustard

HDOH Hawaii Department of Health

HMTA Hazardous Materials Transportation Act

HOC halogenated organic compounds

HSWA Hazardous and Solid Waste Amendments of 1984

HT combination of HD and T-mustard

IAC Illinois Administrative Code

IAC Indiana Administrative Code

IC Iowa Code

IDAPA Idaho Rules of Practice and Procedures (Rules Promulgated in Accordance with

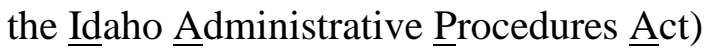

IDEM Indiana Department of Environmental Management

IDEQ Idaho Department of Environmental Quality

IDNR Iowa Department of Natural Resources

IEMA Illinois Emergency Management Agency

IEPA Illinois Environmental Protection Agency

KAR Kentucky Administrative Regulations

KDEP Kentucky Department of Environmental Protection

KDHE Kansas Department of Health and Environment

KRS Kentucky Revised Statutes

KyEM Kentucky Division of Emergency Management

KyERC Kentucky Emergency Response Commission

L lewisite

LAC Louisiana Administrative Code

LC lethal concentration

LD lethal dose

LDEQ Louisiana Department of Environmental Quality

LDR Land Disposal Restrictions (RCRA) 


\section{NOTATION (Cont.)}

LEPC local emergency planning committee

MAC Michigan Administrative Code

MDE Maryland Department of the Environment

MDEP Massachusetts Department of Environmental Protection

MDEQ Michigan Department of Environmental Quality

MDEQ Mississippi Department of Environmental Quality

MDNR Missouri Department of Natural Resources

MGL Massachusetts General Law

MSDS material safety data sheet

NAC Nevada Administrative Code

NCAC North Carolina Administrative Code

NCDENR North Carolina Department of Environment and Natural Resources

NDEP Nevada Department of Conservation and Natural Resources, Division of Environmental Protection

NDEQ Nebraska Department of Environmental Quality

NEMA Nebraska Emergency Management Agency

NIOSH National Institute of Occupational Safety and Health

N.J.A.C. New Jersey Administrative Code

NJDEP New Jersey Department of Environmental Protection

NJSA New Jersey Statutes Annotated

NMAC New Mexico Administrative Code

NMED New Mexico Environment Department

NPDES National Pollutant Discharge Elimination System

NYCRR New York Code, Rules and Regulations

NYDEC New York Department of Environmental Conservation

OAC Ohio Administrative Code

OAR Oregon Administrative Rules

O.C.G.A. Official Code of Georgia Annotated

ODEQ Oregon Department of Environmental Quality

OEPA Ohio Environmental Protection Agency

ORS Oregon Revised Statutes

OSHA Occupational Safety and Health Administration

PAH polycyclic aromatic hydrocarbon

PC Pennsylvania Code

PCB polychlorinated biphenyl

PDEP Pennsylvania Department of Environmental Protection

PEMC Pennsylvania Emergency Management Council

ppm parts(s) per million 


\section{NOTATION (Cont.)}

\begin{tabular}{|c|c|}
\hline RCRA & Resource Conservation and Recovery Act \\
\hline RMP & Risk Management Plan \\
\hline RPP & $\begin{array}{l}\text { Rules of Practice and Procedures, Nebraska Department of Environmental } \\
\text { Quality }\end{array}$ \\
\hline RRST & Rules and Regulations of the State of Tennessee \\
\hline RTECS & Registry of Toxic Effects of Chemical Substances (NIOSH) \\
\hline SARA & Superfund Amendments and Reauthorization Act \\
\hline SCDHEC & South Carolina Department of Health and Environmental Control \\
\hline SCHWMR & South Carolina Hazardous Waste Management Regulations \\
\hline SDCL & South Dakota Codified Law \\
\hline SDDENR & South Dakota Department of Environment and Natural Resources \\
\hline SERC & state emergency response commission \\
\hline TAC & Texas Administrative Code \\
\hline TAP & toxic air pollutant \\
\hline TCDD & 2,3,7,8-tetrachlorodibenzo-p-dioxin \\
\hline TCLP & toxicity characteristic leaching procedure \\
\hline TDEC & Tennessee Department of Environment and Conservation \\
\hline TEMA & Tennessee Emergency Management Agency \\
\hline TNRCC & Texas Natural Resource Conservation Commission \\
\hline TRI & toxics release inventory \\
\hline TSDF & treatment, storage and disposal facility \\
\hline UAR & Utah Administrative Rules \\
\hline UCA & Utah Code Annotated \\
\hline UDEQ & Utah Department of Environmental Quality \\
\hline U.S.C. & United States Code \\
\hline VAC & Virginia Administrative Code \\
\hline VDEQ & Virginia Department of Environmental Quality \\
\hline VDES & Virginia Department of Emergency Services \\
\hline VERC & Virginia Emergency Response Council \\
\hline VIDEP & Virgin Island Division of Environmental Protection \\
\hline WAC & Washington Administrative Code \\
\hline WDE & Washington Department of Ecology \\
\hline WDEQ & Wyoming Department of Environmental Quality \\
\hline WHWRR & Wyoming Hazardous Waste Rules and Regulations \\
\hline
\end{tabular}




\title{
APPLICABILITY OF FEDERAL AND STATE HAZARDOUS WASTE REGULATORY PROGRAMS TO WASTE CHEMICAL WEAPONS AND CHEMICAL WARFARE AGENTS
}

by

\author{
R. Haffenden and T. Kimmell
}

\begin{abstract}
This report reviews federal and state hazardous waste regulatory programs that govern the management of chemical weapons or chemical warfare agents. It addresses state programs in the eight states with chemical weapon storage facilities managed by the U.S. Army: Alabama, Arkansas, Colorado, Indiana, Kentucky, Maryland, Oregon, and Utah. It also includes discussions on 32 additional states or jurisdictions with known or suspected chemical weapons or chemical warfare agent presence (e.g., disposal sites containing chemical agent identification sets): Alaska, Arizona, California, Florida, Georgia, Hawaii, Idaho, Illinois, Iowa, Kansas, Louisiana, Massachusetts, Michigan, Mississippi, Missouri, Nebraska, Nevada, New Jersey, New Mexico, New York, North Carolina, Ohio, Pennsylvania, South Carolina, South Dakota, Tennessee, Texas, the U.S. Virgin Islands, Virginia, Washington, Washington, D.C., and Wyoming. Resource Conservation and Recovery Act (RCRA) hazardous waste programs are reviewed to determine whether chemical weapons or chemical warfare agents are listed hazardous wastes or otherwise defined or identified as hazardous wastes. Because the U.S. Environmental Protection Agency (EPA) military munitions rule specifically addresses the management of chemical munitions, this report also indicates whether a state has adopted the rule and whether the resulting state regulations have been authorized by EPA. Many states have adopted parts or all of the EPA munitions rule but have not yet received authorization from EPA to implement the rule. In these cases, the states may enforce the adopted munitions rule provisions under state law, but these provisions are not federally enforceable.
\end{abstract}

\section{SUMMARY}

This report reviews federal and state hazardous waste regulatory programs that govern the management of chemical weapons or chemical warfare agents. It addresses state programs in the eight states with chemical weapon storage facilities managed by the U.S. Army: Alabama, Arkansas, Colorado, Indiana, Kentucky, Maryland, Oregon, and Utah. It also includes discussions on 32 additional states or jurisdictions with known or suspected chemical weapons or chemical warfare agent presence (e.g., disposal sites containing chemical agent identification sets [CAISs]). They are Alaska, Arizona, California, Florida, Georgia, Hawaii, Idaho, Illinois, Iowa, 
Kansas, Louisiana, Massachusetts, Michigan, Mississippi, Missouri, Nebraska, Nevada, New Jersey, New Mexico, New York, North Carolina, Ohio, Pennsylvania, South Carolina, South Dakota, Tennessee, Texas, the U.S. Virgin Islands, Virginia, Washington, Washington, D.C., and Wyoming.

Resource Conservation and Recovery Act (RCRA) hazardous waste programs are reviewed to determine whether chemical weapons or chemical warfare agents are listed hazardous wastes or otherwise defined or identified as hazardous wastes. Because the U.S. Environmental Protection Agency (EPA) military munitions rule specifically addresses the management of chemical munitions, this report also indicates whether a state has adopted the rule and whether the resulting state regulations have been authorized by EPA.

Six of the eight states with chemical weapon or chemical warfare agent storage or disposal facilities have designated these chemicals as listed hazardous wastes: Colorado, Indiana, Kentucky, Maryland, Oregon, and Utah. None of the other states or jurisdictions with known or suspected presence of chemical weapons or chemical warfare agents (e.g., CAIS disposal sites) have specifically designated chemical weapons or chemical warfare agents as listed hazardous wastes. Even in these states and jurisdictions, however, additional federal and state-specific statutory or regulatory provisions exist that could cause chemical weapons or chemical warfare agents to be governed as hazardous wastes.

Statutory or regulatory provisions outside the hazardous waste programs can also apply to the management of chemical weapons or chemical warfare agents that are wastes, including those that are newly discovered, accidentally spilled, or excavated as part of a facility remediation. For instance, under the Emergency Planning and Community Right-to-Know Act of 1986 (EPCRA), EPA has designated a List of Extremely Hazardous Substances (Appendix A in Title 40, Part 355 of the Code of Federal Regulations). All six chemical warfare agents addressed in this report are so listed. As an extremely hazardous substance, when a chemical warfare agent is present in any amount equal to or in excess of its threshold planning quantity, the facility where the agent resides must participate in EPCRA notification of the state emergency response committee and the local emergency planning committee, and it must cooperate in emergency response planning and coordination. In addition, releases of extremely hazardous substances and toxic chemicals are subject to certain reporting requirements.

The table in Section 4 summarizes the statutory and regulatory provisions that may apply to chemical weapons or chemical warfare agents in the states and jurisdictions discussed in this report. 


\section{INTRODUCTION}

This report reviews federal and state hazardous waste regulatory programs that govern the management of chemical weapons or chemical warfare agents. It addresses state programs in the eight states with chemical weapon storage facilities managed by the U.S. Army: Alabama, Arkansas, Colorado, Indiana, Kentucky, Maryland, Oregon, and Utah. It also includes discussions on 32 additional states or jurisdictions with known or suspected chemical weapons or chemical warfare agent presence (e.g., disposal sites containing chemical agent identification sets [CAISs]). They are Alaska, Arizona, California, Florida, Georgia, Hawaii, Idaho, Illinois, Iowa, Kansas, Louisiana, Massachusetts, Michigan, Mississippi, Missouri, Nebraska, Nevada, New Jersey, New Mexico, New York, North Carolina, Ohio, Pennsylvania, South Carolina, South Dakota, Tennessee, Texas, the U.S. Virgin Islands, Virginia, Washington, Washington, D.C., and Wyoming.

Resource Conservation and Recovery Act (RCRA) hazardous waste programs are reviewed to determine whether chemical weapons or chemical warfare agents are listed hazardous wastes or otherwise defined or identified as hazardous wastes. Because the U.S. Environmental Protection Agency (EPA) military munitions rule specifically addresses the management of chemical munitions, this report also indicates whether a state has adopted the rule and whether the resulting state regulations have been authorized by EPA. As indicated in Section 3 of this report, many states have adopted parts or all of the EPA munitions rule but have not yet received authorization from EPA to implement the rule. In these cases, the states may enforce the adopted munitions rule provisions under state law, but these provisions are not federally enforceable.

Often, statutory or regulatory provisions outside the hazardous waste programs can apply to the management of chemical weapons or chemical warfare agents that are wastes, including those that are newly discovered, accidentally spilled, or excavated as part of a facility remediation. For instance, under the Emergency Planning and Community Right-to-Know Act of 1986 (EPCRA), EPA has designated a List of Extremely Hazardous Substances (Appendix A in Title 40, Part 355 of the Code of Federal Regulations [40 CFR 355]). All six chemical warfare agents addressed in this report are so listed. As an extremely hazardous substance, when a chemical warfare agent is present in any amount equal to or in excess of its threshold planning quantity, the facility where the agent resides must participate in EPCRA notification of the state emergency response committee and the local emergency planning committee, and it must cooperate in emergency response planning and coordination. In addition, releases of extremely hazardous substances and toxic chemicals are subject to certain reporting requirements.

\subsection{REPORT ORGANIZATION}

This report first discusses the federal environmental regulatory provisions applicable to chemical weapons or chemical warfare agents (Section 2). In Section 3, each designated state or jurisdiction is addressed in a separate subsection. 
Each state subsection first discusses the state's hazardous waste regulations, particularly the status of chemical weapons or chemical warfare agents as listed hazardous wastes. Then any additional pertinent hazardous waste regulatory or statutory provisions that differ from the federal program and that may impact the regulation of chemical weapons or chemical warfare agents in the state are identified. Finally, any additional federal or state regulations outside hazardous waste programs that could be applicable to chemical weapons or chemical warfare agents are discussed.

The table in Section 4 summarizes the statutory and regulatory provisions that may apply to chemical weapons or chemical warfare agents in the states and jurisdictions discussed in this report.

\subsection{METHODOLOGY}

The application of RCRA regulations to the management of chemical weapons or chemical warfare agents has become an important issue, both in states with stockpile storage facilities and in other jurisdictions, because of the potential for discovery of chemical weapons or chemical warfare agents during emergency response or remediation activities. For example, such items have been discovered at Spring Valley in Washington, D.C., and at the Rocky Mountain Arsenal in Colorado. Therefore, this report first reviews federal RCRA regulations to determine whether chemical weapons or chemical warfare agents are regulated as listed hazardous wastes by EPA (40 CFR 261 Subpart D). RCRA characteristic wastes are also addressed.

Other federal statues and regulations may also impact the management of chemical weapons or chemical warfare agents, including the Comprehensive Environmental Response, Compensation, and Liability Act (CERCLA), EPCRA, Clean Water Act (CWA) (including the National Pollutant Discharge Elimination System [NPDES] program), Clean Air Act (CAA), and Hazardous Materials Transportation Act (HMTA). These federal statutes and regulations are therefore also reviewed.

Statutes and environmental regulations for each state and jurisdiction are then reviewed. State RCRA statutes and regulations are reviewed for references to chemical weapons or chemical warfare agents and for provisions of a general nature that could extend their applicability to chemical weapons or chemical warfare agents (e.g., a broader definition of the toxicity listing criteria or of one of the characteristics of hazardous waste than is contained in the EPA regulations). Specifically, state statutes and regulations are examined to determine whether the state definition of hazardous waste differs from that of the federal regulatory program, or whether the regulatory body or state legislature has established listing criteria for acute or toxic hazardous wastes other than those criteria that are delineated under the federal RCRA program. State EPCRA, CWA, and CAA statutes and regulations are also examined to determine whether they regulate chemical weapons or chemical warfare agents as hazardous substances, hazardous pollutants, or hazardous materials. 
Federal and state statutes and regulations are reviewed for references to the chemical weapons or chemical warfare agents listed in Table 1, below. Each search or review is based upon the common name of the chemical or the Chemical Abstract Service (CAS) Registry numbers identified for those chemicals in applicable Material Safety Data Sheets (MSDSs).

It is recognized that there are other chemicals or chemical mixtures that may be considered chemical warfare agents in certain contexts; however, these are not specifically reviewed because they are not generally managed by the Army on a regular basis. Nevertheless, if these other chemicals are included in state regulations in the context of chemical warfare agents, they are covered in this report under the discussions of state-specific regulations. These include, for example, the chemicals BZ, CX (phosgene oxime), GD (soman), GF, HL (a combination of HD and L), and HN-1, -2 , and -3 (forms of nitrogen mustard).

Note that many of the passages in this report reflect the actual language used in state statutes and regulations. Although some of these passages may be written poorly or be unclear, repeating the actual language was determined to be the best course of action, rather than speculating on what was intended.

TABLE 1 Chemical Weapons or Chemical Warfare Agents Managed by the U.S. Army

\begin{tabular}{lc}
\hline \multicolumn{1}{c}{ Common Chemical Name } & CAS Number \\
\hline $\begin{array}{l}\text { Phosgene (CG) } \\
\text { Mustard gas (H, HD) }\end{array}$ & $75-44-5$ \\
(HD is the distilled form of H) & $505-60-2$ \\
HT (HT is a 60:40 combination of & $63918-89-8^{\mathrm{b}}$ \\
H/HD with T-Mustard) & \\
Sarin (GB) & $107-44-8$ \\
VX & $50782-69-9$ \\
Tabun (GA) & $77-81-6$ \\
Lewisite (L) & $541-25-3$ \\
\hline & \\
a & \\
The search conducted for HT was based on mustard \\
b
\end{tabular}




\section{FEDERAL ENVIRONMENTAL PROGRAMS}

\subsection{RESOURCE CONSERVATION AND RECOVERY ACT}

\subsubsection{Listed Hazardous Waste Designation}

Phosgene (CAS No. 75-44-5) is the only chemical warfare agent that is a listed hazardous waste under the federal RCRA program [40 CFR 261.33(e)]. It is listed as an acute hazardous waste commercial chemical or manufacturing chemical intermediate and is assigned the EPA hazardous waste code of P095.

Under these regulations, the phrase "commercial chemical product or manufacturing chemical intermediate having the generic name listed in..." has a specific meaning. It refers to a chemical substance which is manufactured or formulated for commercial or manufacturing use and consists of the commercially pure grade of the chemical, any technical grades of the chemical that are produced or marketed, and all formulations in which the chemical is the sole active ingredient. It does not refer to a material, such as a manufacturing process waste, that simply contains a substance listed in these regulations (40 CFR 261.33).

Pursuant to the RCRA mixture and derived-from rules [40 CFR 261.3(a)(2)(iv) and 40 CFR 261.3(c)(2)(i), respectively], wastes that are mixed with listed hazardous waste, or that are derived-from the treatment, storage, or disposal of listed hazardous waste (e.g., treatment residues), are themselves regulated as the listed hazardous waste.

Under the RCRA rules, any residue remaining in a container or in an inner liner removed from a container that has held any listed commercial chemical product or manufacturing chemical intermediate is a listed hazardous waste, unless the container is empty as defined under the regulations. A container is determined to be empty, and therefore not hazardous waste, based on a number of criteria:

A container is empty if all wastes have been removed that can be removed using the practices commonly employed to remove materials from that type of container, e.g., pouring, pumping, and aspirating, and no more than 2.5 centimeters (one inch) of residue remains on the bottom of the container or inner liner, or no more than 3 percent by weight of the total capacity of the container remains (if the container is less than or equal to 110 gallons in size), or no more than 0.3 percent by weight of the total capacity of the container remains (if the container is greater than 110 gallons in size) [40 CFR 261.7(b)(1)].

However, a container that has held an acute hazardous waste is determined to be empty if the container or inner liner has been triple rinsed using a solvent capable of removing the commercial chemical product or manufacturing chemical intermediate or has been cleaned by another method that has been shown in scientific literature or by tests conducted by the generator to achieve equivalent 
removal or the inner liner, which protected the inner surface of the container, has been removed and disposed of properly [40 CFR 261.7(b)(3)].

Any residue or contaminated soil, water, or debris resulting from the cleanup of a spill into or on any land or water of any listed commercial chemical product or manufacturing intermediate waste [40 CFR 261.33(e) and (f)], is a listed waste bearing the same hazardous waste code as the spilled listed waste (unless the responsible regulatory agency determines that it no longer contains the hazardous waste).

Appendix VIII to 40 CFR Part 261 identifies the universe of "hazardous constituents" of concern under RCRA and is used by EPA primarily to identify wastes that should be considered for listing (40 CFR 261.11). It consists of chemicals that have toxic, carcinogenic, mutagenic, or teratogenic effects on humans or other life forms. Mustard gas (CAS No. 505-60-2) is the only chemical warfare agent listed as a hazardous constituent under Appendix VIII. The list includes chemicals that are:

- Listed as priority pollutants under the Clean Water Act,

- Considered hazardous to transport by the U.S. Department of Transportation (DOT),

- Identified as carcinogens by EPA's Carcinogen Assessment Group, or

- Identified by the National Institute of Occupational Safety and Health (NIOSH) Registry of Toxic Effects of Chemical Substances (RTECS) as having a high acute toxicity.

The EPA, and most states that have adopted EPA's RCRA regulations, also have a general provision for designating materials as hazardous wastes for purposes of protecting human health and the environment from imminent and substantial endangerment. Under this section [40 CFR 261.1(b)(2)], the regulation states:

This part identifies only some of the materials which are solid wastes and hazardous wastes under sections 3007, 3013, and 7003 of RCRA. A material which is not defined as a solid waste in this part, or is not a hazardous waste identified or listed in this part, is still a solid waste and a hazardous waste for purposes of these sections if:

(i) In the case of sections 3007 and 3013, EPA has reason to believe that the material may be a solid waste within the meaning of section 1004(27) of RCRA and a hazardous waste within the meaning of section 1004(5) of RCRA; or

(ii) In the case of section 7003, the statutory elements are established. 
Available public information does not reference an instance where EPA has invoked this general provision to declare a solid waste a hazardous waste, even when the solid waste does not demonstrate one of the regulatory hazardous characteristics and is not listed in the regulations (however, see Connecticut Coastal Fisherman's Association vs. Remington Arms Co., 989 F2d 1305 [2d Circuit 1993]). Also, under this section, it is feasible that EPA, and presumably any state with EPA authorization to implement the RCRA program, could declare a solid waste (e.g., discarded or abandoned chemical warfare agent or munitions) a hazardous waste when the regulatory body has reason to believe that the waste is being handled, stored, treated, transported, or disposed of so as to present an imminent and substantial endangerment to health or the environment under RCRA (RCRA Section 7003; 42 United States Code [U.S.C.] 6973) and meets the statutory definition of a solid waste and hazardous waste (RCRA Section 1004; 42 U.S.C. 6903).

\subsubsection{Hazardous Waste Characteristics}

A waste may also be designated hazardous when it exhibits any of the federal RCRA hazardous waste characteristics. These characteristics include ignitability, corrosivity, reactivity, and toxicity (40 CFR 261.21-261.24), as follows:

Ignitability (40 CFR 261.21) - An ignitable waste is a waste that (1) is a liquid, other than an aqueous solution containing less than 24 percent alcohol by volume, and has a flash point less than $60^{\circ} \mathrm{C}$ or $140^{\circ} \mathrm{F}$ as determined by various test methods; (2) is not a liquid and is capable, under standard temperature and pressure, of causing fire through friction, absorption of moisture, or other spontaneous chemical changes and, when ignited, burns so vigorously and persistently that it creates a hazard; (3) is an ignitable compressed gas; or (4) is an oxidizer as defined in U.S. Department of Transportation (DOT) regulations.

Corrosivity (40 CFR 261.22) - A corrosive waste is a waste that (1) is aqueous and has a $\mathrm{pH}$ less than or equal to 2 or greater than or equal to 12.5 ; or (2) is a liquid and corrodes steel (SAE 1020) at a rate greater than $6.35 \mathrm{~mm}(0.250 \mathrm{inch})$ per year at a test temperature of $55^{\circ} \mathrm{C}\left(130^{\circ} \mathrm{F}\right)$.

Reactivity (40 CFR 261.23) - A reactive waste is a waste that (1) is normally unstable and readily undergoes violent change without detonating; (2) reacts violently with water; (3) forms potentially explosive mixtures with water; (4) when mixed with water or, when it is a cyanide- or sulfide-bearing waste that, when exposed to $\mathrm{pH}$ conditions between 2.0 and 12.5, can generate toxic gases, vapors, or fumes in a quantity sufficient to present a danger to human health or the environment; (5) is capable of detonation or explosive reaction if it is subjected to a strong initiating source or if heated under confinement; (6) is readily capable of detonation or explosive decomposition or reaction at standard temperature and pressure; or (7) is a forbidden explosive as defined in DOT regulations. 
Toxicity (40 CFR 261.24) - A toxic waste is a waste that contains concentrations of certain listed contaminants above established thresholds when tested using the Toxicity Characteristic Leaching Procedure (TCLP), a leaching test. Contaminants include both organic (e.g., pesticides, chlorinated organics) and inorganic contaminants (e.g., heavy metals, including $\mathrm{As}, \mathrm{Ba}, \mathrm{Cd}, \mathrm{Cr}, \mathrm{Hg}, \mathrm{Pb}$, Se, and $\mathrm{Ag}$ ).

Unlike listed hazardous waste, wastes that exhibit one or more of the RCRA characteristics are not subject to the RCRA mixture or derived-from rules. Wastes may be both listed hazardous waste and exhibit one or more characteristics.

Whether some or all of the chemical warfare agents listed in Table 1 exhibit any of the RCRA characteristics has been a subject of debate. The one exception is lewisite, which, because it contains arsenic, will typically exhibit the RCRA toxicity characteristic. Chemical warfare agents do not appear to be ignitable. Mustard agents and GB could be considered corrosive; however, because these chemicals are not aqueous, the RCRA corrosivity characteristic $\mathrm{pH}$ test would not apply. The agents, including mustard, might fall under the corrosivity characteristic via the steel corrosion criterion. Under the high heat conditions of the SAE 1020 test, however, the agents are likely to degrade or volatize before the steel could be corroded at the designated rate.

Whether the agents exhibit reactivity is less clear. Whereas stockpile or nonstockpile items that are explosively configured would exhibit the characteristic of reactivity, the agents themselves appear to not meet the conditions established by the reactivity characteristic. The only aspect of reactivity that may pertain to chemical warfare agents is the criterion of "when mixed with water or, when it is a cyanide- or sulfide-bearing waste that, when exposed to $\mathrm{pH}$ conditions between 2.0 and 12.5, can generate toxic gases, vapors, or fumes in a quantity sufficient to present a danger to human health or the environment." The agents are liquids at standard temperature and pressure; under most conditions, mixing with water would not evolve the agent to the gaseous phase. The more likely result of mixing with water would be rapid agent hydrolysis. For this reason, agent neutralents (also called hydrolysates) and decontamination fluids are typically aqueous in nature; however, some toxic gases could be generated by the agents upon mixing with water.

The most likely characteristic that the chemical warfare agents might exhibit is toxicity. The heavy metals would be of primary concern. With the exception of lewisite, which contains arsenic, the agents themselves do not contain metals. From years of close association with the metal casing in stockpile and nonstockpile items, however, metals may have leached into the agent formulations. Some agent formulations may also contain one or more of the organic contaminants included under the RCRA toxicity characteristic. Of particular note are the chlorinated organics, which could be present in mustard-containing stockpile and nonstockpile items.

Secondary wastes, contaminated media, and other wastes could also exhibit one or more of the RCRA characteristics. Some neutralents are aqueous and caustic, for example, and may exhibit the characteristic of corrosivity. They may also contain heavy metals or organic constituents and in cases could exhibit the RCRA toxicity characteristic. 
Although it seems that whether certain chemical agents exhibit RCRA characteristics is questionable, these chemicals may nevertheless be considered to exhibit RCRA characteristics under state hazardous waste laws or interpretations.

Under the RCRA program, the waste generator is responsible for determining, using either knowledge of the waste or actual testing, whether the waste exhibits any of the RCRA characteristics. Waste generators may also choose to manage their wastes as hazardous waste even when the waste is not defined as hazardous under the RCRA program. In the Final Programmatic Environmental Impact Statement for Transportable Treatment Systems for NonStockpile Chemical Warfare Materiel (February 2001), for example, the Army indicates the following (in which CWM stands for chemical warfare materiel):

The Army intends to consider (1) all recovered CWM, (2) solid waste that has come into contact with this CWM via the mixture rule [40 CFR 261.3(a)(2)(iii and iv)], and (3) solid waste generated from the treatment, storage, or disposal of this CWM via the derived from rule [40 CFR 261.3(c)(2)(i)] ... as statutory hazardous waste. In accordance with RCRA, CWM in any physical state including solid, liquid, semisolid, or contained gaseous material - would be included in this consideration. As such, the Army would then manage this waste as regulatory hazardous waste subject to all appropriate RCRA regulations.

\subsubsection{The RCRA Military Munitions Rule}

The Military Munitions Rule was proposed by EPA on November 8, 1995 (60 Federal Register [FR] 56467) and finalized on February 12, 1997 (62 FR 6621). These regulations were mandated by Section 107 of the Federal Facility Compliance Act (FFCA) of 1992. That section amended RCRA by adding a new Section 3004(y) requiring EPA to propose regulations, after consultation with the Department of Defense (DOD) and appropriate state officials, that would identify when conventional and chemical military munitions become hazardous waste under RCRA, and would provide for the safe storage and transportation of such wastes.

The final rule clarifies application of the regulatory definition of solid waste as it applies to three specific categories of military munitions: (1) unused munitions, (2) munitions being used for their intended purpose, and (3) used or fired munitions. Unused munitions are considered to be solid waste for regulatory purposes when the unused munition:

- Is abandoned by being disposed of, burned, incinerated, or treated prior to disposal;

- Is removed from storage for the purposes of disposal or treatment prior to disposal; 
- Is deteriorated, leaking or damaged to the point that it can no longer be put back into serviceable condition, and cannot be reasonably recycled or used for other purposes; or

- Is determined by an authorized military official to be a solid waste.

A munition is not solid waste for regulatory purposes when it:

- Is being used for its intended purpose, including when it is used for training purposes, for research, development, testing and evaluation purposes, or when it is destroyed during range clearance operations at active and inactive ranges; or

- Has not been used or discharged and it, or any of its components, is repaired, reused, recycled, reclaimed, disassembled, reconfigured, or otherwise subject to materials recovery activities.

The rule also specifies that used or fired munitions are solid wastes when they are removed from their landing spot and then either managed off-range (i.e., transported, stored, reclaimed, treated or disposed of), or disposed of on-range (i.e., buried or landfilled). In both of these cases, the used or fired munition is potentially subject to regulation as a hazardous waste. Also, munitions that land off-range and that are not promptly retrieved are considered to be solid waste as defined by the RCRA statute. However, the rule defers final action on the status of used or fired munitions or residues at closed, transferred, or transferring ranges.

In addition to the above, the final rule provides conditional exemptions from specific RCRA requirements in two cases. First, the rule conditionally exempts from RCRA manifest and container marking requirements, waste nonchemical military munitions that are shipped from one military-owned or -operated treatment, storage, and disposal facility (TSDF) to another in accordance with DOD military munitions shipping controls. Second, waste nonchemical military munitions subject to DOD Explosive Safety Board storage standards are conditionally exempt from RCRA storage requirements. Waste chemical munitions are not eligible for these conditional exemptions, and must comply with RCRA storage requirements as established in 40 CFR 264, 265, and 266. The rule does clarify, however, that chemical munitions are not subject to the Land Disposal Restrictions (LDRs) storage prohibition established in RCRA Section 3004(j).

Other aspects of the rule apply specifically to chemical munitions. Accordingly, the rule and preamble should be reviewed for additional information. In addition, state regulations that implement the munitions rule should be reviewed. However, since EPA has declared the munitions rule to be less stringent than existing federal RCRA regulations pertaining to storage and transportation of hazardous wastes, states and other jurisdictions are not required to implement its provisions. Even so, those that do adopt the munitions rule provisions may choose to establish standards that are more stringent or broader in scope. 


\subsubsection{State RCRA Authorization Programs}

RCRA was intended by Congress to be a state-implemented program. EPA was charged with developing federal regulations that would establish a cradle-to-grave system for management of hazardous wastes. However, provisions were included for states and other jurisdictions, which must first be found qualified by EPA, to take over administration and enforcement of the RCRA program within their boundaries. EPA implements the program within states and other jurisdictions that choose not to adopt and implement a hazardous waste program.

Those states or jurisdictions that choose to implement the RCRA program within their boundaries must receive RCRA base authorization, which consists of authorization to administer and enforce the portion of the federal hazardous waste program sanctioned by RCRA provisions (as amended) that predate the Hazardous and Solid Waste Amendments of 1984 (HSWA). States may also become authorized on a case-by-case basis to administer and enforce portions of the federal hazardous waste program sanctioned by the HSWA (e.g., LDRs and corrective action requirements). Hence, some states and other jurisdictions only have authorization to implement certain portions of the RCRA program.

After a state or other jurisdiction becomes authorized to implement any portion of the federal RCRA hazardous waste program, it must update its regulations to reflect any changes made by EPA to the federal hazardous waste regulations that are more stringent. In addition, it may at any time adopt regulations that are more stringent or broader in scope than the federal hazardous waste program. If EPA adopts less stringent federal regulations, authorized jurisdictions have the option to leave their programs unchanged.

There are three ways for states or jurisdictions to adopt federal RCRA regulations. First, states can adopt rules that are structured or worded differently from federal regulations, as long as they are no less stringent and equivalent in effect. Second, states can adopt the federal regulations verbatim. In this case, the states merely transcribe the federal regulations into their own regulatory programs. Lastly, states have the option of adopting RCRA regulations by reference. As will be seen in Section 3 of this document, most states have chosen to adopt the federal regulations verbatim, but some include important differences as well. As long as these differences result in a program that is no less stringent than the federal program, they may be authorized by EPA.

\subsection{COMPREHENSIVE ENVIRONMENTAL RESPONSE, COMPENSATION, AND LIABILITY ACT}

Phosgene is the only chemical weapon or chemical warfare agent identified as one of the hazardous substances under Section 101(14) of CERCLA [42 U.S.C. 9601(14)]. Phosgene has a designated reportable quantity of 10 pounds $(4.54 \mathrm{~kg}$ ) (40 CFR 302, Table 302.4).

Under CERCLA, if there has been a release of a hazardous substance in excess of the reportable quantity, notification must be made immediately to the National Response Center. In addition, the person having control of the facility with a release of a hazardous substance is 
responsible for initiating any removal or remediation actions that may be required. Such removal or remediation must be conducted under the oversight of the appropriate lead agency, which can be the EPA, the appropriate federal agency (e.g., the Department of Defense [DOD]), or a state or political subdivision operating pursuant to a contract or cooperative agreement with EPA.

CERCLA cleanup actions require very specific evaluations, identification of regulatory chemical remediation standards and levels, health assessments, and public participation (40 CFR 300). Remediation activities must also comply with applicable, relevant, and appropriate regulations, including RCRA and other federal and state environmental statutes and regulations (40 CFR 300.430).

\subsection{EMERGENCY PLANNING AND COMMUNITY RIGHT-TO-KNOW ACT}

The Emergency Planning and Community Right-to-Know Act, or EPCRA, codified at 42 U.S.C. 11001-11050, was enacted in 1986 as Title III of the Superfund Amendments and Reauthorization Act (Public Law 99-499). There are four major provisions of EPCRA: emergency planning, emergency release notification, hazardous chemical inventory reporting, and toxic chemical release inventory reporting. Because the statutory definition of "person" does not include the federal government, EPCRA does not apply to federally owned and operated facilities. However, Executive Order 12856 (August 3, 1993), requires all federal facilities to comply with EPCRA.

Under EPCRA, EPA has designated a List of Extremely Hazardous Substances (EPCRA Section 302; 40 CFR 355, Appendix A). The chemical weapons or chemical warfare agents listed in Table 2 are designated as extremely hazardous substances under EPCRA. The corresponding reportable quantity and threshold planning quantity for each chemical warfare agent are shown in the table.

\subsubsection{EPCRA Emergency Planning}

Section 301 of EPCRA establishes state emergency response commissions (SERCs) and local emergency planning committees (LEPCs) to develop and implement procedures for responding to a release of hazardous materials. If a facility has present an extremely hazardous substance in an amount equal to or in excess of its threshold planning quantity, the facility must notify the LEPC and participate in emergency response planning and coordination (40 CFR 355.30). Upon request of the LEPC, the owner of the facility shall promptly provide any information necessary for development or implementation of the local emergency plan. The threshold planning quantity for each chemical weapon or chemical warfare agent is shown in Table 2. 
TABLE 2 Chemical Weapons or Chemical Warfare Agents Listed as Extremely Hazardous Substances under EPCRA Emergency Planning and Emergency Release Notification Program (40 CFR 355, Appendix A)

\begin{tabular}{lcc}
\hline \multicolumn{1}{c}{ Chemical } & $\begin{array}{c}\text { Threshold Planning } \\
\text { Quantity (lb) }\end{array}$ & $\begin{array}{c}\text { Reportable Quantity } \\
(\mathrm{lb})\end{array}$ \\
\hline Lewisite & 10 & 10 \\
Mustard gas & 500 & 500 \\
Phosgene & 10 & 10 \\
Sarin (GB) & 10 & 10 \\
Tabun & 10 & 10 \\
VX & 100 & 100 \\
\hline
\end{tabular}

\subsubsection{EPCRA Emergency Release Notification}

Releases of EPCRA extremely hazardous substances (40 CFR 355, Appendix A) or CERCLA hazardous substances (40 CFR 302.4) in excess of the reportable quantity must be reported to the LEPC and SERC (EPCRA Section 304; 40 CFR 355.40). This requirement does not apply to releases which result in exposure to persons solely within the boundaries of the facility, federally permitted releases, or any releases that are exempt or do not meet the definition of a release under CERCLA [40 CFR 302.8; CERCLA Section 103(a) or 101(22)]. The reportable quantities for chemical weapons or chemical warfare agents are shown in Table 2. (Note: The only listed chemical agent that is a CERCLA hazardous substance is phosgene. The reportable quantity for phosgene under both EPCRA and CERCLA is the same - 10 pounds.)

Many states also specifically reference the EPCRA List of Extremely Hazardous Substances or EPA "List of Lists," which includes EPCRA Section 302 Extremely Hazardous Substances, CERCLA Hazardous Substances, EPCRA Section 312 Toxic Chemicals, and Clean Air Act Section 112(r) Regulated Chemicals for Accidental Release Prevention, as the basis for chemicals and reportable quantities for state-specific emergency response legislation and implementing regulations.

\subsubsection{EPCRA Emergency and Hazardous Chemical Inventories}

Facilities that store or use hazardous chemicals in excess of specified threshold levels must supply an initial chemical inventory to the LEPC, SERC, and local fire department (EPCRA Sections 311 and 312; 40 CFR 370). Hazardous chemicals are defined as any chemical required by Occupational Safety and Health Administration (OSHA) regulations to have an MSDS [29 CFR 1910.1200(c)]. The minimum reporting quantity for EPCRA extremely hazardous substances is the threshold planning quantity or 500 pounds, whichever is lower. For all other hazardous chemicals with MSDSs, with certain exceptions, the threshold is 
10,000 pounds. Notably, hazardous wastes, as defined in and regulated by RCRA, are not required to have MSDSs. Therefore, if the chemical weapons or chemical warfare agents have been declared hazardous waste and are being managed under RCRA, these inventory reporting sections of EPCRA would not apply. Otherwise, as EPCRA extremely hazardous substances, the minimum threshold for chemical inventory reporting is the threshold reporting quantity shown in Table 2 . This initial chemical inventory must be updated when the facility begins storing a newly covered chemical or when significant new information on already reported chemicals comes to light.

In addition, each March 1, the affected facility must submit to the SERC, LEPC, and local fire department an annual report providing information on hazardous chemicals stored or used on-site during the previous year. This report can be submitted on either an EPA Tier I or Tier II form. Tier I forms allow the facility to report an estimate of the maximum amount of chemicals for each of five categories (fire hazard, sudden release of pressure, reactivity, immediate/acute health hazard, and delayed/chronic health hazard) present at the facility at any time during the preceding calendar year, the average daily amount in each category, and the general location. The Tier II form solicits this information, as well as the name of the specific chemicals and a brief description of the manner of storage.

Approximately 33 states require regulated facilities to submit Tier II forms, and most of the remaining states recommend that facilities submit Tier II forms. In some states, the SERC or LEPC may have modified the federal Tier II form to provide for the collection of additional information under state and local laws. They may even call their form by another name. However, if a state form meets federal requirements, a facility usually need only submit a single form to meet its EPCRA reporting requirements.

\subsubsection{EPCRA Toxics Release Inventory Reporting}

Phosgene and mustard gas are listed as toxic chemicals under EPCRA Section 313 (40 CFR 372.65). As such, facilities that manufacture, process, or otherwise use phosgene or mustard gas in excess of the applicable annual threshold quantity must submit a toxics release inventory (TRI) report, certification, and notification to EPA and to the state in which the facility is located (40 CFR 372.30). Because chemical weapons and chemical warfare agents are not currently being manufactured or processed by DOD components, the annual threshold reporting quantity for phosgene and mustard gas would be the annual threshold reporting quantity established for chemicals "otherwise used" at a facility, which is 10,000 pounds (40 CFR 372.25). For this purpose, an "otherwise use" of a toxic chemical at a facility is any use not constituting manufacturing or processing, with the exception of disposal, stabilization, or treatment for destruction of wastes generated on-site (40 CFR 372.3).

Each year, a facility that otherwise uses toxic chemicals in excess of the TRI annual threshold reporting quantity must submit a TRI Report (EPA Form R). This EPCRA requirement is not for emergency release reporting, but is to determine the total amount of toxic chemicals released to the environment during the year. For purposes of completing the form, release is defined as any spilling, leaking, pumping, pouring, emitting, emptying, discharging, injecting, 
escaping, leaching, dumping, or disposing into the environment (including disposal off-site). The information reported on the EPA Form $\mathrm{R}$ is submitted to both the state and the EPA. Many states do not require additional reporting; however, two states, New Jersey and Massachusetts, have passed laws with more stringent reporting requirements than those found in federal TRI reporting provisions.

\subsection{CLEAN WATER ACT}

Under the EPA NPDES program, no permit may be issued for the discharge of any radiological, chemical, or biological warfare agent [33 U.S.C. 1311(f); 40 CFR 122.4(f)]. Therefore, no NPDES permit (or state equivalent) can be issued to allow the discharge of any chemical warfare agent to the waters of the United States or waters of the applicable state. Nineteen of the states discussed herein have NPDES permitting authority and have adopted the NPDES restriction against issuing permits for the discharge of chemical warfare agents [40 CFR 123.25(a)(1)]. Four of the states discussed herein do not have EPA authorization for general permitting authority and the NPDES program is implemented by the appropriate EPA Regional Office (i.e., Alaska, Arizona, Massachusetts, and Texas). Because the CWA prohibition against permitting discharge of chemical warfare agents is in effect in all states, this prohibition is not separately identified in the state-specific discussions in Section 3.

Phosgene is a listed hazardous substance under Section 311 of the CWA 33 U.S.C. 1321; 40 CFR 116.4). Notification of an unpermitted discharge of a designated hazardous substance from a vessel or facility in quantities equal to or exceeding the reportable quantity (in any 24-hour period) must be made to the appropriate agency (40 CFR 117.21). The reportable quantity for a discharge of phosgene is 10 pounds (4.54 kg) (40 CFR 117.3).

\subsection{CLEAN AIR ACT}

Phosgene is a hazardous air pollutant (HAP) under Section 112(r) of the Clean Air Act [42 U.S.C. 7412(r)]. Under the EPA Accidental Release Prevention Program, any person who stores or uses more than a threshold amount of a HAP must develop a Risk Management Plan (RMP) (40 CFR 68.12). Therefore, if more than the threshold amount of phosgene (500 pounds) is to be stored, an RMP has to be developed and filed with the EPA or the state implementing agency (not all states, however, have received delegation to implement the RMP program).

Those states with EPA delegation have adopted and implemented verbatim the EPA Accidental Release Prevention Program regulations (40 CFR 68). For those without delegation, the same regulations are implemented by the appropriate EPA regional office. Therefore, EPA's Accidental Release Prevention Program regulations are not discussed in Section 3 as statespecific requirements. 


\subsection{HAZARDOUS MATERIALS TRANSPORTATION ACT}

DOT regulates the transportation of hazardous materials on the public highways, including classifying and packaging of hazardous materials, marking of containers, and placarding of vehicles (49 U.S.C. 5103; 49 CFR 173). Under DOT regulations, hazardous material means a substance or material that has been determined by the Secretary of Transportation to be capable of posing an unreasonable risk to health, safety, and property when transported in commerce, and which has been so designated. The term includes hazardous substances, hazardous wastes, marine pollutants, elevated-temperature materials, materials designated as hazardous by the Secretary of Transportation, and materials that meet the defining criteria for hazard classes and divisions as provided in the regulations (49 CFR 171.8). Of the chemical weapons and chemical warfare agents, only phosgene is specifically listed as a hazardous material (i.e., poisonous gas) under DOT regulations (49 CFR 172.101, Hazardous Materials Table); therefore, the transportation of phosgene would have to comply with DOT requirements in all states. Some states also reference DOT hazardous material classifications in their hazardous material release/response regulations. 


\section{STATE ENVIRONMENTAL PROGRAMS}

This section identifies state or jurisdictional environmental programs that may apply to the management of chemical warfare agents or chemical weapons. For each state or jurisdiction, two discussions are presented. Hazardous waste regulations are discussed first. The status of the state's authorization to implement the federal military munitions rule is reported, and any differences between the federal and state hazardous waste programs that may affect chemical warfare agents and chemical weapons are identified. Some state regulations, for example, are stricter or broader in scope than the federal regulations, causing chemical warfare agents or chemical weapons that are not regulated as hazardous wastes under the federal program to be so regulated under the state program. State hazardous waste regulations that specifically apply to chemical warfare agents or chemical weapons are highlighted.

The second discussion identifies other regulatory programs being implemented by the state that could impact the management of chemical warfare agents or chemical weapons in that state. For most states, this discussion focuses primarily on the state program that implements

EPCRA. When the state program is basically the same as the federal program (discussed in Section 2), either no additional state-specific information is provided, or minimal information identifying the state's SERC is given, when available. For a few states, state-only programs, such as the state-specific emergency response program, are also mentioned.

State-specific CERCLA-like programs, including voluntary and nonvoluntary remediation provisions, are not discussed because such programs do not generally apply directly to federal facilities or federal activities. Under Executive Order 12580, compliance with CERCLA notification and remediation provisions are delegated to the Secretary of Defense, "with respect to releases or threatened releases where either the release is on or the sole source of the release is from any facility or vessel under the jurisdiction, custody or control of" the Department of Defense. Under CERCLA, state environmental agencies participate, along with the EPA, in developing remedial actions at federal facilities. Although there may be a case where a release or threatened release of chemical warfare agent or chemical weapons could occur on nonfederal property or outside federal (e.g., DOD) jurisdiction, custody, or control, such events would be probably be handled on a case-by-case basis.

\subsection{ALABAMA}

\subsubsection{Hazardous Waste Regulations}

The Alabama Department of Environmental Management (ADEM) has adopted hazardous waste regulations that basically reflect the federal RCRA program (Alabama Administrative Code Revised [Admin. Code R.] 335-14-2). ADEM has not specifically designated chemical warfare agents or chemical weapons as listed hazardous wastes; therefore, the Alabama RCRA program is generally the same as the federal RCRA program and only those 
chemical agents/weapons listed in the federal RCRA program are listed hazardous wastes in Alabama.

Alabama has adopted the federal military munitions rule (Admin. Code R. 335-14-7-13), but it has yet to receive EPA authorization. Because states may enforce state-specific rules under state law, the military munitions rule is in effect but not federally enforceable in Alabama.

\subsubsection{Additional Pertinent Statutory or Regulatory Provisions}

Alabama Executive Order No. 4 establishes the Alabama Emergency Response Commission (AERC). The LEPCs are the focal points and repositories for all EPCRA information within Alabama counties.

\subsection{ALASKA}

\subsubsection{Hazardous Waste Regulations}

Alaska does not have authorization from EPA to implement or enforce a state RCRA program. The federal RCRA program is in force in Alaska, and is implemented by EPA Region X. Only those chemical agents/weapons listed in the federal RCRA program are listed hazardous wastes in Alaska (i.e., phosgene). Likewise, the federal RCRA military munitions rule is in effect in Alaska.

The Alaskan Water, Air, Energy, and Environmental Conservation Statute requires the Alaska Department of Environmental Conservation (ADEC) to adopt regulations for the identification and management of hazardous waste as defined by EPA, and hazardous waste that exhibits the characteristic of toxicity, persistence, or carcinogenicity (Alaska Statutes [AS] 46.03.299). Accordingly, the current Alaska hazardous waste regulations (18 Alaska Admin. Code [AAC], Part 62), adopt the federal regulations for identification and listing of hazardous wastes [18 AAC 62.020(a)]. However, the state, through legislative disinvestments, transferred responsibility for RCRA implementation to EPA. EPA Region X assumed primary responsibility for hazardous waste management in Alaska on July 1, 1996.

\subsubsection{Additional Pertinent Statutory or Regulatory Provisions}

Under Alaskan law, ADEC may, without prior hearing, order a person by notice to discontinue, abate, or alleviate a condition or activity (AS 46.03.800) whenever the Department finds, after investigation, that a person is causing, engaging in, or maintaining a condition or activity that, in the judgment of its commissioner:

- Presents an imminent or present danger to the health or welfare of the people of the state, or 
- Would result in or be likely to result in irreversible or irreparable damage to the natural resources or environment, and

- It appears to be prejudicial to the interests of the people of the state to delay action until an opportunity for a hearing can be provided.

Also, any person in charge of a vehicle, vessel, or container from which a hazardous substance is released is required to promptly report the release to ADEC and appropriate public safety agencies (18 AAC 75.300). A person who causes a release of a hazardous substance is also required to make reasonable efforts to contain and clean up the hazardous substance promptly, unless ADEC determines that cleanup:

- Is technically infeasible,

- Will cause greater environmental damage than if the release were not contained or cleaned up, or

- Would pose a greater threat to human life or health than if the release were not contained or cleaned up (AS 46.09.010; 18 AAC 75.300).

A hazardous substance is defined in AS 46.09.900 as:

(A) An element or compound that, when it enters into or on the surface or subsurface land or water of the state, presents an imminent and substantial danger to the public health or welfare, or to fish, animals, vegetation, or any part of the natural habitat in which fish, animals, or wildlife may be found; or

(B) A substance defined as a hazardous substance under CERCLA (e.g., phosgene).

A release of chemical agent would present an imminent and substantial danger to the public health or welfare, or to fish, animals, vegetation, or any part of the natural habitat, and therefore would be subject to these requirements.

The Alaska Disaster Act establishes the Alaska Division of Emergency Services (ADES), a division of the Department of Military and Veterans' Affairs, as the SERC (AS 26.23.030). ADEC is co-chair of the SERC. The SERC is the implementing agency for EPCRA in Alaska.

ADEC or the adjutant general of the Department of Military and Veterans' Affairs may request the governor to determine that an actual or imminent release of a hazardous substance constitutes a disaster emergency. ADEC and the adjutant general are required to respond appropriately in the relief of the actual or imminent release under the relevant provisions of the applicable incident command system (AS 46.09.030). 


\subsection{ARIZONA}

\subsubsection{Hazardous Waste Regulations}

The Arizona Department of Environmental Quality (ADEQ) has adopted the federal EPA regulations to implement its hazardous waste program. The state's hazardous waste rules are generally composed of the federal regulations authorized by Subtitle C of RCRA. Arizona periodically amends its regulations to incorporate the text of federal regulations. The Arizona Administrative Register states, "[M]odifications to the text incorporated by reference are intended to make the language consistent with the state terminology, and not make a substantive change to the content." Except for certain specific changes, the Arizona RCRA program is the same as the federal RCRA program and only those chemical agents/weapons listed in the federal RCRA program are listed hazardous wastes in Arizona (i.e., phosgene).

ADEQ regulations adopt the federal EPA regulations for hazardous waste identification and listing of hazardous waste (40 CFR 261), and the accompanying appendices amended as of July 1, 1999. The only pertinent amendment is to substitute the Director of the ADEQ for the Administrator of the EPA to conclude whether a waste will be listed under 40 CFR 261.11(a) [Arizona Admin. Code (AAC) R18-8-261(M)]. To date, the Director has not designated any state-specific listed wastes.

ADEQ regulations adopt the federal EPA regulations for hazardous waste management (40 CFR 260; AAC R18-8-260), with certain amendments. A pertinent amendment in the state regulations adds a specific definition of Acute Hazardous Waste, as follows:

... waste found to be fatal to humans in low doses or, in the absence of data on human toxicity, that has been shown in studies to have an oral lethal dose (LD) 50 toxicity (rat) of less than 50 milligrams per kilogram, an inhalation lethal concentration (LC) 50 toxicity (rat) of less than 2 milligrams per liter, or a dermal LD 50 toxicity (rabbit) of less than 200 milligrams per kilogram or that is otherwise capable of causing or significantly contributing to an increase in serious irreversible, or incapacitating reversible, illness. [AAC R18-8-260(E)(1)]

Therefore, chemical weapons or chemical warfare agents could be, by definition, acute hazardous wastes. However, the Arizona regulations do not list any chemical weapons or chemical warfare agents as state-specific acute hazardous wastes (e.g., P-code wastes).

Arizona has adopted the federal military munitions rule [AAC R18-8-266(A)], but EPA authorization has not yet been received. Because states may enforce state-specific rules under state law, the military munitions rule is in effect but not federally enforceable in Arizona. 


\subsubsection{Additional Pertinent Statutory or Regulatory Provisions}

The Arizona Pollution Prevention statutes (Arizona Revised Statutes [ARS] 49-962) provide that any person required to submit a federal EPCRA toxic chemical release report (EPA Form R) must also file a state report with ADEQ. In addition, even when a facility is not required to file under the federal TRI program, if it generated an average of one kilogram per month of acutely hazardous waste, or 1,000 $\mathrm{kg}$ per month of hazardous waste (exclusive of an episodic, accidental, or remediation-related release or occurrence), the facility is a "State TRI Filer" and must file certain documents with ADEQ. ADEQ requires any facility that manufactured, processed, or otherwise used a toxic substance in excess of a threshold quantity set under EPCRA (as found on the EPA EPCRA toxic chemical list for report year 1999), to submit an annual toxic data report and to develop and implement a pollution prevention plan (ARS 49962). The annual toxic data report includes an annual progress report, a copy of the EPA Form R, and any pollution prevention plan amendments.

In addition, any person who has knowledge of any release of a hazardous substance from their facility must immediately notify the ADEQ Director if the release is in a quantity equal to or greater than that specified under Section 103 of CERCLA (40 CFR 302, Table 302.4), or ADEQ regulations (ARS 49-284). Spills that must be reported under the Arizona Water Quality Assurance Revolving Fund/Superfund Law (ARS 49-284) include any contaminants regulated under:

- The Aquifer Protection Permit regulations,

- Hazardous waste regulations,

- Solid waste management regulations,

- Special waste regulations,

- Underground storage tank regulations,

- Water quality assurance revolving fund regulations, and

- Any other programs under ARS Title 49 which regulates soil remediation, including voluntary cleanup and greenfields programs.

No specific references to chemical agents, outside those already contained in the federal programs, are contained in these spill reporting requirements. 


\subsection{ARKANSAS}

\subsubsection{Hazardous Waste Regulations}

The Arkansas Department of Environmental Quality (ADEQ) has promulgated hazardous waste regulations that basically reflect the federal RCRA program (ADEQ Regulation No. 23). ADEQ has not specifically designated chemical agents or chemical weapons as listed hazardous wastes (ADEQ Regulation No. 23, Section 261). The Arkansas RCRA program is generally the same as the federal RCRA program, and only those chemical agents/weapons listed in the federal RCRA program are listed hazardous wastes in Arkansas.

Arkansas has adopted the federal military munitions rule [ADEQ Regulation No. 23, Section 266.205(d)], but EPA authorization has not yet been received. Because states may enforce state-specific rules under state law, the military munitions rule is in effect but not federally enforceable in Arkansas.

\subsubsection{Additional Pertinent Statutory or Regulatory Provisions}

Under the Arkansas Hazardous and Toxic Materials Emergency Notification Act (Arkansas Code [AC] 12-79), any release of hazardous and toxic materials into the environment which requires, or may require, emergency response or recovery actions by local response organizations is required to be reported as soon as possible. Under the Act, hazardous and toxic materials means:

(A) Those substances, except natural gas, manufactured, refined, or found in their natural state which, when released into the environment, by any means, have an immediate or potential threat to human, animal, or plant life and meet other criteria established under federal regulations, guidelines, or laws defining hazardous and toxic substances in a quantity and form which may pose an unreasonable risk to health and safety or property when transported in commerce, and which is designated as "hazardous material" in regulations prescribed by the United States Secretary of Transportation under Title 49 of the Code of Federal Regulations; and

(B) Any other substance or pollutant designated by regulations of the director promulgated under this chapter. (AC 12-79-103)

An incident or accident means the spilling, leaking, pouring, emitting, emptying, discharging, injecting, escaping, leaching, dumping, or disposing of hazardous and toxic materials into the environment. Any incident or accident which involves a fatality or hospitalization of any person due to fire, explosion, or exposure to any hazardous and toxic materials, or which results in a continuing danger to life, health, or property at the place of the accident, must be reported to the State Emergency Operations Center (AC 12-79-105). The chemical weapons or chemical warfare agents discussed in this report would have an immediate 
or potential threat to human, animal, or plant life and meet other criteria defining hazardous substances established under federal regulations (e.g., 40 CFR 355). Therefore, these regulations would apply to the release of such chemical weapons or warfare agents.

\subsection{CALIFORNIA}

\subsubsection{Hazardous Waste Regulations}

The California Department of Toxic Substances Control (DTSC) regulations restate the federal EPA identification and listing of hazardous waste regulations (22 California Code of Regulations [CCR] Section 66261). The California RCRA program is generally the same as the federal RCRA program, and only those chemical agents/weapons listed in the federal RCRA program are listed hazardous wastes in California.

California has not adopted the EPA military munitions regulations; however, a proposed preliminary draft regulation (R-97-20) was the topic of workshops held by the DTSC in April 2001. The proposed preliminary draft regulation would adopt the EPA military munitions regulations, including those addressing chemical munitions. Until these regulations are adopted, the military munitions rule is not in effect in California.

In California, the definition of a hazardous waste also includes any waste that is listed in, or contains a constituent listed in, Appendix X to 22 CCR Division 4.5 (this listing should not be confused with that pertaining to a listed hazardous waste). Lewisite, GB, and VX are among the hazardous constituents listed in Appendix X; mustard gas and tabun are not. Although lewisite, $\mathrm{GB}$, and VX are therefore hazardous wastes in California, they are not listed hazardous wastes in the RCRA context and the RCRA mixture and derived-from rules do not apply to these wastes.

Appendix $\mathrm{X}$ also lists general categories of hazardous waste, including obsolete explosives and retrograde explosives, which may include obsolete weapons containing chemical agent.

In addition, California hazardous waste regulations expand the definition of characteristic hazardous wastes. A characteristic toxic waste is defined in 22 CCR, Section 66261.24(a)(3) through (6), as any waste that has:

(1) An acute oral $\mathrm{LD}_{50}$ less than 5,000 milligrams per kilogram (mg/k);

(2) An acute dermal $\mathrm{LD}_{50}$ less than $4,300 \mathrm{mg} / \mathrm{k}$;

(3) An acute inhalation $\mathrm{LC}_{50}$ less than 10,000 parts per million (ppm) as a gas or vapor; or

(4) An acute aquatic 96-hour $\mathrm{LC}_{50}$ less than 500 milligrams per liter (mg/l) when measured in soft water. 
Therefore, under California regulations, chemical warfare agents would probably be characteristic toxic hazardous wastes.

California also has an "extremely hazardous waste" category. An extremely hazardous waste is defined in 22 CCR 66261.110(a) as any waste or material that has:

(1) An acute oral $\mathrm{LD}_{50}$ less than $50 \mathrm{mg} / \mathrm{k}$;

(2) An acute dermal $\mathrm{LD}_{50}$ less than $43 \mathrm{mg} / \mathrm{k}$; or

(3) An acute inhalation $\mathrm{LC}_{50}$ less than $100 \mathrm{ppm}$ as a gas or vapor.

In addition, any material or waste that has been shown, through experience or testing, to likely result in death, disabling personal injury, or serious illness, because of the carcinogenicity, high acute or chronic toxicity, bioaccumulative properties, or persistence in the environment, is also an extremely hazardous waste. Any waste or material that is water reactive is an extremely hazardous waste, as well [22 CCR 66261.110(a)].

Even when chemical warfare agents do not meet the lethal dose limits for extremely hazardous waste, it could be argued that exposure to these agents has been shown, through experience or testing, to likely result in death, disabling personal injury, or serious illness. Therefore, it is likely chemical warfare agents would be considered extremely hazardous wastes under California hazardous waste regulations.

There are specific requirements for handling extremely hazardous wastes, including reduced minimum threshold quantities, similar to those for RCRA acute hazardous wastes (e.g., a small-quantity generator may only store $1 \mathrm{~kg}$ of extremely hazardous waste or acute wastes as compared with 1,000 kg of hazardous waste) (22 CCR 57430.4). At one time, special extremely hazardous waste permits were required; however, although such permits are still reflected in some of the California regulations, the requirement has been repealed and is no longer enforced by DTSC.

\subsubsection{Additional Pertinent Statutory or Regulatory Provisions}

In November 1986, California voters approved Proposition 65, also known as the Safe Drinking Water and Toxic Enforcement Act of 1986. Proposition 65 requires the Governor to publish a list of chemicals that are known to the State of California to cause cancer, birth defects, or other reproductive harm. Agents that cause cancer are called carcinogens; those that cause birth defects or other reproductive harm are called reproductive toxicants. This list must be updated at least once a year. The latest list was published on April 20, 2001. Any company with 10 or more employees that operates within the state or sells products in California must comply with the requirements of Proposition 65. Under Proposition 65, businesses are prohibited from knowingly discharging listed chemicals into sources of drinking water and are required to provide a "clear and reasonable" warning before knowingly and intentionally exposing anyone to a listed chemical. This warning can be given by a variety of means, such as by labeling a 
consumer product, by posting signs at the workplace, or by publishing notices in a newspaper. Mustard gas is the only chemical agent listed in Proposition 65's List of Chemicals Known to the State to Cause Cancer or Reproductive Toxicity.

Under the California Penal Code (Hertzberg-Alarcon California Prevention of Terrorism Act), any person, without lawful authority, who possesses, develops, manufactures, produces, transfers, acquires, or retains any weapon of mass destruction is guilty of a felony punishable by incarceration in the state prison. Weapons of mass destruction include chemical warfare agents. The code specifically lists, but is not limited to, nerve agents (GA, GB, GD, GF, and VX); choking agents (phosgene and diphosgene); blood agents (hydrogen cyanide, cyanogens chloride, and arsine); blister agents (mustards and arsenicals, such as lewisite); urticants, such as CX; and incapacitating agents (BZ) (California Penal Code, Sections 11415-11419).

\subsection{COLORADO}

\subsubsection{Hazardous Waste Regulations}

The Colorado Department of Public Health and Environment (CDPHE) has promulgated hazardous waste regulations that basically mirror the federal standards (6 Code of Colorado Regulation [CCR] 1007-3). However, under these regulations, CDPHE has specifically designated the following additional wastes as listed hazardous wastes:

- Mustard, mustard agent, mustard gas, H, and HD as Hazardous Waste No. P909; and

- Mustard, mustard agent, mustard gas, and HT as Hazardous Waste No. P910. [6 CCR 1007-3, Section 261.33(e)]

In addition, on June 19, 2001, CDPHE adopted amendments to its hazardous waste regulations to add:

- Waste sarin to the list of hazardous waste from discarded commercial chemical products, off-specification species, container residues, and spill residues thereof (Hazardous Waste No. P911); and

- Waste chemical weapons (Hazardous Waste No. K901) and environmental media, debris, and containers contaminated through contact with Waste Chemical Weapons (Hazardous Waste No. K902) to the list of hazardous wastes from specific sources.

These wastes from specific sources (K901 and K902) are listed as acute hazardous wastes. The regulatory analysis, which accompanied the listing proposal, specifically refers to secondary wastes (i.e., contaminated media, debris, and containers) as solid wastes generated as a result of the treatment, storage, or disposal of Waste Chemical Weapons. In addition, the regulatory 
analysis states that wastes that meet the listing description for secondary wastes (Hazardous Waste No. K902) would not carry the listing for Waste Chemical Weapons (Hazardous Waste No. K901), which might otherwise be applied to these wastes based on the federal mixture and derived-from rules.

Further, the regulatory analysis accompanying the listing proposal states:

Components that are removed from a Waste Chemical Weapon and that can be demonstrated to not be contaminated by chemical agent need not be managed as Waste Chemical Weapons. Also, chemical weapons that undergo baseline reconfiguration before they become wastes do not meet the listing description for Waste Chemical Weapons.

Appendices VII and VIII to Part 261 of the CDPHE regulations have also been amended to add sarin, mustard agent, and mustard HT agents as the specific chemical agents that are the basis of the listing (Appendix VII) and as hazardous constituents (Appendix VIII). In addition, the definition of chemical weapons in Section 260.10 was amended to read,

... agent or munition that, through its chemical properties, produces lethal or other damaging effects on human beings, except that such term does not include riot control agents, chemical herbicides, smoke and other obscuration materials.

These amendments were published in the Colorado Register on July 10, 2001, and became effective on July 30, 2001.

CDPHE has adopted only portions of the federal military munitions rule. The CDPHE regulations do not adopt the conditional exemption for conventional weapons that are used for their intended purpose (e.g., training, research, recovery of unexploded ordnance) or under repair or reclamation [40 CFR 266.202(a)]. They also do not adopt the federal definition of when a munition becomes a solid waste [40 CFR 266.202(b)], or the alternative storage requirements found in 40 CFR 264 Subpart EE.

CDPHE did adopt the definition of used or fired military munitions that land off-range as being a solid waste subject to RCRA corrective action or imminent and substantial endangerment authorities [40 CFR 266.202(d); 6 CCR 1007-3, Section 267.202]. In addition, CDPHE adopted the expanded "on-site" determination for the use of shipping manifests [40 CFR 262.20(f) and 6 CCR 1007-3, Section 262.20(f)]. These limited provisions of the federal military munitions rule have been adopted by CDPHE and are in effect in Colorado. EPA authorization, however, has not yet been received. Hence, these rules are not federally enforceable.

\subsubsection{Additional Pertinent Statutory or Regulatory Provisions}

When a chemical spill or release occurs in Colorado, a number of reporting and notification requirements must be met. Any emergency release from a fixed facility that exceeds the reportable quantity for that specific chemical, as designated in the EPA List of Lists (which 
includes chemical warfare agents listed on the EPCRA List of Extremely Hazardous Substances in 40 CFR 355, Appendix A), must be reported to the following entities:

- The National Response Center,

- The Colorado Emergency Planning Commission (CEPC), which is represented by the CDPHE, and

- The Local Emergency Planning Committee.

In addition to telephone notification, the responsible party must also send written notification to both the CEPC and the LEPC. In addition, any releases of hazardous chemicals to the water or air must be reported to the CDPHE immediately [5 CCR 1002-61, Section 61.8(5)(d), and 5 CCR 1001-5, Part C, Section VII(A)].

\subsection{FLORIDA}

\subsubsection{Hazardous Waste Regulations}

The Florida Department of Environmental Protection (FDEP) has incorporated, by reference, the federal hazardous waste regulations (Florida Admin. Code [FAC] Rule 62-703). The FDEP has not specifically designated chemical agents or chemical weapons as listed hazardous wastes. The Florida RCRA program is generally the same as the federal RCRA program, and only those chemical agents/weapons listed in the federal RCRA program are listed hazardous wastes in Florida.

Florida has adopted the federal military munitions rule (FAC Rule 62-703.181) but has yet to receive EPA authorization. Because states may enforce state-specific rules under state law, the military munitions rule is in effect but not federally enforceable in Florida.

\subsubsection{Additional Pertinent Statutory or Regulatory Provisions}

The Florida SERC, a division of the Florida Department of Community Affairs (DCA), is responsible for implementing EPCRA in Florida. The Florida DCA Department of Community Affairs, Office of Emergency Management, is the lead agency and provides staff support to the SERC. Under the Florida Hazardous Materials Emergency Response and Community Right-toKnow Act of 1988 (Chapter 252, Part II, Florida Statutes), any facility that stores or uses in excess of the threshold quantities of EPCRA extremely hazardous substances must provide notification and file a chemical inventory and TRI report with the SERC and appropriate LEPC. In addition, under Section 304 of EPCRA, if there is a release of an EPCRA extremely hazardous substance or a CERCLA hazardous material in excess of its listed reportable quantity, the facility must report it to the SERC, the appropriate LEPC, and, for CERCLA hazardous substances, to the National Response Center. 


\subsection{GEORGIA}

\subsubsection{Hazardous Waste Regulations}

The Georgia Department of Natural Resources Environmental Protection Division (EPD) regulations adopt the federal EPA definitions found in 40 CFR 260.10-260.11 (EPD Rule 391-311-.02), and the federal EPA regulations for identification and listing of hazardous waste found in 40 CFR 261, as amended June 8, 2000 [EPD Rule 391-3-11-.07(2)]. Therefore, the Georgia RCRA program is generally the same as the federal RCRA program, and only those chemical agents/weapons listed in the federal RCRA program are listed hazardous wastes in Georgia.

EPD has adopted the federal EPA regulations for military munitions [EPD Rule 391-3-11-.10(3)] and received EPA authorization (published in the Federal Register on October 14, 1999; 64 FR 55,629). Therefore, the military munitions rule is in effect in Georgia.

In addition, under the Georgia Hazardous Waste Management Act, the Board of Natural Resources may identify as a designated hazardous waste any solid waste that the Board concludes is capable of posing a substantial present or potential hazard to human health or the environment when improperly treated, stored, transported, or disposed of, or otherwise managed. This determination is based on the factors set forth in regulations promulgated by EPA pursuant to RCRA, provided such solid waste contains any substance which is listed on any one or more of the following lists, in force and effect on February 1, 1996:

1. List of Hazardous Constituents codified as 40 CFR 261, Appendix VIII;

2. Ground-water Monitoring List, codified as 40 CFR 264, Appendix IX;

3. List of Hazardous Substances and Reportable Quantities, codified as 40 CFR 302, Table 302.4;

4. List of Regulated Pesticides, codified as 40 CFR 180;

5. List of Extremely Hazardous Substances and Their Threshold Planning Quantities, codified as 40 CFR 355, Appendix A; or

6. List of Chemicals and Chemical Categories, codified as 40 CFR 372.65. (Official Code of Georgia Annotated [O.C.G.A.] Section 12-8-62)

Although chemical agents are included on the designated lists (e.g., EPCRA extremely hazardous substances), no wastes, including any of the chemical weapons and chemical warfare agents of concern, have been designated as hazardous wastes in the EPD regulations. 


\subsubsection{Additional Pertinent Statutory or Regulatory Provisions}

Under the Georgia Hazardous Site Response Act, the Board of Natural Resources has the power to:

... adopt, promulgate, modify, amend, and repeal rules and regulations ... as the board may deem necessary to provide for corrective action for releases of hazardous wastes, hazardous constituents, and hazardous substances into the environment that pose a present or future danger to human health. (O.C.G.A. Section 12-8-97)

This Act also provides for immediate notification of the EPD whenever there is a spill or release of a hazardous substance that causes the concentration in groundwater to exceed the naturally occurring background concentration, or that causes the concentration in soil to exceed a concentration listed in Appendix I to the regulation (O.C.G.A. Section 12-8-92; EPD Rule 391-3-19-.04). Chemical weapons and chemical warfare agents of concern are listed in Appendix I to this regulation, including any substance listed on:

- The List of Hazardous Substances and Reportable Quantities, codified as 40 CFR 302, Table 302.4, in force and effect on February 1, 1996;

- The List of Extremely Hazardous Substances and Their Threshold Planning Quantities, codified as 40 CFR 355, Appendix A, in force and effect on February 1, 1996; and

- Any hazardous constituents listed in 40 CFR 261, Appendix VIII.

Appendix I of the regulation provides the state-specific soil concentrations that trigger notification requirements. For tabun, sarin, VX, mustard gas, and lewisite, Appendix I refers to federal reportable quantities (List of Hazardous Substances and Reportable Quantities, 40 CFR 302, Table 302.4; and List of Extremely Hazardous Substances and Their Threshold Planning Quantities, 40 CFR 355). For phosgene, the soil concentration limit provided in Appendix I is the detection limit.

Under the Georgia Oil or Hazardous Spills or Releases Act (O.C.G.A. Section 12-14-1 et seq.), any person owning or having control over a hazardous substance and that has knowledge of any spill or release equal to or exceeding the reportable quantity must immediately notify EPD. A hazardous substance is:

- Any substance designated pursuant to Section 311(B)(2)(A) of the federal CWA;

- Any element, compound, mixture, solution, or substance designated pursuant to Section 102 of CERCLA; 
- Any hazardous waste having the characteristics identified under or listed pursuant to RCRA;

- Any toxic pollutant listed under the federal CWA;

- Any hazardous air pollutant listed under Section 112 of the federal CAA; and

- Any imminently hazardous chemical substance or mixture with respect to which the administrator of the EPA has taken action under the Toxic Substances Control Act (e.g., PCBs).

Reportable quantities are those listed by EPA for CERCLA reportable quantities (40 CFR 302) (i.e., phosgene and mustard gas).

\subsection{HAWAII}

\subsubsection{Hazardous Waste Regulations}

Hawaii received final authorization from EPA to operate its RCRA program on November 1, 2001 (66 FR 55115; November 1, 2001). The Hawaii Department of Health $(\mathrm{HDOH})$, Solid and Hazardous Waste Branch, has promulgated hazardous waste regulations that adopt almost verbatim the federal RCRA program effective through May 25, 1998 (11 Hawaii Admin. Rules [HAR] Chapter 260 et seq.). The HDOH has not specifically designated chemical agents or chemical weapons as listed hazardous wastes (11 HAR Chapter 261-33). Therefore, the Hawaii RCRA program is generally the same as the federal RCRA program, and only those chemical agents/weapons listed in the federal RCRA program are listed hazardous wastes in Hawaii. Hawaii has adopted the federal military munitions rule (11 HAR Chapter 261-200 et seq.), and the federal RCRA military munitions rule is in effect in Hawaii.

\subsubsection{Additional Pertinent Statutory or Regulatory Provisions}

The Hawaii Environmental Response Law (Hawaii Revised Statutes, Chapter 128D et seq.) provides for reporting and cleanup of releases of hazardous substances from any facility. Hazardous substances are defined as:

... any substance designated pursuant to section 311(b)(2)(A) of the Clean Water Act; any element, compound, mixture, solution, or substance designated pursuant to section 102 of CERCLA; any hazardous waste having the characteristics identified under or listed pursuant to section 3001 of the Solid Waste Disposal Act; any toxic pollutant listed under section 307(a) of the Clean Water Act; any hazardous air pollutant listed under section 112 of the Clean Air Act, as amended (42 U.S.C. \$\$7401-7626); any imminently hazardous chemical substance or mixture regulated under section 7 of the Toxic Substance Control Act, as 
amended (15 U.S.C. §§2601-2671); oil, trichloropropane, and any other substance or pollutant or contaminant designated by rules adopted pursuant to this chapter.

In adopting rules, the director shall consider any substance or mixture of substances, including but not limited to feedstock materials, products, or wastes, which, because of their quantity, concentration, or physical, chemical, or infectious characteristics, may:

(1) Cause or significantly contribute to an increase in serious irreversible or incapacitating reversible illness; or

(2) Pose a substantial present or potential hazard to human health, to property, or to the environment when improperly stored, transported, released, or otherwise managed.

Regulations to implement the Hawaii Environmental Response Law are found in the State Contingency Plan (11 HAR Chapter 451). Thereunder, the HDOH has listed the following hazardous substances subject to the notification requirements of the law:

(1) The list of elements, compounds, and hazardous substances contained in 40 CFR 355, Appendices A and B;

(2) The list of elements, compounds, and hazardous substances contained in 40 CFR 302, Table 4; and

(3) Any unlisted (i.e., characteristic) hazardous waste defined in 11 HAR 261-3 (i.e., 40 CFR 261.3).

Because lewisite, mustard gas, phosgene, sarin, tabun, and VX are EPCRA extremely hazardous substances (40 CFR 355); phosgene is a CERCLA hazardous substance (40 CFR 302, Table 302.4); and phosgene is an EPA-listed hazardous waste (P095), the release of any of these chemicals in excess of the federal reportable quantity would have to be reported to HDOH.

\subsection{IDAHO}

\subsubsection{Hazardous Waste Regulations}

The Idaho Department of Environmental Quality (IDEQ) has incorporated, by reference, the federal hazardous waste regulations [Idaho Rules of Practice and Procedures (IDAPA) 58.01.05]. IDEQ has not specifically designated chemical agents or chemical weapons as listed hazardous wastes. The Idaho RCRA program is generally the same as the federal RCRA program, and only those chemical agents/weapons listed in the federal RCRA program are listed hazardous wastes in Idaho. 
Idaho has adopted the federal military munitions rule (IDAPA 58.01.05.010) but has yet to receive EPA authorization. Because states may enforce state-specific rules under state law, the military munitions rule is in effect but not federally enforceable in Idaho.

\subsubsection{Additional Pertinent Statutory or Regulatory Provisions}

Effective July 1, 1997, the name of the State Emergency Response Commission was changed to Idaho Bureau of Hazardous Materials (BHM). BHM carries out the requirements of EPCRA and the Idaho Hazardous Substance Emergency Response Act (Idaho Code 39-7101 through 39-7115). It serves as an emergency response coordination and liaison organization for Idaho and works in cooperation with state and federal agencies to prepare for, respond to, and recover from hazardous materials incidents. BHM keeps records concerning hazardous material storage, transport, and release within Idaho, including the TRI reports. Organizationally, BHM is within the Idaho Military Division under the Office of the Governor and reports to the Adjutant General of the Idaho National Guard.

Any person who has responsibility for reporting a release of CERCLA hazardous materials or EPCRA extremely hazardous substances (e.g., sarin) must, as soon as practicable after gaining knowledge of the reportable release, notify BHM (Idaho Code 38-7108).

\subsection{ILLINOIS}

\subsubsection{Hazardous Waste Regulations}

The Illinois Environmental Protection Agency (IEPA) has adopted regulations that parallel the federal hazardous waste regulations (35 Illinois Admin. Code [IAC] 720 et seq.). IEPA has not specifically designated chemical agents or chemical weapons as listed hazardous wastes. The Illinois RCRA program is generally the same as the federal RCRA program, and only those chemical agents/weapons listed in the federal RCRA program are listed hazardous wastes in Illinois.

Illinois has adopted the federal military munitions rule (35 IAC 726.300 et seq.) but has yet to receive EPA authorization. Because states may enforce state-specific rules under state law, the military munitions rule is in effect but not federally enforceable in Illinois.

\subsubsection{Additional Pertinent Statutory or Regulatory Provisions}

The Illinois Emergency Management Agency (IEMA) is designated as the SERC. The owner or operator of a facility where there has been a release of an EPCRA extremely hazardous substance or a CERCLA hazardous material must make immediate telephone notification to the IEMA, the LEPC, and the National Response Center (29 IAC 430 and 29 IAC 620). 


\subsection{INDIANA}

\subsubsection{Hazardous Waste Regulations}

The Indiana Department of Environmental Management (IDEM) regulations incorporate by reference the federal RCRA regulations concerning the identification and listing of hazardous waste [329 Indiana Admin. Code (IAC) 3.1-6-1(b)]. In addition to the list of hazardous waste incorporated by reference, the following chemical munitions are added to the list of hazardous waste:

(1) GA

(2) GB

(3) H, HD

(4) $\mathrm{HT}(60 \% \mathrm{HD}$ and $40 \% \mathrm{~T})$

(5) $\mathrm{L}$

(6) $\mathrm{VX}$

The above-listed chemical munitions are identified by Indiana Hazardous Waste Number I001.

Indiana has adopted the federal regulations governing military munitions and has received EPA authorization (66 FR 733; January 4, 2001); therefore, the military munitions rule is in effect in Indiana.

\subsubsection{Additional Pertinent Statutory or Regulatory Provisions}

Any spills of hazardous substances, extremely hazardous substances, or objectionable substances must be reported to the IDEM Office of Environmental Response when they:

(1) Damage the waters of the state so as to cause death or acute injury or illness to humans or animals;

(2) Are from a facility that has been notified in writing that it is located in a delineated public water supply wellhead protection area and the amount of hazardous substances or extremely hazardous substances spilled exceeds 100 pounds or the reportable quantity, whichever is less, or any amount of objectionable substances; 
(3) Damage waters of the state and are located within 50 feet of a known private drinking water well or within 100 yards of protected waters (e.g., exceptional use or salmonid fishery); or

(4) Are directly released to surface water or to soils beyond the facility boundary and exceed 100 pounds or the reportable quantity of hazardous substances or extremely hazardous substances, whichever is less, or are releases of hazardous substances or extremely hazardous substances within the facility boundary and exceed the pertinent reportable quantity. (327 IAC 2-6.1-5)

Extremely hazardous substance is defined as a substance identified under EPCRA (i.e., 40 CFR 355, Appendix A). Hazardous substance is defined as a substance identified under CERCLA (i.e., 340 CFR 302, Table 302.4). Objectionable substance is defined as a substance that is of a quantity and a type, and present for a duration and in a location, so as to damage waters of the state. Any spill must be reported within two hours of the time it becomes known. These regulations would be applicable to a spill of any of the chemical agents discussed in this report.

\subsection{IOWA}

\subsubsection{Hazardous Waste Regulations}

Iowa does not have authorization from the EPA to implement or enforce a state RCRA program, and the state has not sought such authorization from EPA. EPA Region VII implements the RCRA program within Iowa. Only those chemical agents/weapons listed in the federal RCRA program are listed hazardous wastes in Iowa.

Because the federal RCRA program is in force in Iowa, the federal RCRA military munitions rule is in effect there.

The current Iowa hazardous waste regulations (Iowa Admin. Code [IAC] 567-141.2) adopt the federal regulations for identification and listing of hazardous wastes. Although the Iowa Hazardous Waste and Substance Management statute provides for the listing of additional hazardous waste (Iowa Code [IC] 455B.464), the Iowa Department of Natural Resources (IDNR) has not designated any additional state-specific listed hazardous wastes.

\subsubsection{Additional Pertinent Statutory or Regulatory Provisions}

Under the Iowa Hazardous Conditions provisions of the Solid Waste Disposal Statute (IC 455B.386) and IDNR regulations (IAC 567-131.2), any person storing, handling, transporting, or disposing of a hazardous substance must notify IDNR of the occurrence of a hazardous condition as soon as possible but not later than 6 hours after the onset of the hazardous condition or discovery of the hazardous condition. A hazardous condition is defined as any 
situation involving the actual, imminent, or probable spillage, leakage, or release of a hazardous substance onto the land, into the water, or into the atmosphere, which creates an immediate or potential danger to the public health or safety or to the environment. In addition, any site which is a hazardous waste or hazardous substance disposal site is a hazardous condition by definition (IC 455B.381; IAC 567-131.1).

When any hazardous condition exists, the director of IDNR may remove or provide for the removal or disposal of the hazardous substance at any time, unless the director determines such removal will be properly and promptly accomplished by the owner of the vehicle, container, or other facility (IC 455B.387). Hazardous substance is defined as any substance or mixture of substances that presents a danger to the public health or safety and includes, but is not limited to, a substance that is toxic, corrosive, or flammable, or that is an irritant or that generates pressure through decomposition, heat, or other means. This includes:

- Any hazardous waste identified or listed by the EPA,

- Any toxic pollutant listed under sections 307 or 311 of the CWA, or

- Any hazardous material designated under the HMTA (IC 455B.381; IAC 567131.1).

Since phosgene is an EPA-listed hazardous waste (P095) and the other chemical weapons or chemical warfare agents probably would be considered hazardous substances, the release of these chemicals would present a danger to the public health or safety and would require notification to and/or oversight of IDNR.

\subsection{KANSAS}

\subsubsection{Hazardous Waste Regulations}

The Kansas Department of Health and Environment (KDHE) has adopted, by reference, the federal hazardous waste regulations, except that the state also regulates small hazardous waste generators that are conditionally exempt under federal regulations (Kansas Admin. Regulations 28-31 et seq.). KDHE has not specifically designated chemical agents or chemical weapons as listed hazardous wastes; therefore, the Kansas RCRA program is generally the same as the federal RCRA program, and only those chemical agents/weapons listed in the federal RCRA program are listed hazardous wastes in Kansas.

Kansas has not adopted the federal military munitions rule. Therefore, the federal RCRA military munitions rule is not in effect in Kansas. 


\subsubsection{Additional Pertinent Statutory or Regulatory Provisions}

The Kansas Commission on Emergency Planning and Response (CEPR) is responsible for facilitating a coordinated effort for mitigation, preparedness, response, and recovery from emergencies and disasters and to carry out all requirements of EPCRA. The owner or operator of the facility where a release of any EPCRA extremely hazardous substance occurs is responsible for providing notification to the county emergency coordinator as the LEPC, and to the CEPR as the SERC.

Under the Kansas Emergency Management Act, hazardous material means any substance or material in a quantity or form that may be harmful or injurious to the health and safety of humans, animals, crops, or property when released into the environment. Hazardous material includes, but is not limited to, explosives; radioactive materials; disease-causing agents; flammable liquids, solids, or gases; combustible liquids; poisons; poisonous gases; oxidizing materials; corrosive materials; irritants; nonflammable gases; cryogenics; and blasting agents (Kansas Statute 48-904). Therefore, a release of a chemical warfare agent (e.g., a poisonous gas or irritant) in an amount above the EPCRA reporting threshold would require notification of the CEPR and the LEPC.

\subsection{KENTUCKY}

\subsubsection{Hazardous Waste Regulations}

The Kentucky Department of Environmental Protection (KDEP), in the Kentucky Natural Resources and Environmental Protection Cabinet, has promulgated hazardous waste regulations that basically reflect the federal standards (401 Kentucky Admin. Regulations [KAR] 32-38). The regulations define hazardous waste on the basis of the waste's hazardous characteristics (i.e., characteristic hazardous wastes) or the specific regulatory listing of the waste (i.e., listed hazardous wastes) (401 KAR 31). However, as directed by statute [Kentucky Revised Statutes (KRS) 224.50-130(2)], the KDEP has designated the following wastes as listed hazardous wastes:

- GB is designated as Hazardous Waste No. N001,

- VX is designated as Hazardous Waste No. N002, and

- $\mathrm{H}$ and related compounds are designated as Hazardous Waste No. N003.

Kentucky has not adopted the military munitions rule, so it is not in effect in Kentucky.

An amendment to the Kentucky statutes governing the management of chemical munition wastes (KRS 224.50-130) became effective on July 14, 2000 (Kentucky Legislature House Bill 579; Kentucky Acts, Chapter 482, Section 1). This amendment sets new criteria to be used by KDEP in determining whether to issue, deny, or establish conditions for a permit for 
treatment or disposal of chemical munitions waste. Under the amended statute, treatment includes:

... the manual or mechanical handling of the chemical compounds listed in subsection (2) of this section [GB, VX, and $\mathrm{H}$ ] and of any munitions containing the compounds during the processing of munitions to remove the compounds, to separate munitions compounds, and to otherwise prepare the components and compounds for destruction, neutralization, dismantling, or decommissioning.

Treatment does not, however, include:

... the handling, movement, or overpacking of containers or munitions containing a compound listed in subsection (2) of this section within the fenced boundaries of an area used for the storage of those munitions if:

(A) A plan for the handling, movement or overpacking is submitted and approved by the cabinet, after public notice and opportunity to be heard, before the handling, movement, or overpacking occurs; or

(B) An emergency has occurred and the handling, movement, or overpacking is necessary to protect human health, safety, or the environment, if a report describing the handling, movement, or overpacking is submitted to the cabinet as soon as possible after the emergency is abated.

Under the amendment, before the issuance, conditional issuance, or denial of a permit, the applicant must affirmatively demonstrate and the KDEP must find that the following has occurred:

The proposed treatment or destruction technology has been fully proven in an operational facility of scale, configuration, and throughput comparable to the proposed facility, or has been demonstrated as effective, within the chemical weapons disposal programs as directed in Pub. L. 104-208 and other applicable federal laws, sufficient to provide assurance of destruction or neutralization at an efficiency of ninety-nine and nine thousand, nine hundred, and ninety-nine ten thousandths percent (99.9999\%) for each compound listed in subsection (2) of this section that is proposed to be treated or destroyed, with an efficiency to be demonstrated as achievable under all operating conditions. During the occurrence of malfunctions, upsets, or unplanned shutdowns, all quantities of any compound listed in subsection (2) of this section shall be contained, reprocessed or otherwise controlled so as to ensure that the required efficiency is attained prior to any release to the environment.

In addition, the amended statute provides that:

An emergency response plan must have been submitted to the Cabinet and approved, after public notice and an opportunity to be heard, providing for 
sufficient training, coordination, and equipment for state and local emergency response personnel, including health, police, fire, and other responders, to assure the ability of the community to respond to releases from such a facility. The plan shall demonstrate the capability of evacuating prior to exposure, or otherwise mitigating exposure for all individuals that might be exposed to releases from the facility during a credible worst-case release. ... If such plan has not been fully implemented at the time of permit approval, the Division of Emergency Management shall advise the cabinet of critical shortcomings. Any permit issued shall include, as conditions, the resolution of critical shortcomings in the implementation of the plan, and shall not allow actual destruction of any of the compounds identified in subsection (2) of this section to begin until those permit conditions have been met to the satisfaction of the Division of Emergency Management.

The statute goes on to provide that KDEP can conduct no technical review of an application for a permit for treatment or disposal until notified in writing by the Division of Emergency Management that the draft plan has been approved. In addition, KDEP must conduct an alternatives analysis and make an affirmative finding, after public notice and an opportunity to be heard, that no alternative method of treatment or disposal exists in an operational facility or alternative disposal program that creates less risk of release, acute or chronic health effect, or adverse environmental effect.

Current KDEP regulations concerning the treatment of nerve and blister agents (401 KAR 34:350), effective November 22, 1989, have not yet been modified to reflect the new legislation referred to above. However, existing regulations also require

... an affirmative demonstration that the proposed treatment or destruction technology is proven in an operational facility having a scale, configuration, and throughput comparable to those of the proposed facility for a period of time sufficient to provide assurance of $99.9999 \%$ destruction or neutralization of each substance proposed to be treated or destroyed.

Monitoring data from the comparable facility must reflect the absence of emissions from stack or fugitive sources, including, but not limited to, the products of combustion and incomplete combustion, which alone or in combination, present an adverse effect on human health or the environment. In addition, provisions must have been made for development and funding of sufficient training, coordination, and equipment for state and local emergency response personnel, including the health, police, fire, and emergency response fields, to assure the ability of the community to respond to releases from such a facility. This must include development and funding of an evacuation plan that demonstrates the capability of removing individuals from the largest area of risk from a worst-case release. 


\subsubsection{Additional Pertinent Statutory or Regulatory Provisions}

The Kentucky Emergency Response Commission (KyERC) was established to implement all provisions of EPCRA, the associated federal regulations, and subsequent legislation and regulations related to hazardous substances (KRS 39E.010). A hazardous substance is a substance specified in the federal EPCRA regulations, or a state-specified substance. Under this statute, owners or operators of facilities that manufacture, use, or store extremely hazardous substances, as identified in 40 CFR 355, in quantities as identified in administrative regulations for the Division of Emergency Management (KyEM) must advise the Commission, the LEPC, and the fire department in whose jurisdiction the facility resides, of the name of the substance and its quantity (KRS 39E.120).

The KyEM adopts the EPA reporting threshold of 10,000 pounds for CERCLA hazardous chemicals (40 CFR 302) and 500 pounds for EPCRA extremely hazardous chemicals (40 CFR 355). Since all of the chemical warfare agents discussed in this report are EPCRA extremely hazardous substances, the threshold for reporting for chemical agents is 500 pounds. Whenever a release of a substance covered under this chapter occurs in a reportable quantity, the owner or operator of the facility must notify the local and state warning points within a certain time period established in administrative regulations. Releases of hazardous substances must be reported immediately to KyERC and the LEPC. In addition, a written follow-up report must be filed as soon as practicable.

\subsection{LOUISIANA}

\subsubsection{Hazardous Waste Regulations}

The Louisiana Department of Environmental Quality (LDEQ) hazardous waste regulations basically restate the federal RCRA regulations concerning the identification and listing of hazardous wastes (Louisiana Admin. Code [LAC] 33:V.4901). Only those chemical agents/weapons listed in the federal RCRA program are listed hazardous wastes in Louisiana.

Louisiana has adopted the federal military munitions rule (LAC 33:V.5303) and has received EPA authorization (September 2, 1999; 64 FR 48,099). Therefore, the federal RCRA military munitions rule is in effect in Louisiana.

\subsubsection{Additional Pertinent Statutory or Regulatory Provisions}

LDEQ has established regulations governing the identification, investigation, and remediation of sites where hazardous substances could have been disposed of and from which such hazardous substances could be discharged (LAC 33:VI). Hazardous substance is defined as any gaseous, liquid, or solid material that, because of its quantity, concentration, or physical, chemical, or biological composition when released into the environment, poses a substantial present or potential hazard to human health, the environment, or property regardless of whether it 
is intended for use, reuse, or is to be discarded. The term includes all hazardous wastes, hazardous constituents, hazardous materials, and pollutants. Certain substances have been designated as hazardous by regulation, including:

(1) Hazardous wastes (LAC 33:V, Subpart 1),

(2) Pollutants listed in LAC 33:I.3931 (i.e., materials found in 40 CFR 117.3 [Section 311 of the CWA] and 302.4 [CERCLA hazardous substances]),

(3) Toxic air pollutants listed in LAC 33:III.5112 [Section 112(r) of the CAA], and

(4) Hazardous materials listed in LAC 33:V, Subpart 2 (Louisiana Department of Public Safety Hazardous Materials/Hazardous Waste Transportation Regulations [e.g., DOT hazardous materials]).

In addition, the regulation of inactive and abandoned hazardous substance sites specifically extends the definition of hazardous waste beyond those identified by LDEQ to include the RCRA statutory definition of hazardous waste, as referred to earlier.

A hazardous substance site is any place where hazardous substances have come to be located, including without limitation, any building, structure, installation, equipment, pipe or pipeline, well, pit, pond, lagoon, impoundment, ditch, landfill, storage container, motor vehicle, rolling stock, aircraft, or any other place or area where a hazardous substance has been deposited, stored, disposed or placed or otherwise come to be located (LAC 33:VI.117). Therefore, the disposal or discharge of any chemical weapons or chemical warfare agents found to be hazardous substances or statutory hazardous waste could be under LDEQ jurisdiction for identification, investigation, and remediation.

In addition, Louisiana requires any facilities reporting under federal law to submit annual inventory forms to the Louisiana Emergency Response Commission, operating within the Department of Public Safety and Corrections, to the LEPC in the parish where the facility is located, and to the local fire department having jurisdiction over the facility (LAC 33:V.10101). These reporting requirements pertain to:

- The EPCRA List of Extremely Hazardous Substances (40 CFR 355, Appendix A), and

- Any material required to have an MSDS under OSHA regulations (29 CFR 1910.1200). 
Furthermore, Louisiana requires that releases meeting or exceeding reportable quantities of substances on the following lists be reported immediately to the Louisiana Emergency Response Commission, the LEPC with jurisdiction, and any other agency with jurisdiction (e.g., LDEQ, EPA, the National Response Center):

- The EPCRA List of Extremely Hazardous Substances (40 CFR 355, Appendix A),

- $\quad$ The CERCLA Hazardous Substance List (40 CFR 302, Table 302.4),

- $\quad$ The DOT Hazardous Substance List (49 CFR 172.101), and

- Any material required to have an MSDS under OSHA regulations (29 CFR 1910.1200).

Therefore, the storage or release of lewisite, mustard gas, phosgene, sarin, tabun, or VX in quantities above the federal threshold reportable quantities must be reported to the appropriate entity.

\subsection{MARYLAND}

\subsubsection{Hazardous Waste Regulations}

The Maryland Department of the Environment (MDE) has promulgated regulations that restate the federal RCRA regulations concerning the identification and listing of hazardous wastes (Code of Maryland Regulations [COMAR] 26.13.02.16 et seq.). In addition, the MDE regulations (COMAR 26.13.02.17 and 26.13.02.18) list the following state-specific hazardous wastes:
(1) GA (K991)
(2) GB (K992)
(3) GD (K993)
(4) VX (K994)
(5) L (K995)
(6) Adamsite (K996)
(7) Sulfur mustard HD (K997)
(8) T (K998) 
(9) Waste military chemical warfare agents (chemical surety agents) having substances K991 through K998 as active or principal ingredients, or ingredients of K991 through K998 with a characteristic of hazardous waste (K999)

(10) Residues from the treatment of wastes K991 through K999 (MD02)

These state-specific listed hazardous wastes are designated as acute hazardous wastes [COMAR 26.13.02.15(E)].

Certain decontaminated chemical agent hazardous wastes have been excluded from regulation as hazardous waste (i.e., delisted) in Maryland (COMAR 26.13.02.26). These include chemical surety materials GA, GB, GD, VX, L, and HD at the U.S. Army Aberdeen Proving Ground. To be excluded these chemical surety materials must have been decontaminated according to the protocol presented in Section 4.2 of the report, To Support the Delisting of Decontaminated Liquid Surety Materials as Hazardous Waste from Specific Sources COMAR 26.13.02.17 and 26.13.02.18, K991-K999 and Residues from K991-K999 (U.S. Army Chemical Research, Development and Engineering Center). This report is incorporated into the regulation by reference. The decontamination protocol identified in the report includes very specific treatment/decontamination procedures. Maryland.

MDE has not adopted the federal military munitions rule; therefore, it is not in effect in

\subsubsection{Additional Pertinent Statutory or Regulatory Provisions}

Under MDE air quality regulations, chemical surety materials are Class 1 Toxic Air Pollutants (TAPs) (COMAR 26.11.16.08). Any installation that discharges a Class 1 TAP into the ambient air is subject to permitting requirements. The installation must quantify the emissions, and must demonstrate that allowable emissions will not unreasonably endanger human health, both because of potential carcinogenic effects and because of other potential toxic effects (COMAR 26.11.15.03, 26.11.15.04, and 26.11.15.07). Compliance must be demonstrated using a screening analysis based on established levels (COMAR 26.11.16.02 and 26.11.16.09).

\subsection{MASSACHUSETTS}

\subsubsection{Hazardous Waste Regulations}

Massachusetts Department of Environmental Protection (MDEP) regulations restate the federal regulations for the classification and listing of hazardous wastes. MDEP has also 
specifically listed certain additional wastes (310 Code of Massachusetts Regulations [CMR] 30.130), including:

- Residues from incineration or thermal treatment of soil contaminated with halogenated organic carbon wastes (F028);

- Waste oil (MA01);

- $\quad$ PCBs equal to or greater than 50 ppm (MA02); and

- Waste generated in the manufacture of paint if the paint is formulated with one or more ingredients which are listed as hazardous constituents (i.e., 40 CFR 261, Appendix VIII) (MA04).

Similar to the federal RCRA regulations allowing EPA to designate materials as hazardous wastes for purposes of protecting human health and the environment from imminent and substantial endangerment [40 CFR 261.1(b)(2)], MDEP regulations contain a general waste code for wastes designated as hazardous during inspections. Specifically, the MDEP regulations designate waste code MA00 as waste that is not identified or otherwise described in the MDEP regulations classifying and listing hazardous waste, if the MDEP, in the course of inspecting any premises, has reason to believe such waste meets the general criteria of a hazardous waste and the MDEP believes an imminent threat may exist (310 CMR 20.130 and 30.144). The general criteria referred to in this listing includes a waste, or combination of wastes, which because of its quantity, concentration, or physical, chemical, or infectious characteristics may:

- Cause, or significantly contribute to, an increase in mortality or an increase in serious irreversible, or incapacitating reversible, illness, or

- Pose a substantial present or potential hazard to human health, safety, or welfare, or to the environment, when improperly stored, treated, transported, or disposed of, or otherwise managed. (310 CMR 30.111)

This Massachusetts general criterion mirrors the federal statutory definition of hazardous waste [42 U.S.C. 6903(5)]. Therefore, the Massachusetts RCRA program is basically the same as the federal RCRA program, and those chemical agents/weapons listed in the federal RCRA program are listed hazardous wastes in Massachusetts.

MDEP has not adopted the military munitions rule; therefore, it is not in effect in Massachusetts.

\subsubsection{Additional Pertinent Statutory or Regulatory Provisions}

Under the Massachusetts Oil and Hazardous Material Releases Prevention and Response Act (Massachusetts General Laws [MGL], Chapter 21E), a release of a hazardous material must be reported to MDEP. In addition, whenever MDEP has reason to believe that a hazardous 
material has been released or that there is a threat of release, it may take or arrange for response actions it reasonably deems necessary under the Massachusetts Contingency Plan (MGL 21E Section 4; 310 CMR 40.340). Hazardous materials are defined as including, but not limited to, any material, in whatever form, which, because of its quantity, concentration, chemical, corrosive, flammable, reactive, toxic, infectious or radioactive characteristics, either separately or in combination with any substance or substances, constitutes a present or potential threat to human health, safety, welfare, or to the environment, when improperly stored, treated, transported, disposed of, used, or otherwise managed. Hazardous materials specifically listed by MDEP include lewisite, phosgene, mustard gas, sarin, tabun, and VX (310 CMR 40.1600). Therefore, the release of or remediation activity from the release of any of the above-named chemical warfare agents would require notification to MDEP and could result in MDEP regulation/oversight of remediation activities.

Under the Massachusetts Toxics Use Reduction Act, every facility that is required to file a TRI report under Section 313 of EPCRA (EPA Form R) must file a state Form S with MDEP. Form $S$ requires more information than the EPA Form $\mathrm{R}$, including the percentage reduction of toxic by-products from production units and the toxic use reduction techniques used to reduce the wastes. Phosgene is listed pursuant to Section 313 of EPCRA; therefore, any affected facility storing or using phosgene in excess of the regulatory thresholds also would be required to file a report with MDEQ. Under the Massachusetts program, federal facilities, by definition, are not required to develop the state-specific report.

\subsection{MICHIGAN}

\subsubsection{Hazardous Waste Regulations}

The Michigan Department of Environmental Quality (MDEQ) has adopted hazardous waste regulations that basically reflect the federal RCRA program (Michigan Admin. Code [MAC] R 299.9101 et seq.). Therefore, the Michigan RCRA program is generally the same as the federal RCRA program. However, in addition to the chemical agents/weapons listed in the federal RCRA program (i.e., phosgene), mustard gas is also a listed hazardous waste in Michigan (Michigan Hazardous Waste No. 093U) (MAC R 299.9220, Table 203c).

Michigan has adopted the federal military munitions rule (September 11, 2000) but has yet to receive EPA authorization. Because states may enforce state-specific rules under state law, the military munitions rule is in effect but not federally enforceable in Michigan.

\subsubsection{Additional Pertinent Statutory or Regulatory Provisions}

As soon as practical after detection of a release, the owner, operator, or manager of the facility that releases any polluting material in excess of a threshold reporting quantity must notify MDEQ (MAC R 324.2007). A polluting material includes oil, salt, and any material specified in the regulations, which specifically list phosgene and mustard gas. In addition, any compound or 
product that contains $1 \%$ or more, by weight, of any of these materials is also a polluting material. The Michigan threshold reporting quantity for both phosgene and mustard gas is 10 pounds (MAC R 324.2009).

\subsection{MISSISSIPPI}

\subsubsection{Hazardous Waste Regulations}

The Mississippi Department of Environmental Quality (MDEQ) regulations adopt the federal RCRA hazardous waste identification and listing regulations (MDEQ Hazardous Waste Management Regulations, Part 261). Therefore, the Mississippi RCRA program is the same as the federal RCRA program, and only those chemical agents/weapons listed in the federal RCRA program are listed hazardous wastes in Mississippi.

The MDEQ regulations adopt the federal RCRA military munitions rule (MDEQ Hazardous Waste Management Regulations, Part 266), but EPA authorization has not yet been received. Because states may enforce state-specific rules under state law, the military munitions rule is in effect but not federally enforceable in Mississippi.

\subsubsection{Additional Pertinent Statutory or Regulatory Provisions}

Under the Mississippi Pollution Prevention law (Mississippi Code 49-31-21), every facility that is required to file a TRI report under Section 313 of EPCRA (EPA Form R) must file a hazardous waste minimization plan with MDEQ. Phosgene and mustard gas are listed pursuant to Section 313 of EPCRA; therefore, any facility storing or using these chemicals in excess of the regulatory thresholds would also be required to file a report with MDEQ.

\subsection{MISSOURI}

\subsubsection{Hazardous Waste Regulations}

The Missouri Department of Natural Resources (MDNR) regulations adopt the federal RCRA hazardous waste identification and listing regulations (10 Code of State Regulations [CSR] 25-4.261). However, MDNR has designated additional wastes as acute listed hazardous wastes:

- Any residue or contaminated soil, water, or other debris resulting from the cleanup of a spill of waste listed as F020, F021, F022, F023, F026, or F027 in 
the RCRA regulations (40 CFR 261.23), regardless of the quantity or time of the spill or release (MH01); and

- 2,3,7,8-tetrachlorodibenzo-p-dioxin (TCDD) (MH02).

No chemical weapons or chemical warfare agents have been so listed in Missouri.

Upon receipt of information that an activity governed by the MDNR/RCRA regulations may present an imminent hazard, MDNR has the power to take action necessary to protect the health of humans and the environment. Such action may include issuing an order directing the hazardous waste generator or facility operator who has control of the waste to eliminate the hazard or to file for a temporary restraining order, temporary injunction, or permanent injunction against the activity (Missouri Revised Statutes 260.420).

Missouri has adopted the federal military munitions rule (10 CSR 25-7.266), but EPA authorization has not yet been received. Because states may enforce state-specific rules under state law, the military munitions rule is in effect but not federally enforceable in Missouri.

\subsubsection{Additional Pertinent Statutory or Regulatory Provisions}

Any release of a hazardous substance must be reported to MDNR at the earliest possible moment (10 CSR 24-3.010). A hazardous substance is defined as any substance or mixture of substances that presents a danger to the public health or safety or the environment and includes any:

(A) Hazardous waste identified or listed by the MDNR;

(B) Element, compound, mixture, solution or substance designated under CERCLA or EPCRA; and

(C) Hazardous material regulated by DOT under the HMTA. (10 CSR 24-2.010)

Because phosgene is a listed hazardous waste, a CERCLA hazardous substance, and a hazardous material under DOT regulations, a release of phosgene would have to comply with these regulations. Also, because lewisite, mustard gas, phosgene, sarin, tabun, and VX are listed as extremely hazardous substances under EPCRA, a release of any of these materials would have to comply with these regulations. 


\subsection{NEBRASKA}

\subsubsection{Hazardous Waste Regulations}

The Nebraska Department of Environmental Quality (NDEQ) has adopted regulations that generally parallel the federal hazardous waste regulations (NDEQ Rules of Practice and Procedures [RPP], Title 128). NDEQ has not specifically designated chemical agents or chemical weapons as listed hazardous wastes. Therefore, the Nebraska RCRA program is generally the same as the federal RCRA program, and only those chemical agents/weapons listed in the federal RCRA program are listed hazardous wastes in Nebraska.

Nebraska has not adopted the federal military munitions rule. Therefore, the federal RCRA military munitions rule is not in effect in Nebraska.

\subsubsection{Additional Pertinent Statutory or Regulatory Provisions}

Any responsible person has the duty to notify the NDEQ of any release or suspected release of a hazardous substance when the release threatens waters of the state, or exceeds 100 pounds or the reportable quantity listed under federal CERCLA or EPCRA regulations, whichever is lower (126 RPP Chapter 18). The Nebraska Emergency Management Agency (NEMA), in the office of the Nebraska Adjutant General, is the SERC under EPCRA. NEMA administers the Nebraska Emergency Management Act (Nebraska State Statutes 81-829.31 through 829.73) and the Nebraska Emergency Planning and Community Right-to-Know Act, which includes receiving EPCRA toxic release information (Nebraska State Statutes 81-15.191 et seq.).

\subsection{NEVADA}

\subsubsection{Hazardous Waste Regulations}

The Nevada Department of Conservation and Natural Resources, Division of Environmental Protection (NDEP) has adopted, by reference, the federal hazardous waste regulations (Nevada Admin. Code [NAC] 444.86325). NDEP has not specifically designated chemical agents or chemical weapons as listed hazardous wastes. Therefore, the Nevada RCRA program is generally the same as the federal RCRA program, and only those chemical agents/weapons listed in the federal RCRA program are listed hazardous wastes in Nevada.

Nevada has adopted the federal military munitions rule and has received EPA authorization (64 FR 4596, January 29, 1999). Therefore, the federal RCRA military munitions rule is in effect in Nevada. 


\subsubsection{Additional Pertinent Statutory or Regulatory Provisions}

The Nevada SERC is tasked with implementing EPCRA at the state level. Copies of TRI reports sent to the EPA are sent to the SERC. Spills in excess of the EPCRA and CERCLA reportable quantities must be reported to NDEP.

In addition to EPCRA, the Nevada Legislature has enacted the Chemical Catastrophe Prevention Act, which directed NDEP to develop and implement an accident prevention program. This program was named the Chemical Accident Prevention Program, or CAPP. Under CAPP, a facility that has highly hazardous substances on its premises must:

(1) Register with NDEP;

(2) Conduct a hazard assessment of its processes;

(3) Develop a prevention program, including operating procedures and training;

(4) Develop an emergency response plan; and

(5) Submit an annual compliance report.

The regulatory list of highly hazardous substances includes phosgene and sarin (NAC 459.9533). In 1997, CAPP statutes were modified to enable NDEP to seek delegation for EPA's Risk Management Program under Section 112(r) of the Clean Air Act. Provisions were also added to require facilities handling highly hazardous substances in quantities less than the program threshold quantities to become subject to CAPP after having two accidental releases within a 12-month period (NAC 459.95486).

\subsection{NEW JERSEY}

\subsubsection{Hazardous Waste Regulations}

The New Jersey Department of Environmental Protection (NJDEP) has adopted, by reference, the federal hazardous waste regulations (New Jersey Admin. Code [N.J.A.C.] 7:26G). NJDEP has not specifically designated chemical agents or chemical weapons as listed hazardous wastes. Therefore, the New Jersey RCRA program is generally the same as the federal RCRA program, and only those chemical agents/weapons listed in the federal RCRA program are listed hazardous wastes in New Jersey.

New Jersey has adopted the federal military munitions rule (N.J.A.C. 7:26G-10.1) but has yet to receive EPA authorization. Because states may enforce state-specific rules under state law, the military munitions rule is in effect but not federally enforceable in New Jersey. 


\subsubsection{Additional Pertinent Statutory or Regulatory Provisions}

Immediately after a discharge of a hazardous substance commences, the person responsible for the discharge must notify NJDEP (N.J.A.C. 7:1E-5.3). A hazardous substance is any substance listed in the regulation, which includes phosgene, mustard gas, sarin, tabun, and VX (N.J.A.C. 7:1E, Appendix A). Discharge prevention regulations, which govern major facilities storing, transferring, processing, or using hazardous substances, require the submission of a Discharge Prevention, Containment, and Countermeasures Plan and a Discharge Cleanup and Removal Plan to NJDEP. A major facility is one that stores more than 20,000 gallons of all combined hazardous substances except petroleum or petroleum products.

The NJDEP Bureau of Chemical Release Information and Prevention collects, processes, and disseminates the chemical inventory, environmental release, and materials accounting data required to be reported under the New Jersey Worker and Community Right to Know Act (New Jersey Statutes Annotated [NJSA] 34:5A) and EPCRA. A facility subject to the reporting requirements of Section 313 of EPCRA must submit a Release and Pollution Report to NJDEP (NJAC 7:1G-4) if it stores or uses hazardous substances in excess of the threshold quantities established in the New Jersey Pollution Prevention Act (NJSA13:1D-35 et seq.). Although the NJDEP regulations allow NJDEP to establish threshold quantities lower than the EPCRA planning and reporting thresholds for EPA extremely hazardous substances, NJDEP has not added any chemical substances and has not established lower threshold quantities for any of the TRI substances (NJAC 7:1K-1.1 et seq.).

\subsection{NEW MEXICO}

\subsubsection{Hazardous Waste Regulations}

The New Mexico Environment Department (NMED) has adopted, by reference, the federal hazardous waste regulations (New Mexico Admin. Code [NMAC] 20.4.1.100 et seq.). The NMED has not specifically designated chemical agents or chemical weapons as listed hazardous wastes (NMAC 20.4.1.200). Therefore, the New Mexico RCRA program is generally the same as the federal RCRA program, and only those chemical agents/weapons listed in the federal RCRA program are listed hazardous wastes in New Mexico.

New Mexico has adopted the federal military munitions rule (NMAC 20.4.1.700) but has yet to receive EPA authorization. Because states may enforce state-specific rules under state law, the military munitions rule is in effect but not federally enforceable in New Mexico.

\subsubsection{Additional Pertinent Statutory or Regulatory Provisions}

Under the New Mexico Hazardous Chemicals Information Act, EPCRA Title III information must be filed with the Public Safety Department (New Mexico Statutes Annotated 74-4E-1 to 74-4E-9). The Office of Emergency Management within the Public Safety 
Department implements EPCRA in New Mexico, including receiving TRI reports. This office is also responsible for managing the coordinated state response to any emergency involving the release of hazardous materials, which includes all EPCRA extremely hazardous substances. The owner, operator, or person in charge of any facility where a discharge has occurred must provide notification of such release to NMED.

Under the New Mexico Department of Health, Office of Epidemiology regulations (NMAC 7.4.3.12), any illness suspected to be caused by the intentional or accidental release of biologic or chemical agents is a "notifiable condition" and must be reported immediately to the Office of Epidemiology.

\subsection{NEW YORK}

\subsubsection{Hazardous Waste Regulations}

The New York Department of Environmental Conservation (NYDEC) regulations restate the federal RCRA regulations concerning identification and listing of hazardous wastes (6 New York Code, Rules and Regulations [NYCRR] 371.1). Therefore, the New York RCRA program is essentially the same as the federal RCRA program, and those chemical agents/weapons listed in the federal RCRA program are listed hazardous wastes in New York. The NYDEC regulations also specifically list PCB wastes, which have been designated as listed hazardous wastes bearing the waste codes B001-B007 (6 NYCRR 371.4).

NYDEC has adopted the federal military munitions rule (6 NYCRR 374.1.13), but EPA authorization has not yet been received. Because states may enforce state-specific rules under state law, the military munitions rule is in effect but not federally enforceable in New York.

\subsubsection{Additional Pertinent Statutory or Regulatory Provisions}

Under the NYDEC regulations for releases of hazardous substances, all releases of specifically listed hazardous substances that exceed a reportable quantity must be reported to the NYDEC (6 NYCRR 595). Pursuant to authorization from the New York Environmental Conservation Law, Article 37, "Substances Hazardous or Acutely Hazardous to Public Health, Safety or the Environment," NYDEC has promulgated a List of Hazardous Substances (6 NYCRR 597). This list includes lewisite, mustard gas, phosgene, sarin, tabun, and VX. All but phosgene and VX are designated as acutely hazardous substances. All but phosgene have a reportable quantity of 1 pound $(0.45 \mathrm{~kg})$ for releases to either air or land. Phosgene has a reportable quantity of 10 pounds for a release to either air or land. These regulations would be applicable if there were a release of any of these chemical weapons or chemical warfare agents that exceeded the reportable quantity. 


\subsection{NORTH CAROLINA}

\subsubsection{Hazardous Waste Regulations}

The North Carolina Department of Environment and Natural Resources (NCDENR) regulations incorporate by reference the federal RCRA regulations concerning identification and listing of waste (15A North Carolina Admin. Code [NCAC] 13A.0106). Therefore, the North Carolina RCRA program is the same as the federal RCRA program, and only those chemical agents/weapons listed in the federal RCRA program are listed hazardous wastes in North Carolina.

NCDENR has also adopted the federal RCRA regulations concerning military munitions [15A NCAC 13A.0111(e)], but EPA authorization has not yet been received. Because states may enforce state-specific rules under state law, the military munitions rule is in effect but not federally enforceable in North Carolina.

\subsubsection{Additional Pertinent Statutory or Regulatory Provisions}

The North Carolina Emergency Management Act provides for emergency response to releases of hazardous materials within the state. Hazardous material means any material defined as a hazardous substance under OSHA regulations [29 CFR 1910.120(a)(3)]. Hazardous substance under OSHA emergency response regulations means:

- Any substance defined under Section 101(14) of CERCLA;

- Any biological agent and other disease-causing agent which after release into the environment and upon exposure, ingestion, inhalation, or assimilation into any person, either directly from the environment or indirectly by ingestion through food chains, will or may reasonably be anticipated to cause death, disease, behavioral abnormalities, cancer, genetic mutation, physiological malfunctions (including malfunctions in reproduction) or physical deformations in such persons or their offspring;

- Any substance listed by DOT as hazardous materials; and

- Hazardous waste as defined under OSHA law.

Hazardous waste is defined under OSHA emergency response regulations as any waste or combination of wastes as defined in 40 CFR 261.3, or those substances defined as hazardous wastes in 49 CFR 171.8 (i.e., any waste requiring a RCRA manifest for shipment). Only phosgene is a CERCLA hazardous substance or a federal RCRA hazardous waste. Only phosgene is specifically listed as a hazardous material (i.e., poisonous gas) under DOT regulations. Therefore, only phosgene is subject to the North Carolina Emergency Management Act. 
Executive Order 18 delegates authority to the Secretary of Crime Control and Public Safety to allocate all available state resources to cope with any emergency or disaster. Under the North Carolina Emergency Operations Plan for Hazardous Materials Response, the NCDENR Division of Air Quality and Water Quality is the lead agency for responding to spills involving hazardous materials, including asserting state jurisdiction and ordering cleanup activities when no federal official has arrived or the spill is outside federal jurisdiction (e.g., not CERCLA or EPCRA).

\subsection{OHIO}

\subsubsection{Hazardous Waste Regulations}

The Ohio Environmental Protection Agency (OEPA) has adopted regulations that parallel the federal hazardous waste regulations (Ohio Admin. Code [OAC] 3745-50 et seq.). OEPA has not specifically designated chemical agents or chemical weapons as listed hazardous wastes (OAC 3745-51-11). Therefore, the Ohio RCRA program is generally the same as the federal RCRA program, and only those chemical agents/weapons listed in the federal RCRA program are listed hazardous wastes in Ohio.

Ohio has not adopted the federal military munitions rule; therefore, the federal RCRA military munitions rule is not in effect in Ohio.

\subsubsection{Additional Pertinent Statutory or Regulatory Provisions}

An owner or operator of a facility is required to report the release of a regulated chemical in excess of its assigned reportable quantity if it leaves the facility property line (Ohio Revised Code 3750.06). The term "regulated chemical" includes CERCLA hazardous materials, EPCRA extremely hazardous substances, and oil. All verbal notifications made under these rules are to be reported to OEPA's Emergency Response Section, the Local Emergency Planning District(s) that may be affected, and the jurisdictional fire department(s) [OAC 3750-25-25(A)(1)(a)]. This verbal notification must be made within 30 minutes of knowledge of the release, unless notification within that timeframe is impractical due to uncertain circumstances [OAC 3750-25$25(\mathrm{~A})(1)(\mathrm{d})$ ]. A follow-up written report is also required. OEPA is the agency designated to implement the EPCRA TRI and planning programs.

\subsection{OREGON}

\subsubsection{Hazardous Waste Regulations}

The Oregon Department of Environmental Quality (ODEQ) has incorporated by reference the federal RCRA regulations for identification and listing of hazardous wastes 
(Oregon Admin. Rules [OAR] 340-101-0001). In addition to the federally listed hazardous wastes for commercial chemical products, manufacturing chemical intermediates, or offspecification commercial chemical products or manufacturing chemical intermediates [40 CFR 261.33(e)], ODEQ regulations for generators list the following state-specific hazardous wastes:

(1) P998 - Blister agents (such as mustard agent)

(2) P999 - Nerve agents (such as sarin and VX)

Oregon regulations include the following as additional state-specific listed hazardous waste from nonspecific sources (40 CFR 261.31):

(1) F998 - Residues from demilitarization, treatment, and testing of blister agents (such as mustard agent).

(2) F999 - Residues from demilitarization, treatment, and testing of nerve agents (such as sarin and VX).

ODEQ regulations specifically define demilitarization as:

... all processes and activities at the Umatilla Chemical Depot and Umatilla Chemical Agent Disposal Facility from February 12, 1997, through ODEQ approval for closure of all permitted treatment, storage, and disposal units and facility-wide corrective actions.

Demilitarization residue is defined as follows:

... any solid waste generated by demilitarization processes and activities, except for waste streams generated from processes or activities prior to the introduction of nerve or blister agent into the treatment unit; and waste streams generated from maintenance or operation of non-agent-contaminated process utility systems. (OAR 340-100-0010)

The regulations note that even when a waste is listed as hazardous waste, the generator still has an opportunity to demonstrate to the ODEQ that the waste from his/her particular facility or operation is not a hazardous waste.

Under the federal regulations, hazardous wastes listed as commercial chemical products, manufacturing chemical intermediates, or off-specification commercial chemical products or manufacturing chemical intermediates, consist only of the commercially pure grade of the chemical, any technical grades of the chemical that are produced or marketed, and all formulations in which the chemical is the sole active ingredient. The federal listing does not include a material, such as a manufacturing process waste, that merely contains any of the 
substances listed in the federal regulations [40 CFR 261.33(e) or (f)]. However, the ODEQ rules include, as additional state-specific listed hazardous wastes:

- Any residue, including but not limited to manufacturing process wastes and unused chemicals, that has a $3 \%$ or greater concentration of any substance or mixture of substances listed as a federal acute hazardous wastes [40 CFR 261.33(e) or P-coded wastes], or

- $10 \%$ or greater concentration of any substance or mixture of substances listed as federal toxic hazardous wastes [40 CFR 261.33(f) or U-coded wastes].

In addition, any residue or contaminated soil, water, or debris resulting from the cleanup of a spill into or on any land or water of these state-specific hazardous waste residues is also a listed hazardous waste [OAR 340-101-0033(2)]. Such listed hazardous waste residues are assigned the hazardous waste letters "OR" followed by the corresponding hazardous waste number(s) in the federal regulation [OAR 340-101-033(3)].

ODEQ has adopted the federal military munitions rule [OAR 430-100-0002(1)]; therefore, a military munitions regulation is in effect in Oregon. EPA authorization has not yet been received; hence, the rule is not federally enforceable in Oregon. In adopting the military munitions rule, ODEQ has included certain regulatory changes that affect the implementation of the rule in Oregon:

- The ODEQ regulations include state-specific additional design and operating standards for units used for the storage of chemical agent munitions and chemical agent bulk items, including vapor containment mechanisms for nerve agents.

- For the purposes of chemical agent munitions and chemical agent bulk items storage, "no migration" in the federal regulations is amended to mean no detectable concentration of chemical agent outside the containment mechanisms of the storage unit, as measured by sampling and analytical methods specified in the ODEQ-approved storage unit operations and management plan. (OAR 340-104-1201)

These requirements are in addition to the requirements in the federal RCRA military munitions regulations for storage of munitions (40 CFR 264 Subpart EE).

More importantly, however, and contrary to the federal regulation's definition of when a military munition becomes a solid waste (40 CFR 266.202), ODEQ has designated chemical agent munitions and chemical agent bulk items in storage as of the date of the rule as "residues" and, specifically, as listed hazardous wastes assigned the same codes discussed above (OAR 340-101-0030). The ODEQ regulations define a residue as a solid waste as defined in the federal RCRA regulations (40 CFR 261.2; OAR 340-100-0010). 
In contrast, the EPA regulations (40 CFR 266.202) enumerate the circumstances when an unused military munition is a solid waste, as follows:

- It is abandoned by being disposed of, burned, detonated, incinerated, or treated prior to disposal;

- It is removed from storage in a military magazine or other storage area for the purpose of being disposed of, burned, or incinerated, or treated prior to disposal;

- It is deteriorated or damaged (e.g., the integrity of the munition is compromised by cracks, leaks, or other damage) to the point that it cannot be put into serviceable condition and cannot reasonably be recycled or used for other purposes; or

- It has been declared a solid waste by an authorized military official.

The ODEQ regulation acknowledges that although it has adopted the federal regulations found at 40 CFR 266, including the federal definition of when military munitions become solid waste, chemical agent munitions and chemical agent bulk items in storage are declared as residues (i.e., solid waste), and specifically as listed hazardous waste. This provision is adopted notwithstanding any otherwise applicable federal regulation or other provision of the ODEQ rules (OAR 340-101-0030). To date, Oregon is the only state that so regulates chemical agent munitions and chemical agent bulk items in storage.

\subsubsection{Additional Pertinent Statutory or Regulatory Provisions}

The Oregon regulations governing oil and hazardous material spills and releases provides for reporting requirements, cleanup standards, and liability that attach to a spill, release, or threatened release of hazardous materials (OAR 340-108-0001). Under these regulations, hazardous material means radioactive wastes, substances listed in CERCLA (40 CFR 302, Table 302.4), and chemical agents (such as nerve agents BG and VX, and blister agent HD) (OAR 340-108-0002). The reportable quantities are those established in federal CERCLA regulations (40 CFR 302) or any quantity of chemical agent (OAR 340-108-0010). The person owning or having control over the hazardous material must report to the Oregon Emergency Management Division if a spill exceeds the reportable quantity. A hazardous material spill must also be reported to the National Response Center. Reporting is not necessary, however, if the spill occurs on public or private property and the spill occurs on a surface impervious to the material and is fully contained, and completely cleaned up without further incident, including fixing or repairing the cause of the release.

The Oregon statute "Hazardous Waste and Hazardous Materials I: Reduction of Use of Toxic Substances and Hazardous Waste Generation" provides for a county assessment of the 
effects of a major recovery or remedial action at any storage or disposal site for chemical agents (Oregon Revised Statutes [ORS] Chapter 465). Under this statute chemical agents are defined as:

(a) Blister agents, such as mustard gas;

(b) Nerve agents, such as sarin and VX;

(c) Residues from demilitarization, treatment, and testing of blister agents; and

(d) Residues from demilitarization, treatment, and testing of nerve agents.

A major recovery action is any activity designed to mitigate the effects of an unintended release of chemical agents into the air, water, or soil that will take more than one year to complete and employ more than 200 individuals. A major remedial action is any activity intended to prevent the release of chemical agents into the air, water, or soil, including the controlled destruction of chemical agents that will take more than one year to complete and employ more than 200 individuals (ORS 465.550).

\subsection{PENNSYLVANIA}

\subsubsection{Hazardous Waste Regulations}

The Pennsylvania Department of Environmental Protection (PDEP) has incorporated, by reference, the federal hazardous waste regulations (25 Pennsylvania Code [PC] Chapter 260 et seq.). PDEP has not specifically designated chemical agents or chemical weapons as listed hazardous wastes (25 PC 261). Therefore, the Pennsylvania RCRA program is the same as the federal RCRA program, and only those chemical agents/weapons listed in the federal RCRA program are listed hazardous wastes in Pennsylvania.

Pennsylvania has adopted the federal military munitions rule (25 PC 266), and has received EPA authorization (65 FR 57,739); therefore, the federal RCRA military munitions rule is in effect but not federally enforceable in Pennsylvania.

\subsubsection{Additional Pertinent Statutory or Regulatory Provisions}

The Hazardous Material Emergency Planning and Response Act (Pennsylvania Act 1990165) implements the planning and preparedness requirements of EPCRA. The Pennsylvania Emergency Management Council (PEMC) serves as the SERC. The Pennsylvania Emergency Management Agency is the executive administrative agent for the PEMC.

The Pennsylvania Worker and Community Right to Know Act (Pennsylvania Act 159 of 1984) requires public sector employers in the Commonwealth to report information about the hazardous chemicals used, produced, or stored at their work sites. Public sector employers 
(excluding the federal government) in Pennsylvania are required by the Pennsylvania Worker and Community Right to Know Act to annually complete a Hazardous Substance Survey Form by April 1 and post it in the workplace. Any hazardous substance found on the Department of Labor and Industry's Hazardous Substance List (34 PC 323, Appendix A) must be listed on the Hazardous Substance Survey Form. This list includes 2,335 substances that have been identified by the Department of Labor as health hazards and/or safety concerns to workers and citizens or that have the potential to be hazardous when released into the environment. The list includes phosgene, tabun, sarin, mustard gas, lewisite, and VX.

\subsection{SOUTH CAROLINA}

\subsubsection{Hazardous Waste Regulations}

The South Carolina Department of Health and Environmental Control (SCDHEC) has adopted regulations that generally parallel the federal hazardous waste regulations (South Carolina Hazardous Waste Management Regulations [SCHWMR] 61-79 et seq.). SCDHEC has not specifically designated chemical agents or chemical weapons as listed hazardous wastes (SCHWMR 61-79.261). However, SCDHEC has specifically listed as a hazardous waste "any solid waste the Department determines constitutes a hazard and requires greater control" (SCHWMR 61-79.261, Appendix XI - Other Designated Wastes). Therefore, the South Carolina RCRA program is generally the same as the federal RCRA program, and only those chemical agents/weapons listed in the federal RCRA program are listed hazardous wastes in South Carolina.

The additional generic designated waste could allow SCDHEC to declare a waste chemical agent/weapon as a listed hazardous waste simply by determining it constituted a hazard that required greater control. There is no publicly available information on SCDHEC having exercised this generic determination.

South Carolina has adopted the federal military munitions rule (SCHWMR 61-79.266) but has yet to receive EPA authorization. Because states may enforce state-specific rules under state law, the military munitions rule is in effect but not federally enforceable in South Carolina.

\subsubsection{Additional Pertinent Statutory or Regulatory Provisions}

The South Carolina SERC implements the federal EPCRA program in the state. Each qualifying facility (e.g., a facility that stores or uses in excess of the reporting threshold of EPCRA hazardous substances) must submit a Tier II report to the SERC. In addition, all responsible parties must immediately report release incidents to SCDHEC. 


\subsection{SOUTH DAKOTA}

\subsubsection{Hazardous Waste Regulations}

The South Dakota Department of Environment and Natural Resources (SDDENR) regulations adopt the federal RCRA regulations concerning identification and listing of hazardous wastes (Administrative Rules [AR] 74:28:22:01). Therefore, the South Dakota RCRA program is the same as the federal RCRA program, and only those chemical agents/weapons listed in the federal RCRA program are listed hazardous wastes in South Dakota. In addition, SDDENR has exerted jurisdiction over wastes containing PCBs in concentrations of $50 \mathrm{ppm}$ and above (AR 74:28:22:01).

SDDENR has adopted the federal military munitions rule (AR 74:28:27:01), but EPA authorization has not yet been received. Because states may enforce state-specific rules under state law, the military munitions rule is in effect but not federally enforceable in South Dakota.

\subsubsection{Additional Pertinent Statutory or Regulatory Provisions}

Under SDDENR regulations, a responsible person must report to the SDDENR a known or suspected discharge of a regulated substance to the environment when one of the following conditions exists:

(1) The discharge threatens or is in a position to threaten the waters of the state;

(2) The discharge causes an immediate danger to human health or safety;

(3) The discharge exceeds 25 gallons or causes a sheen on surface water or it exceeds any SDDENR groundwater quality standard or surface water quality standard;

(4) The discharge harms or threatens to harm wildlife or aquatic life; or

(5) The discharge is required to be reported according to Superfund Amendments and Reauthorization Act (SARA) Title III, Section 304 (1986). (AR 74:34:01)

The following constitute regulated substances:

(1) Substances listed in the Title III List of Lists, Consolidated List of Chemicals Subject to Reporting Under EPCRA (January 1990);

(2) Fertilizers as defined in South Dakota Codified Law (SDCL) 38-19-1(1), (2), (3), (12), (13), and (14), including fertilizer derivatives; 
(3) Pesticides as defined in SDCL 38-20A-1(1), (3), (4), (5), and (6); SDCL 3820A-10; and those substances defined in SDCL 38-21-14(4), (5), (18), (19), (21), and (29), including metabolites and all active and inert ingredients of these substances;

(4) Petroleum and petroleum substances, including oil, gasoline, kerosene, fuel oil, oil sludge, oil refuse, oil mixed with other wastes, refined or blended crude petroleum stock, and any other oil or petroleum substance;

(5) Radiological, chemical, or biological warfare agents or radiological waste; and

(6) Hazardous wastes as described in 40 CFR 261, Subparts C and D (July 1, 1988). (AR 74:34:01.03)

Therefore, the known or suspected discharge of any chemical warfare agent that constitutes a danger to human health/safety or wildlife or a threat to water of the state would require notification of SDDENR.

\subsection{TENNESSEE}

\subsubsection{Hazardous Waste Regulations}

The Tennessee Department of Environment and Conservation (TDEC) regulations generally restate the federal RCRA regulations concerning identification and listing of hazardous wastes (Rules and Regulations of the State of Tennessee [RRST], Rule 1200-1-11-.02). Therefore, the Tennessee RCRA program is the same as the federal RCRA program, and only those chemical agents/weapons listed in the federal RCRA program are listed hazardous wastes in Tennessee.

TDEC has adopted the federal military munitions rule [RRST Rule 1200-1-11-.09(13)] and has received EPA authorization (65 FR 57,307; September 22, 2000); therefore, the military munitions rule is in effect in Tennessee.

\subsubsection{Additional Pertinent Statutory or Regulatory Provisions}

The Tennessee Emergency Management Agency (TEMA) is the administrative coordinator for the State Emergency Response Council. TEMA, an agency within the Tennessee Military Department, is the focal point for EPCRA compliance with Tennessee. 


\subsection{TEXAS}

\subsubsection{Hazardous Waste Regulations}

The Texas Natural Resource Conservation Commission (TNRCC) regulations require each person generating a solid waste to make the following determinations:

(1) If the waste is excluded from being a solid waste;

(2) If the waste is a hazardous waste under the federal RCRA regulations (40 CFR 261.2, 261.3, or 261.4);

(3) If the waste is listed as, mixed with, or derived from a listed hazardous waste identified in the federal RCRA regulations (40 CFR 261, Subpart D); or

(4) If the waste is not listed, whether the waste exhibits any characteristics of a hazardous waste as identified in federal RCRA regulations (40 CFR, Subpart C). (30 Texas Admin. Code [TAC] 335.504)

The Texas RCRA rules for characterization and listing of hazardous waste reference the federal RCRA regulations. Only those chemical agents/weapons listed in the federal RCRA program are listed hazardous wastes in Texas.

The TNRCC regulations adopt the federal military munitions rule (30 TAC 335.272), but EPA authorization has not yet been received. Because states may enforce state-specific rules under state law, the military munitions rule is in effect but not federally enforceable in Texas.

TNRCC also regulates nonhazardous industrial wastes or mixtures of industrial solid wastes, which because of their concentration, or physical or chemical characteristics, are toxic, corrosive, flammable, a strong sensitizer or irritant, a generator of sudden pressure by decomposition, heat, or other means, or may pose a substantial present or potential danger to human health or the environment when improperly processed, stored, transported, or disposed of or otherwise managed.

A nonhazardous industrial solid waste is a Class 1 waste when:

(1) It contains specific constituents which equal or exceed levels listed in the regulations [30 TAC 335 521(a)(1)] [None of the chemical weapons or chemical warfare agents reviewed in this paper is included.];

(2) It is a Class 1 ignitable (it is a liquid with a flash point less than $65.5^{\circ} \mathrm{C}$ or $150 \mathrm{~F}$, or it is a physical solid or semi-solid under which conditions normally incident to storage, transportation, and disposal is capable of causing fires through friction, or retained heat from manufacturing or processing, or which can be ignited readily, and when ignited burns both vigorously and 
persistently such that it creates a serious hazard, including spontaneously combustible and water-reactive materials and substances listed in the regulations) [30 TAC 335.521(a)(2) (ignitable solids) and 49 CFR 173, Subchapter E];

(3) It is a Class 1 corrosive having a $\mathrm{pH}$ less than or equal to 2 or greater than or equal to 12.5

(4) It contains total recoverable cyanides equal to or greater than $20 \mathrm{ppm}$;

(5) There is an absence of analytical data and/or documented process knowledge which proves it is not a Class 1 waste;

(6) It is identified as a Class 1 waste in the regulations (30 TAC 335.508) (List of Specific Industrial Solid Wastes does not include chemical weapons or agents); or

(7) The generator chooses to classify the waste as Class 1 (30 TAC 335.505).

Therefore, chemical weapons or chemical warfare agents could be regulated by TNRCC as Class 1 nonhazardous waste even if they were not specifically regulated as hazardous waste in Texas.

\subsubsection{Additional Pertinent Statutory or Regulatory Provisions}

Upon the determination that a reportable discharge or spill has occurred, the responsible person must notify TNRCC as soon as possible, but not later than 24 hours after the discovery of the spill or discharge. A reportable discharge or spill is a discharge or spill of oil, petroleum product, used oil, hazardous substances, industrial solid waste, or other substances into the environment in a quantity equal to or greater than the reportable quantity in any 24-hour period (30 TAC 327.3). The reportable quantities for hazardous substances are:

(1) For spills or discharges onto land, the quantity designated as the reportable quantity in Table 302.4 in 40 CFR 302.4; or

(2) For spills or discharges into waters in the state, the quantity designated as the reportable quantity in Table 302.4 in 40 CFR 302.4, except where the federal reportable quantity is greater than 100 pounds; then the state-specific reportable quantity is 100 pounds. (30 TAC 327.4)

The reportable quantity for industrial solid waste (e.g., a Class 1 industrial solid waste) or other substance spills or discharges into water in the state is 100 pounds. A hazardous substance is any substance designated by the EPA under CERCLA or regulated under Section 311 of the CWA, or as designated by TNRCC (30 TAC 327.2). Because phosgene is a hazardous substance under CERCLA and other chemical weapons or chemical warfare agents could be designated as 
Class 1 industrial solid wastes, any spill of chemical weapons or chemical warfare agents that exceeds the reportable quantity (e.g., 10 pounds for phosgene and 100 pounds for any chemical weapon/warfare agent considered a Class 1 industrial solid waste) must be reported to TNRCC under these regulations.

\subsection{UTAH}

\subsubsection{Hazardous Waste Regulations}

The Utah Department of Environmental Quality (UDEQ) regulations generally restate the federal RCRA regulations concerning identification and listing of hazardous wastes (Utah Admin. Rules [UAR] R315-2). Therefore, the Utah RCRA program is basically the same as the federal RCRA program, and those chemical agents/weapons listed in the federal RCRA program are listed hazardous wastes in Utah. The UDEQ regulations incorporate by reference the list of hazardous wastes for any discarded commercial chemical products, off-specification species, container residues, and spill residues thereof having the generic name found in 40 CFR 261.33, with the following additional state-specific waste:

Nerve, military, and chemical agents (i.e., CX, GA, GB, GD, H, HD, HL, HN-1, HN-2, HN-3, HT, L, T, and VX) (P999) [UAR R315-2-11(e)(1)].

The UDEQ regulations also incorporate by reference the list of hazardous wastes from nonspecific sources found in 40 CFR 261.31, with the following additional state-specific waste:

Residues from demilitarization, treatment, and testing of nerve, military, and chemical agents CX, GA, GB, GD, H, HD, HL, HN-1, HN-2, HN-3, HT, L, T, and VX (F999) [UAR R315-2-10(e)(1)].

In Utah, chemical agents and the residues from demilitarization, treatment, and testing of chemical agents are listed as acute hazardous wastes. UDEQ has not adopted the federal military munitions rule; therefore, it is not in effect in Utah.

\subsubsection{Additional Pertinent Statutory or Regulatory Provisions}

The Utah Hazardous Chemical Emergency Planning Act (Utah Code Annotated [UCA], Section 63-5-5) established the Hazardous Chemical Emergency Response Commission to carry out all EPCRA requirements. The Commission is composed of a representative of the Utah Department of Public Safety and a representative of UDEQ. The Department of Public Safety's duties are performed by the Division of Comprehensive Emergency Management. UDEQ receives EPCRA chemical information reports and maintains the state chemical inventory for emergency planning and response purposes. The Division of Comprehensive Emergency Management provides assistance to state LEPCs for planning and training purposes. 
Any spill of $1 \mathrm{~kg}$ of acutely hazardous waste, including all P-code wastes, chemical warfare agents (F999) wastes, and any F-coded waste with a hazard code of H, must be reported to the Division of Solid and Hazardous Waste immediately, with a follow-up written report submitted within 15 days [UAR R315-9-1(b)]. Any spill of a CERCLA hazardous substance in excess of reportable quantities (40 CFR 302, Table 302.4) must be reported to the National Response Center. Also, any release of an EPCRA extremely hazardous substance or CERCLA substance over the designated reportable quantity must be reported to the local LEPC and the Hazardous Chemical Emergency Response Commission immediately, with a follow-up report submitted as soon as practicable (40 CFR 355.40).

\subsection{VIRGIN ISLANDS (U.S. TERRITORY)}

\subsubsection{Hazardous Waste Regulations}

EPA has not delegated the RCRA program to the U.S. Virgin Islands. EPA Region II, through the Caribbean Environmental Protection Division, implements and enforces the RCRA program in the U.S. Virgin Islands. Therefore, the RCRA program in the U.S. Virgin Islands is the same as the federal RCRA program, and only those chemical agents/weapons listed in the federal RCRA program are listed hazardous wastes in the U.S. Virgin Islands. Since the federal RCRA program is implemented and enforced in the U.S. Virgin Islands, the military munitions rule is in effect there.

\subsubsection{Additional Pertinent Statutory or Regulatory Provisions}

The U.S. Virgin Island Environmental Emergency Response Commission is responsible for implementing EPCRA programs in the Virgin Islands, including emergency planning and EPCRA reporting (Executive Order 302-1987). Any facility with a release of an EPCRA extremely hazardous substance must report it to the Virgin Island Division of Environmental Protection (VIDEP) if the release is to the ground, and to VIDEP or the U.S. Coast Guard if the release is to the surface water.

\subsection{VIRGINIA}

\subsubsection{Hazardous Waste Regulations}

The Virginia Department of Environmental Quality (VDEQ) has incorporated, by reference, the federal hazardous waste regulations (9 Virginia Admin. Code [VAC] 20-60-260 et seq.). VDEQ has not specifically designated chemical agents or chemical weapons as listed hazardous wastes (9 VAC 20-60-261). Therefore, the Virginia RCRA program is the same as the federal RCRA program, and only those chemical agents/weapons listed in the federal RCRA program are listed hazardous wastes in Virginia. 
Virginia has adopted the federal military munitions rule (9 VAC 20-60-266) but has yet to receive EPA authorization. Because states may enforce state-specific rules under state law, the military munitions rule is in effect but not federally enforceable in Virginia.

\subsubsection{Additional Pertinent Statutory or Regulatory Provisions}

The Virginia Emergency Response Council (VERC) was established as a policy and rulemaking body. VDEQ administers the EPCRA program, including submission of the TRI information and emergency planning notification. The Virginia Department of Emergency Services (VDES) serves as the lead agency for emergency response to the release of a hazardous substance. Immediate notification of the release of EPCRA extremely hazardous substances or CERCLA hazardous substances must be made to the local fire department or LEPC, the VDES, and, for CERCLA hazardous substances, the National Response Center. A follow-up written report is also required.

\subsection{WASHINGTON}

\subsubsection{Hazardous Waste Regulations}

The Washington Department of Ecology (WDE) has adopted "dangerous waste" regulations that are consistent with the federal RCRA hazardous waste regulations; however, WDE's degree-of -risk classification system is unique to Washington State (Washington Admin. Code [WAC] Chapter 173-303). The addition of three state-specific criteria for assessing wastes (i.e., level of toxicity, persistence in nature, and potential carcinogenic risk) supplement the federal system of lists and characteristics, resulting in more wastes being classified as dangerous wastes than as hazardous wastes using the federal regulations alone. The WDE regulations apply to the universe of "dangerous wastes," which includes solid wastes that are federal hazardous wastes and those that have been designated as dangerous waste under state-specific requirements. Generators of solid wastes that are not excluded from regulation in Washington are therefore required to determine whether their solid waste is designated as being within the universe of dangerous wastes by applying the following procedure (WAC 173-303-070):

- Determine if the waste is listed as a discarded chemical product in WAC 173303-081, which includes chemical products designated as federal listed hazardous wastes having P or U waste codes [40 CFR 261.33(e) and (f)];

- Determine if the waste is listed as a dangerous waste source in WAC 173-303082, which includes wastes from general and specific sources designated as federal listed hazardous wastes having F or K waste codes [40 CFR 261.31 and 261.32], as well as discarded PCB transformers, capacitors, and bushings having Washington state waste code W001; 
- If the waste is not listed as either a discarded chemical product or a dangerous waste source, determine if the waste exhibits any dangerous waste characteristics as defined in WAC 173-303-090, which include the four federal hazardous waste characteristics (ignitability, corrosivity, reactivity, and toxicity), as well as a corrosive characteristic for solids that are assigned Washington state waste code WSC2; and

- If the waste is not identified as a dangerous waste by any of the above means, determine if the waste meets any dangerous waste criteria as defined in WAC 173-303-100, which include criteria for toxic dangerous wastes and persistent dangerous wastes, as described below.

To determine whether a waste meets the toxic dangerous waste criteria, the generator may evaluate the waste by following either the instructions for book designation, when its knowledge of the waste is sufficient, or by using biological testing methods. A generator choosing to make a book designation must first determine the toxic category for each known constituent in its wastes. If toxicity data for a constituent cannot be found in the NIOSH Registry of Toxic Effects of Chemical Substances, or from other sources reasonably available to the generator, then the toxic category need not be determined for that constituent [WAC 173-303100(5)(b)(i)]. A toxic category is then assigned using the Toxicity Category Table provided in the regulations (see Table 3 ).

If a waste contains one or more toxic constituents, the generator must determine the equivalent concentration of the waste using a formula set out in the regulations. Once the equivalent concentration is determined, the generator designates the waste as either:

(1) Not dangerous waste (equivalent concentration is less than $0.001 \%$ ),

(2) Dangerous waste by toxicity criteria, assigned waste number WT02 (equivalent concentration is equal to or greater than $0.001 \%$ and less than $1.0 \%)$, or

(3) Extremely hazardous waste by toxicity criteria, assigned waste number WT01 (equivalent concentration is equal to or greater than $1.0 \%$ ).

TABLE 3 Washington State Toxic Categories [WAC 173-303-100(5)(b)]

\begin{tabular}{lcccc}
\hline $\begin{array}{c}\text { Toxic } \\
\text { Category }\end{array}$ & $\begin{array}{c}\text { Fish } \\
\mathrm{LC}_{50}(\mathrm{mg} / \mathrm{L})\end{array}$ & $\begin{array}{c}\text { Oral (Rat) } \\
\mathrm{LD}_{50}(\mathrm{mg} / \mathrm{kg})\end{array}$ & $\begin{array}{c}\text { Inhalation (Rat) } \\
\mathrm{LC}_{50}(\mathrm{mg} / \mathrm{L})\end{array}$ & $\begin{array}{c}\text { Dermal (Rabbit) } \\
\mathrm{LD}_{50}(\mathrm{mg} / \mathrm{kg})\end{array}$ \\
\hline $\mathrm{X}$ & $<0.01$ & $<0.5$ & $<0.02$ & $<2$ \\
$\mathrm{~A}$ & $0.01-<0.1$ & $0.5-<5$ & $0.02-<0.2$ & $2-<20$ \\
$\mathrm{~B}$ & $0.1-<1$ & $5-<50$ & $0.2-<2$ & $20-<200$ \\
$\mathrm{C}$ & $1-<10$ & $50-<500$ & $2-<20$ & $200-<2,000$ \\
$\mathrm{D}$ & $10-100$ & $500-<5,000$ & $20-<200$ & $2,000-<20,000$ \\
\hline
\end{tabular}


A generator choosing to use biological testing methods to evaluate whether a solid waste meets the state toxic dangerous waste criteria must first collect bioassay data. A dangerous waste by toxicity criteria (WT02) is established by means of the $100-\mathrm{mg} / \mathrm{L}$ acute static fish test or the $5,000-\mathrm{mg} / \mathrm{kg}$ oral rat test. An extremely hazardous waste by toxicity criteria (WT01) is established using the fish bioassay at $10 \mathrm{mg} / \mathrm{L}$ or the rat bioassay at $50 \mathrm{mg} / \mathrm{kg}$. These biological testing methodologies are set forth in the regulations [WAC 173-303-110(3)].

To determine whether a waste meets the persistent dangerous waste criteria, the generator must determine whether the waste contains halogenated organic compounds (HOC) or polycyclic aromatic hydrocarbons (PAH) [WAC 173-303-100(6)]. After summing the concentration percentages for all HOC and/or PAH, the generator uses the Persistent Dangerous Waste Table in the regulations to determine the waste designation:

- If the waste contains $0.01 \%$ to $1.0 \%$ of $\mathrm{HOC}$, it is designated a dangerous waste by persistence criteria and assigned number WP02.

- If it contains greater than $1.0 \%$ of $\mathrm{HOC}$, it is designated an extremely hazardous waste by persistence criteria and assigned waste number WP01.

- If it contains greater than $1.0 \%$ of PAH it is designated an extremely hazardous waste by persistence criteria and assigned waste number WP03.

Within the universe of dangerous wastes, the WDE regulations also define a category of wastes called special wastes, which WDE believes can be safely managed with a level of protection that is intermediate between that required for all other dangerous wastes and that required for non-dangerous solid wastes. Special wastes include wastes that are designated as dangerous waste by state regulations, but that are not regulated as hazardous waste under 40 CFR 261, that are solid (i.e., nonliquid, nonaqueous, nongaseous), and that:

- Exhibit the state corrosive characteristic for solids [WAC 173-303090(6)(b)(ii)]; or

- Are dangerous wastes by toxic criteria, but have an equivalent concentration equal to or less than $0.01 \%$ [WAC 173-303-100(5)(b)(iii)(C)]; or

- Are PCB wastes included on the dangerous waste sources list (WAC 173-3039904); or

- Are dangerous wastes by persistence criteria, but are not extremely hazardous wastes [WAC 173-303-100(6)]. (WAC 173-303-040)

WDE has not specifically designated chemical agents or chemical weapons as discarded chemical products, dangerous waste sources, or state-specific dangerous wastes. However, as discussed in Section 2, phosgene has been designated as a federally listed hazardous waste (P095) and chemical warfare agents or chemical weapons may exhibit certain characteristics of hazardous wastes under the federal criteria. Therefore, since the Washington state definition of 
dangerous waste includes all federally listed hazardous wastes and wastes that exhibit any federal hazardous characteristics, phosgene as well as other chemical warfare agents or chemical weapons exhibiting a federal hazardous characteristic are dangerous wastes in the State of Washington. In addition, it is likely that chemical agents/weapons and in some cases, associated wastes (e.g., treatment residues and cleanup wastes) will qualify as dangerous waste by toxic criteria (state waste number WT02 or WT01) or by persistence criteria (WP01 or WP02). This would, however, need to be verified using the state criteria and methodologies described above.

Under WDE regulations, any mixture of a solid waste and a discarded chemical product or dangerous waste source would be designated as a listed dangerous waste (WAC 173-303-81 and 173-303-82). In addition, once a material has been determined to be a dangerous waste, then any solid waste generated from the recycling, treatment, storage, or disposal of that dangerous waste is a dangerous waste unless and until the generator has been able to accurately describe the variability or uniformity of the derivative waste over time, has been able to obtain demonstration samples which are representative of the derivative waste's variability or uniformity, and determined:

- The derivative does not exhibit any of the dangerous waste characteristics defined in WAC 173-303-090;

- If the original waste was a listed waste under WAC 173-303-080 through 173303-083, the derivative has been exempted pursuant to WAC 173-303-910 (e.g., a petition for exemption or exclusion of the waste has been granted by the WDE); and

- If the original waste was designated as dangerous waste only by toxic or persistence criteria under WAC 173-303-100, the derivative does not meet any of the criteria of that section.

Residues, contaminated soil, water, or debris resulting from the cleanup of a spill of any chemical designated on the discarded chemical products list or any waste designated on the dangerous waste sources list are also considered dangerous wastes in Washington if they exceed specified quantities.

Washington has adopted the federal military munitions rule (WAC 173-303-578) but has yet to receive EPA authorization. Because states may enforce state-specific rules under state law, the military munitions rule is in effect but not federally enforceable in Washington.

\subsubsection{Additional Pertinent Statutory or Regulatory Provisions}

The WDE Hazardous Waste and Toxics Reduction Program is the home of the Washington State Hazardous Substance Information Office. This office receives and distributes information on the storage and releases of toxic chemicals under EPCRA, including the Hazardous Chemical Inventory (Tier II) reports and TRI reports. 


\subsection{WASHINGTON, D.C.}

\subsubsection{Hazardous Waste Regulations}

The District of Columbia (Washington, D.C.) has adopted regulations that parallel the federal hazardous waste regulations (D.C. Municipal Regulations [DCMR], Title 20, Subtitle E). The D.C. Department of Health $(\mathrm{DCDOH})$ is designated as the lead agency for implementing the Washington, D.C., hazardous waste program. DCDOH has not specifically designated chemical agents or chemical weapons as listed hazardous wastes (20 DCMR Subtitle E, Chapter 41). Therefore, the RCRA program in Washington, D.C., is generally the same as the federal RCRA program, and only those chemical agents/weapons listed in the federal RCRA program are listed hazardous wastes in Washington, D.C.

Washington, D.C., has adopted the federal military munitions rule (20 DCMR Subtitle E, Chapter 45), but has yet to receive EPA authorization. Because states may enforce state-specific rules under state law, the military munitions rule is in effect but not federally enforceable in Washington, D.C.

\subsubsection{Additional Pertinent Statutory or Regulatory Provisions}

The D.C. Office of Emergency Management (formerly Office of Emergency Preparedness) is the EPCRA SERC. The District of Columbia Local Emergency Planning Council, Inc., was established to monitor and inform the public about the use of hazardous chemicals in Washington, D.C.

\subsection{WYOMING}

\subsubsection{Hazardous Waste Regulations}

The Wyoming Department of Environmental Quality (WDEQ) has adopted regulations that parallel the federal hazardous waste regulations (Wyoming Hazardous Waste Rules and Regulations [WHWRR], WDEQ Chapter 1 et seq.). WDEQ has not specifically designated chemical agents or chemical weapons as listed hazardous wastes (WHWRR, Chapter 2). Therefore, the Wyoming RCRA program is generally the same as the federal RCRA program, and only those chemical agents/weapons listed in the federal RCRA program are listed hazardous wastes in Wyoming.

Wyoming has not adopted the federal military munitions rule; therefore, the federal RCRA military munitions rule is not in effect in Wyoming. 


\subsubsection{Additional Pertinent Statutory or Regulatory Provisions}

Releases of any hazardous substance that enters the waters of the state or is determined to be a threat to waters of the state must be reported to WDEQ immediately (Wyoming Water Quality Rules and Regulations, Chapter 4). A hazardous substance is any substance or waste, which after release, constitutes a threat to public health or welfare, or other aquatic life or wildlife because of its quantity, concentration, chemical, corrosive, flammable, reactive, toxic, infectious, or radioactive characteristics. In addition to spills entering the water, under Section 304 of EPCRA, any releases of EPCRA extremely hazardous substances must be reported to the SERC and the LEPC in the affected area.

In addition, by law, anyone discovering a suspected biological, radioactive, or chemical incident (e.g., attending health care provider or laboratory) must provide immediate notification to the Wyoming Department of Health, Epidemiology Section. 


\section{SUMMARY OF APPLICABLE PROVISIONS IN 40 STATES AND JURISDICTIONS}

The following table (Table 4) summarizes the statutory and regulatory provisions that may apply to chemical weapons or chemical warfare agents in the states and jurisdictions discussed in this report. 


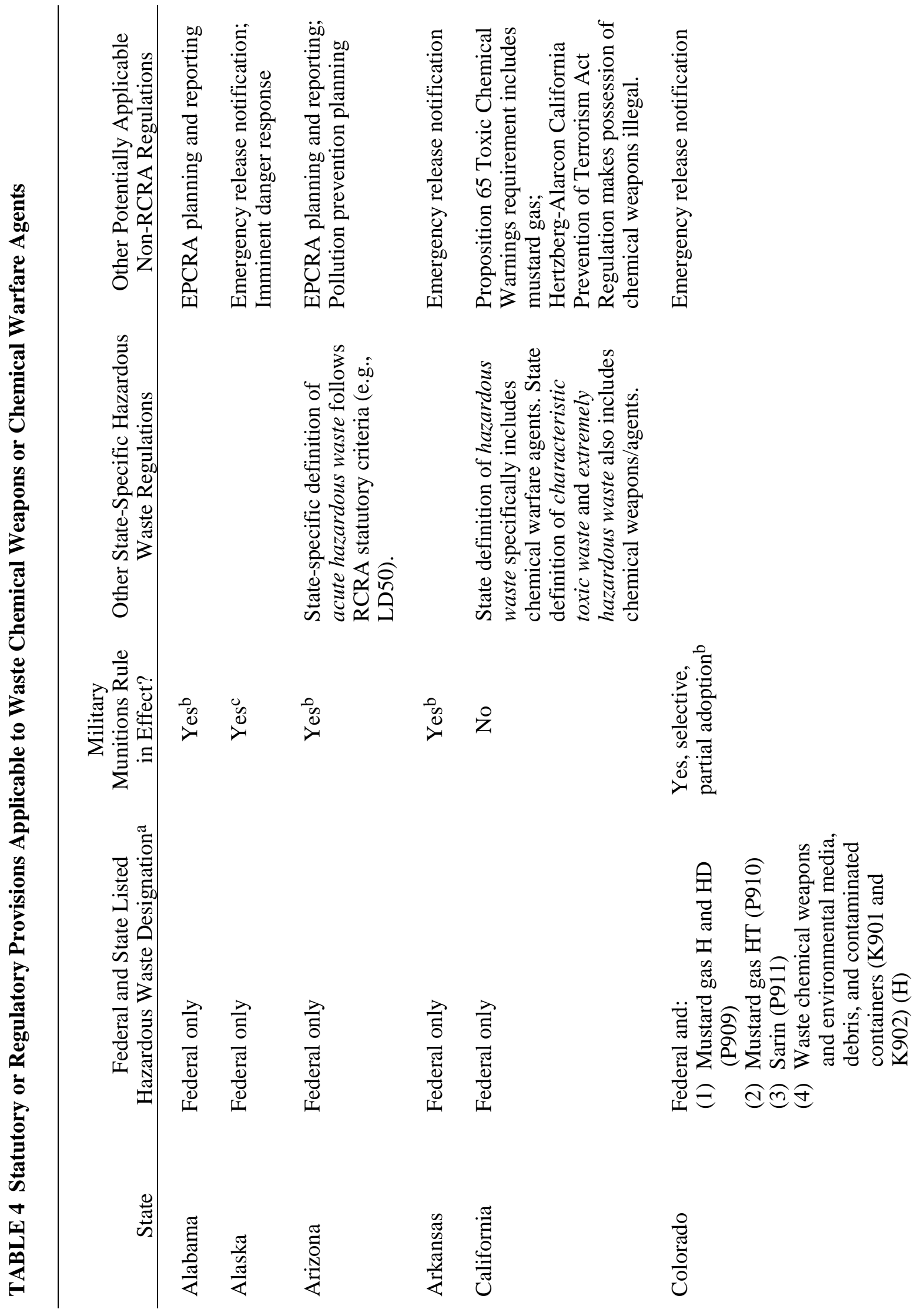




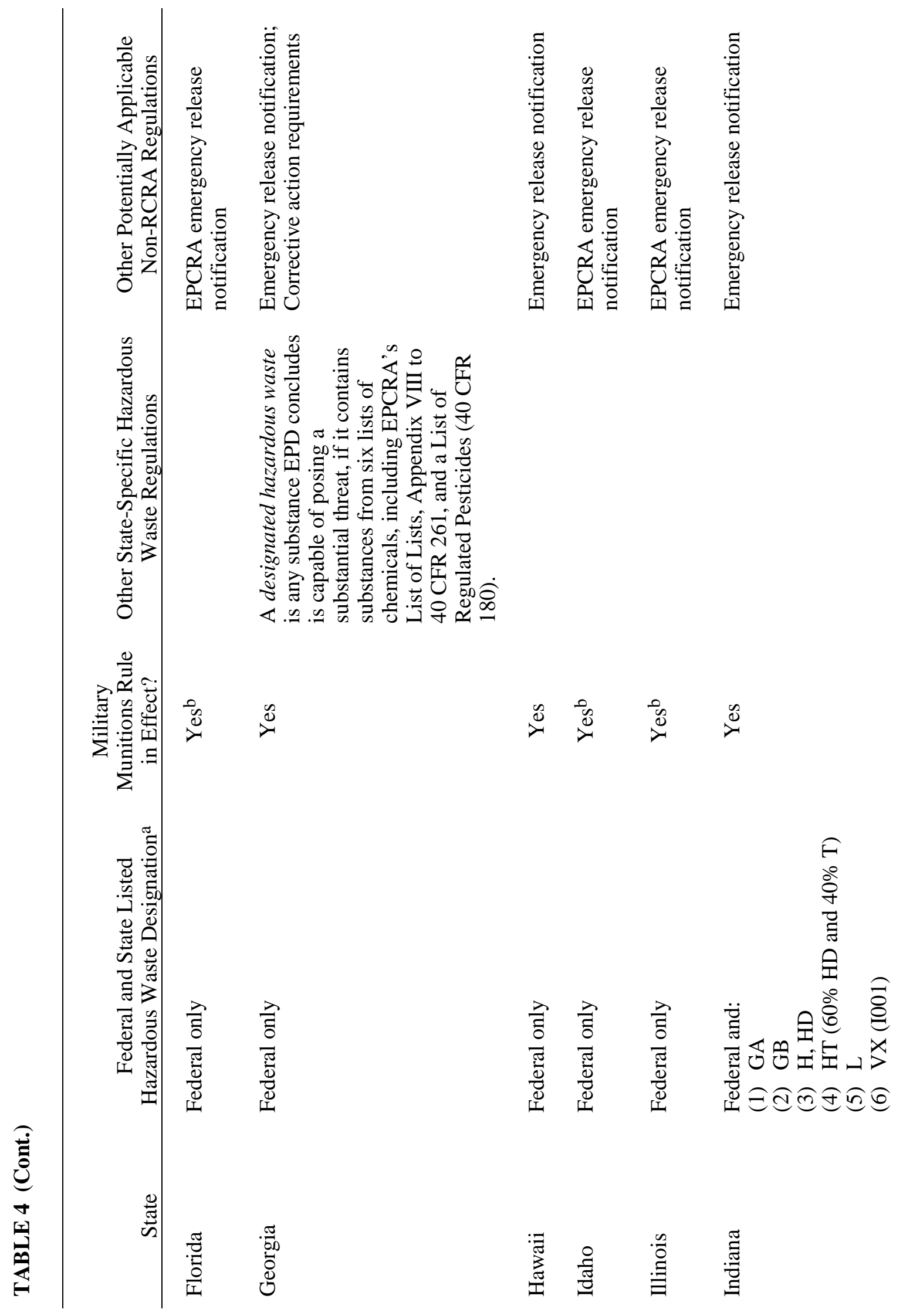




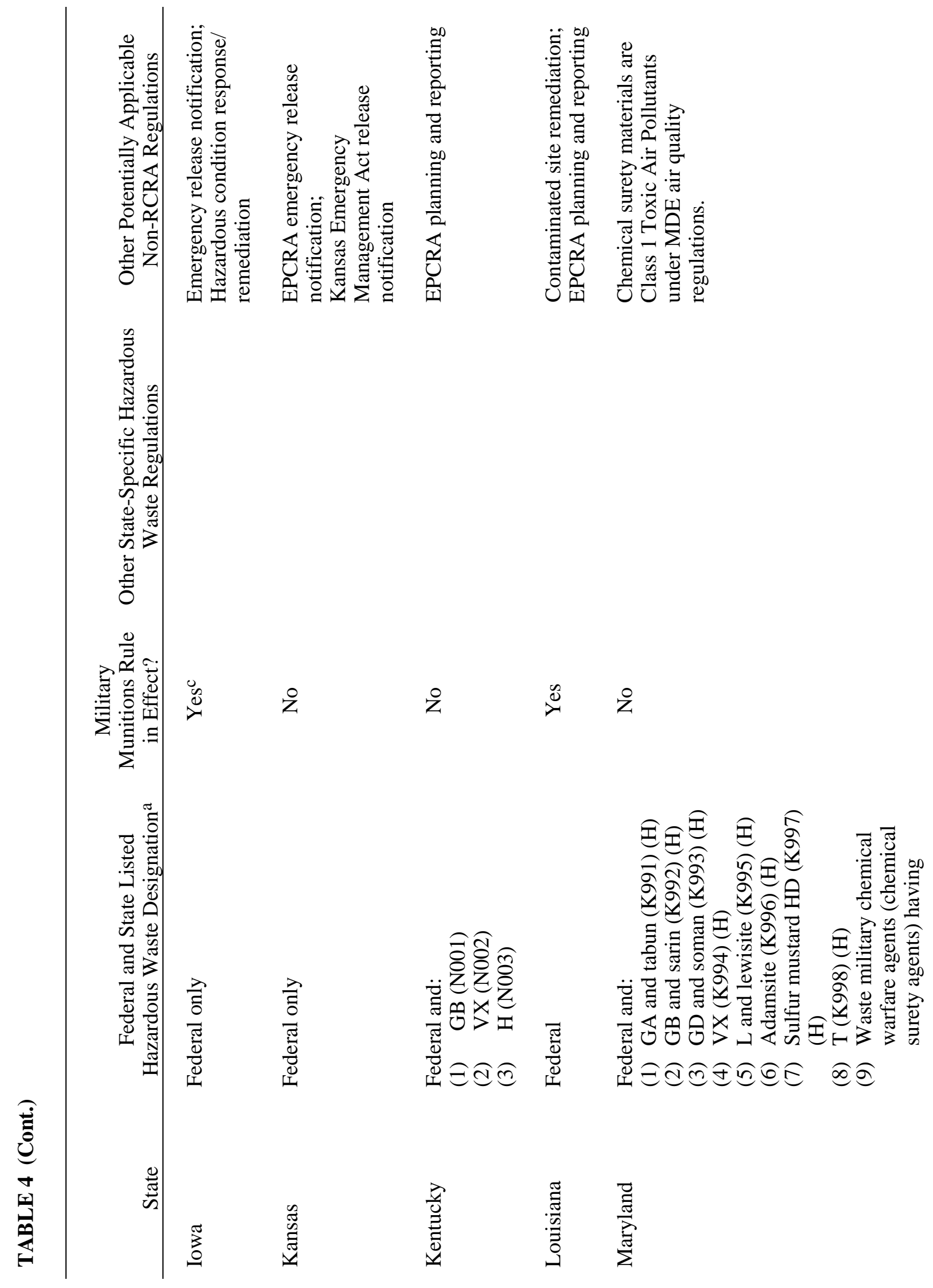




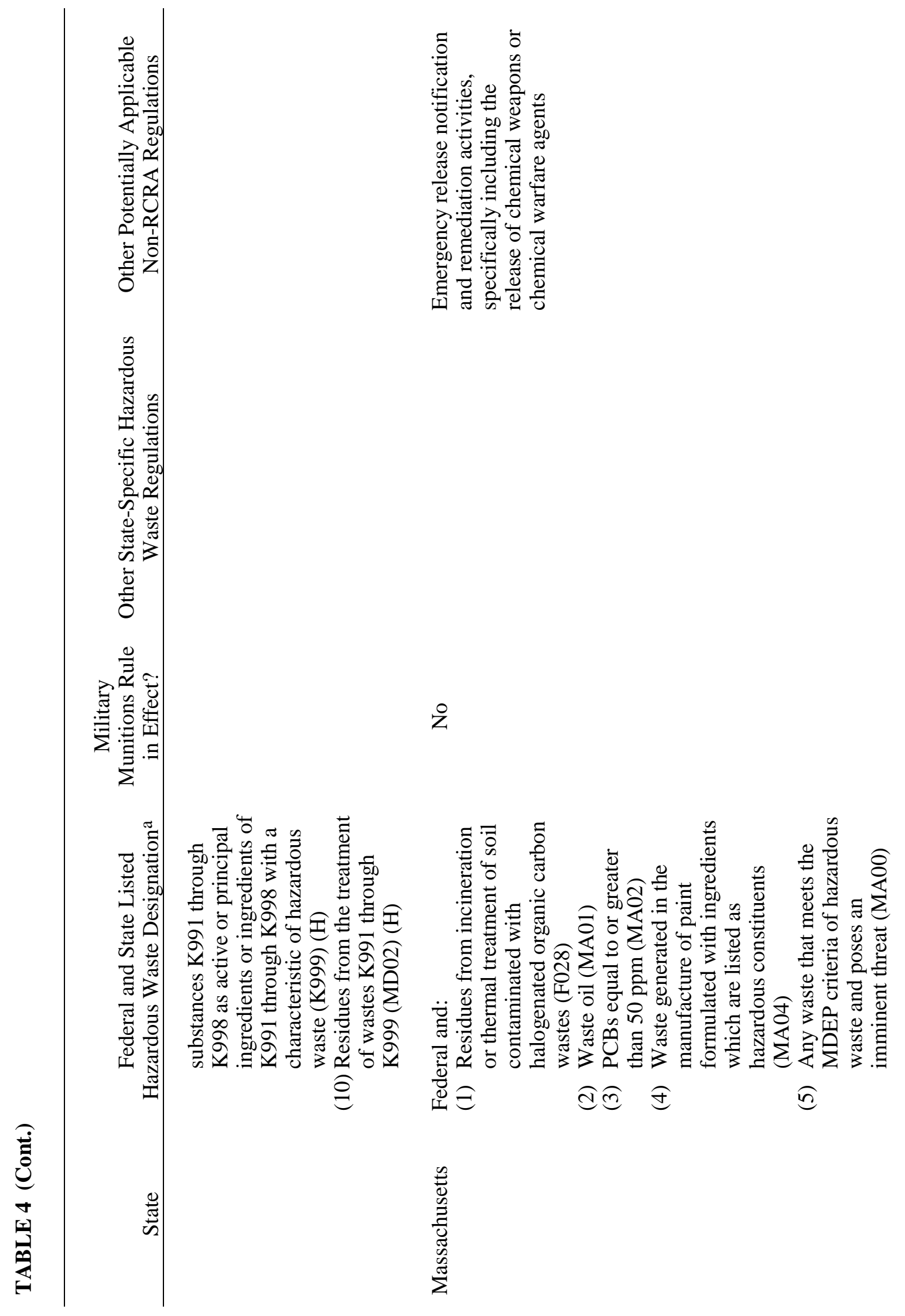




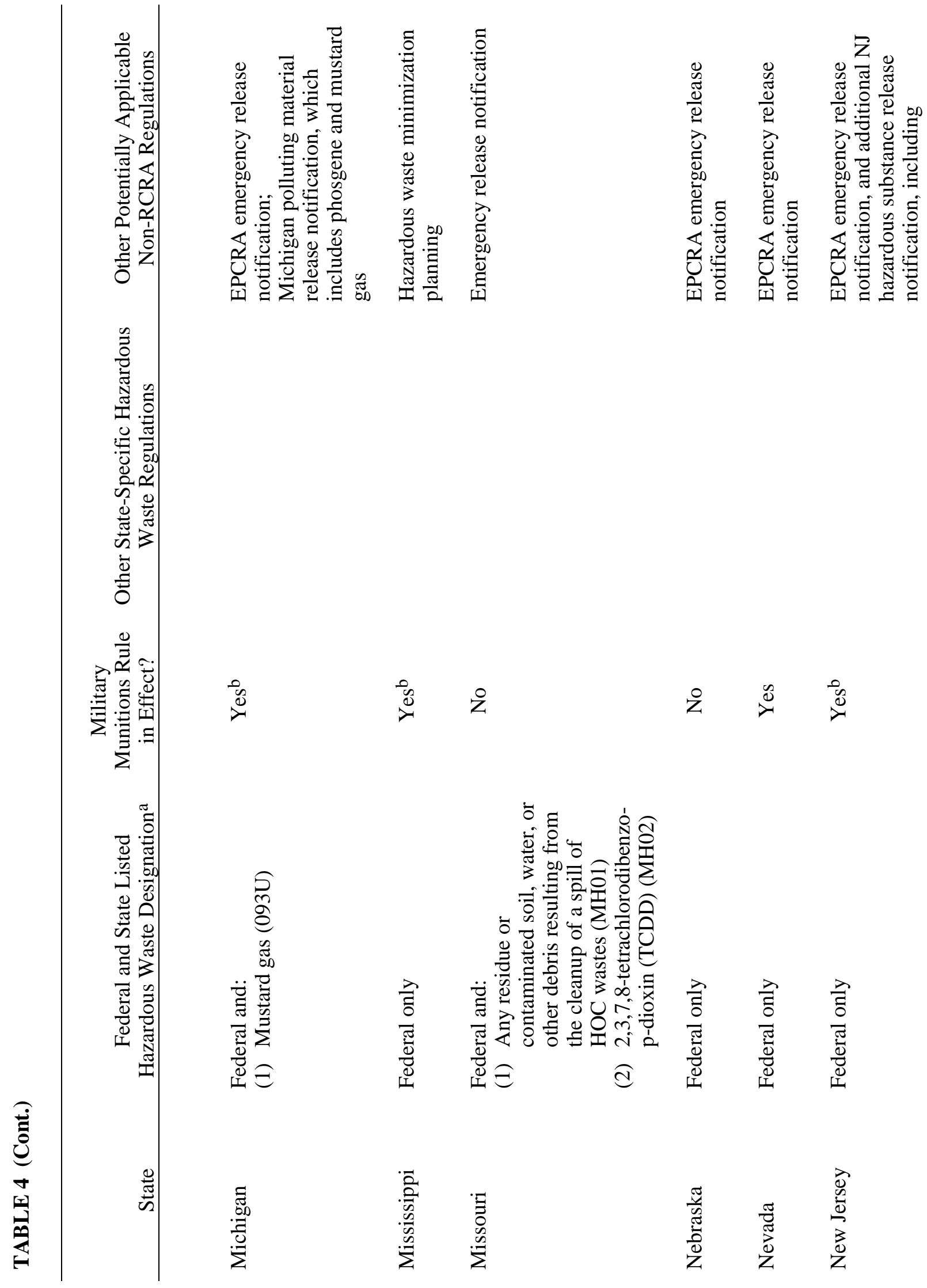




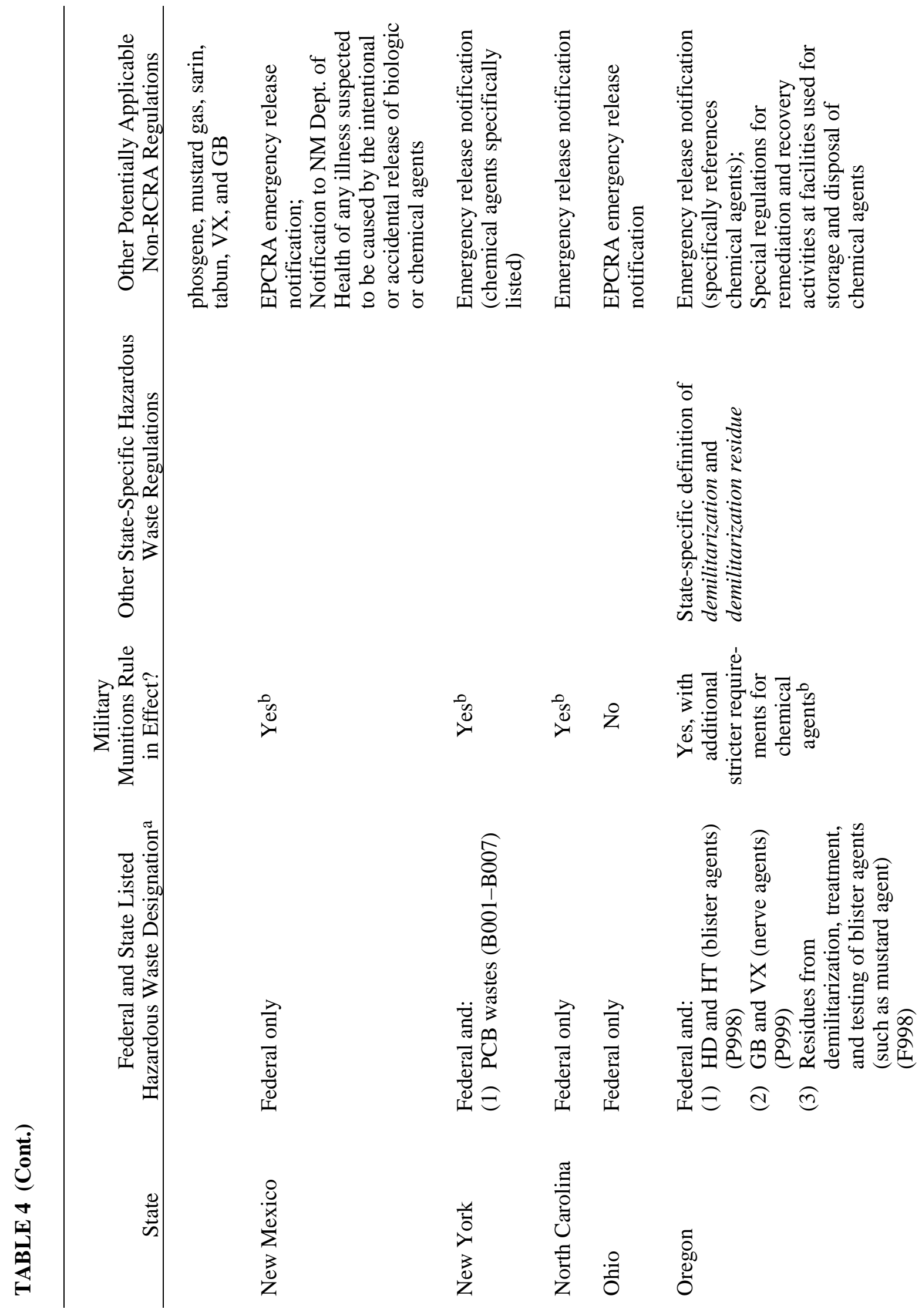




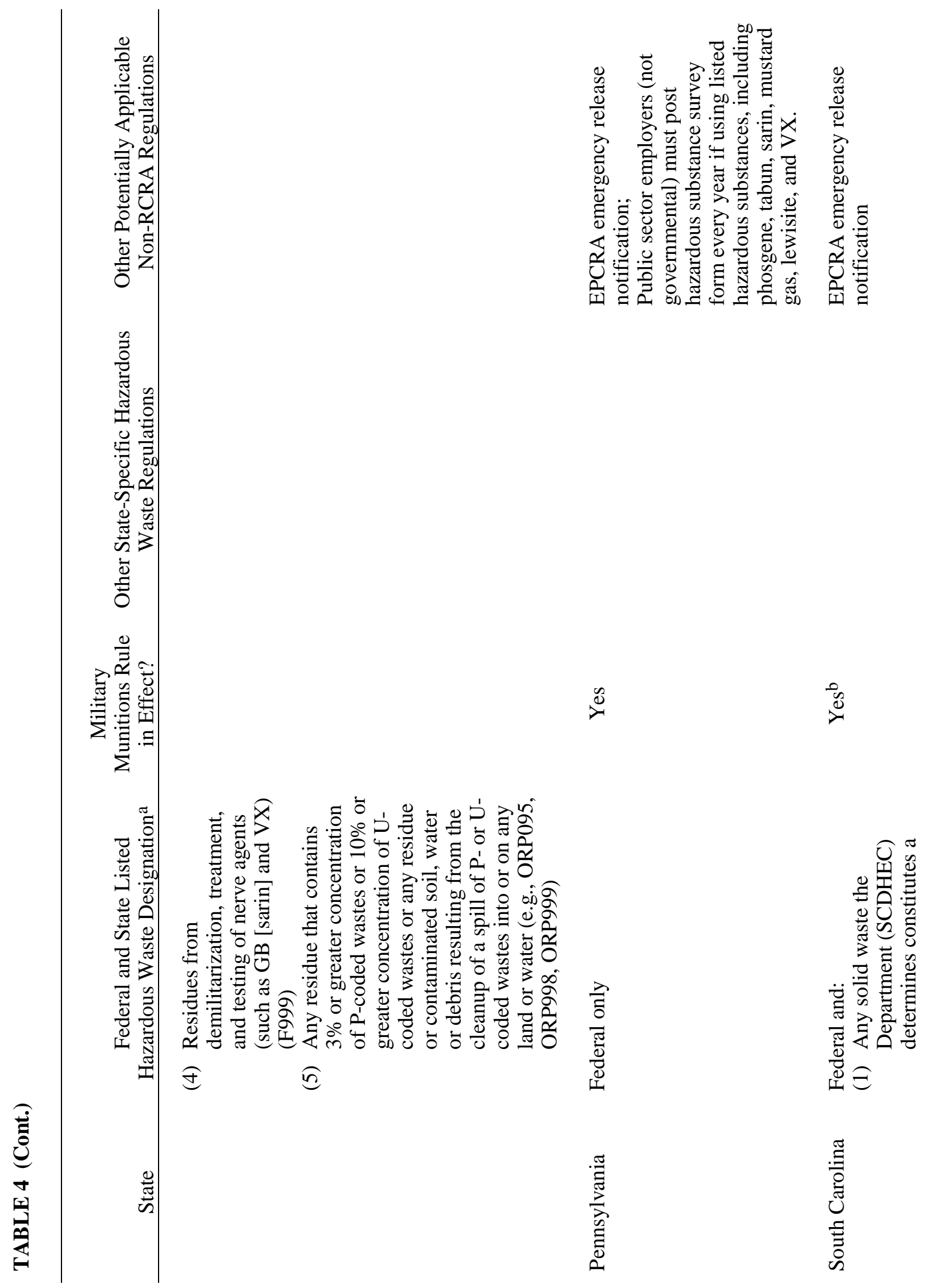




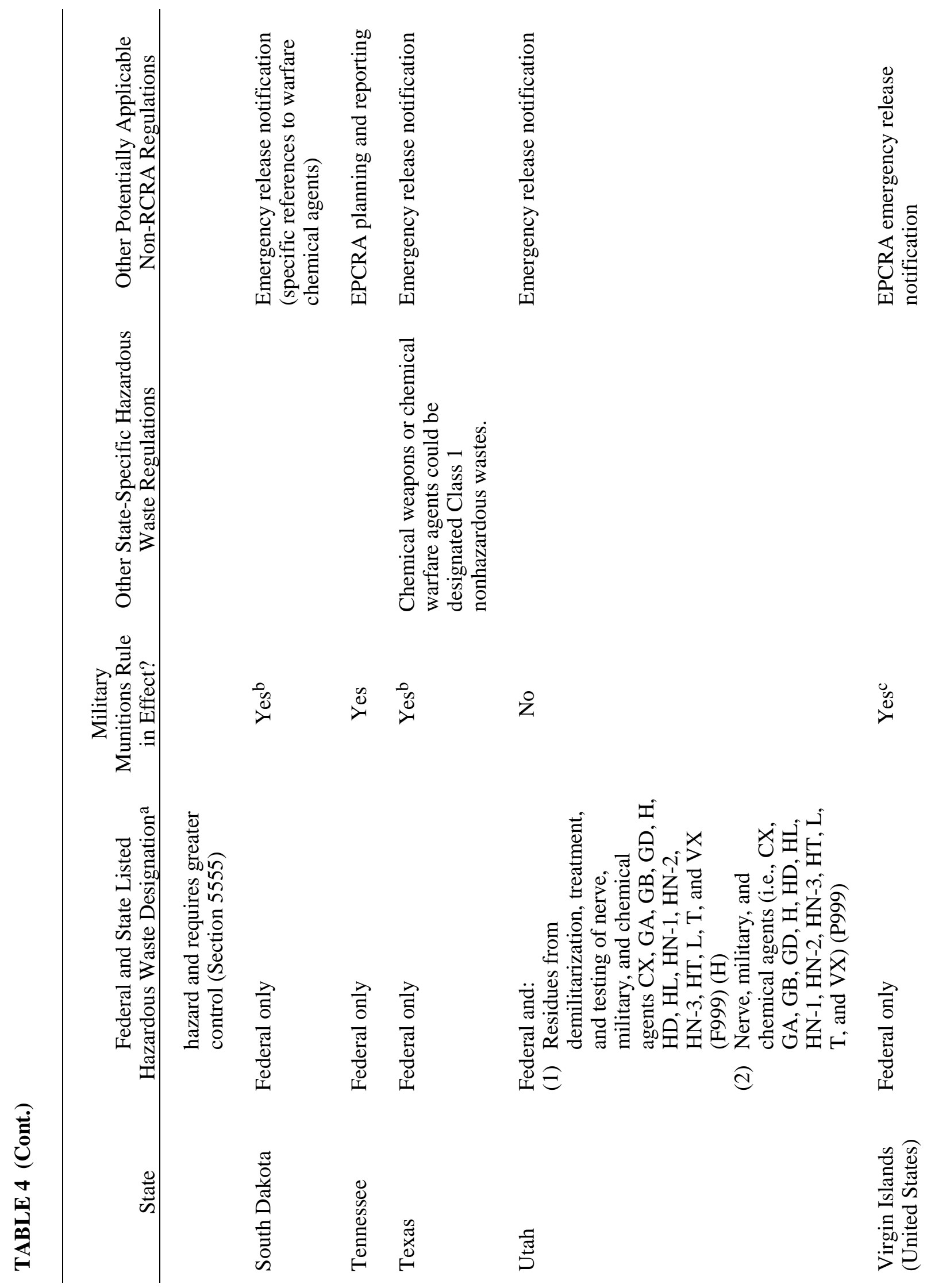




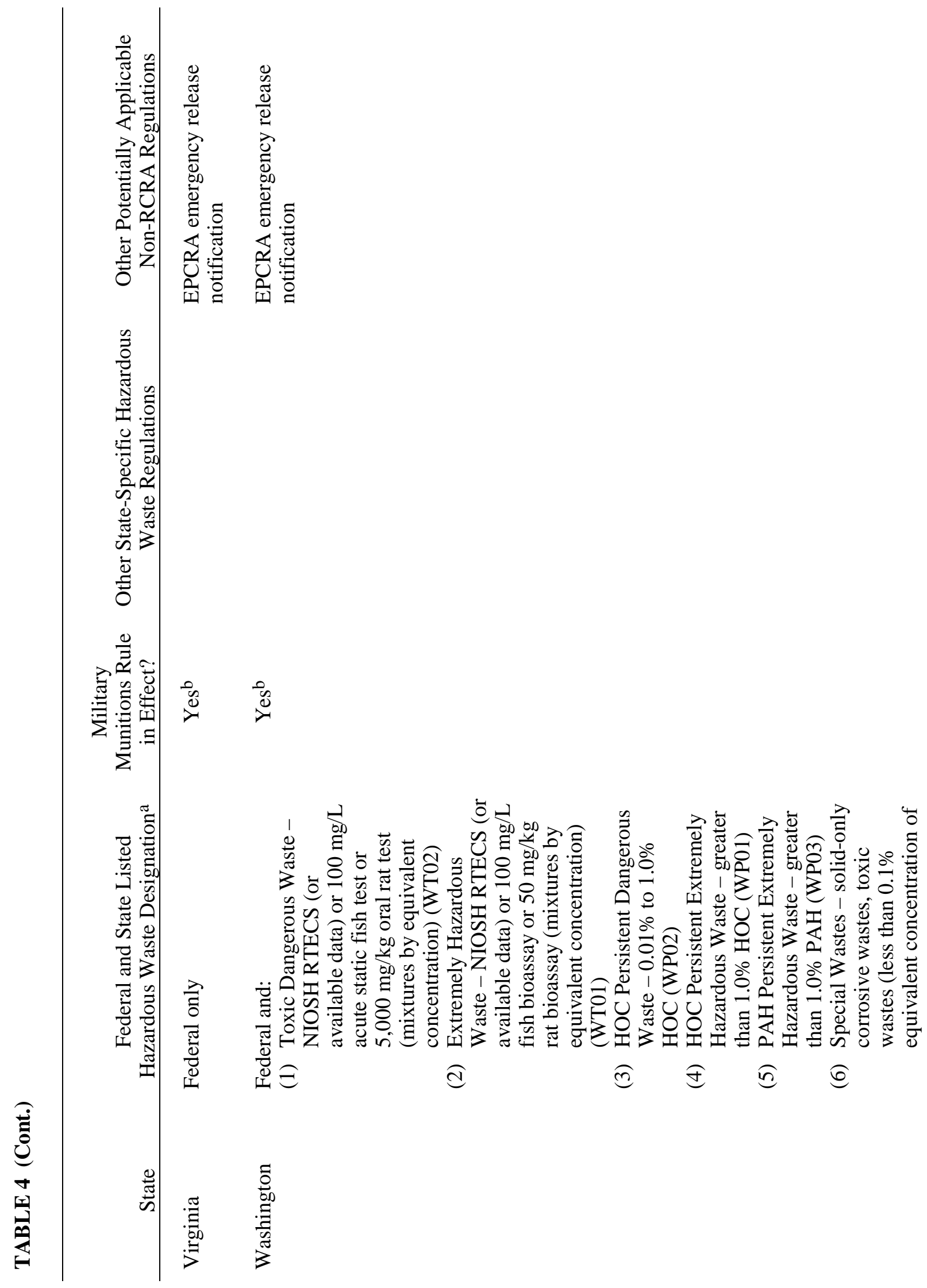




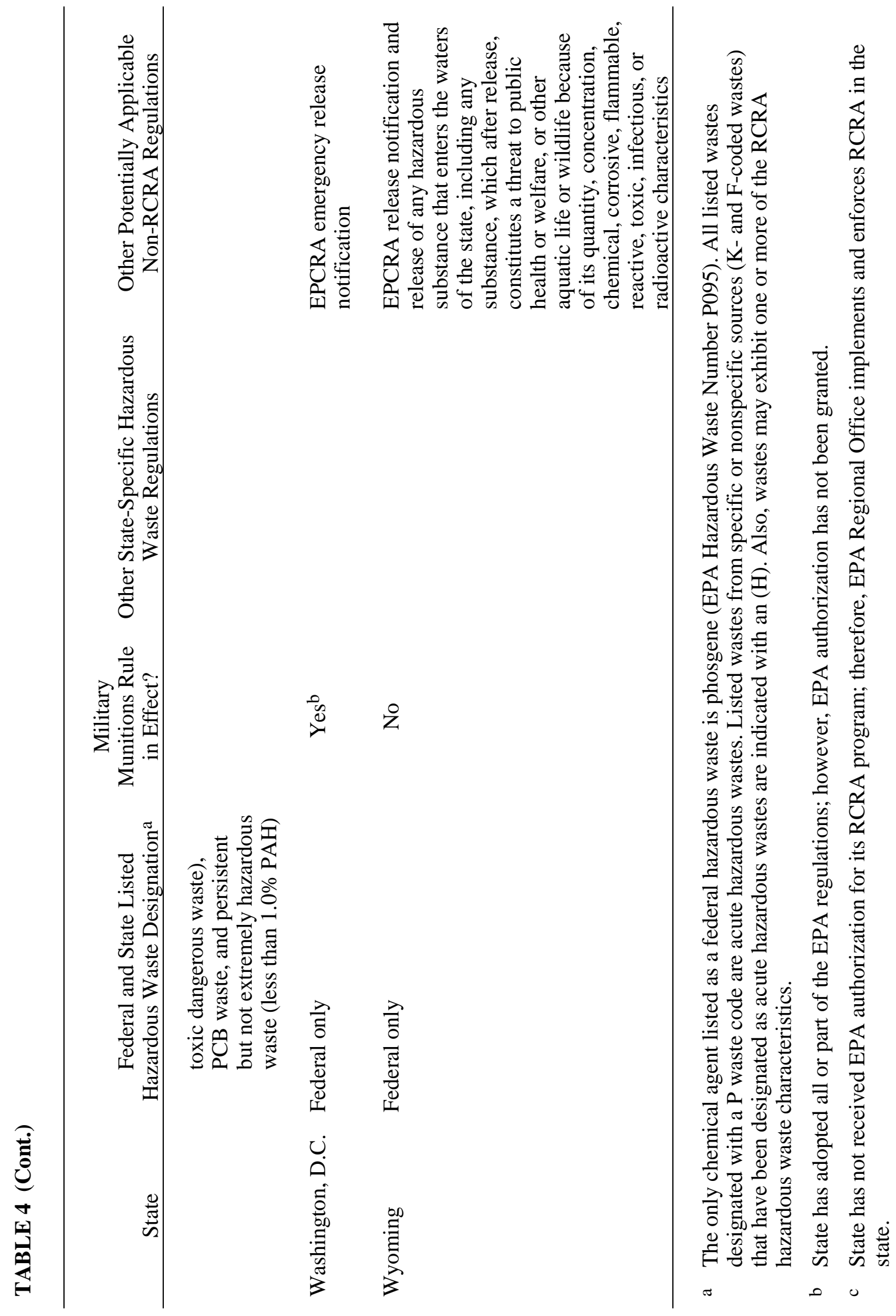


